CAMILA LUISI RODRIGUES

\title{
Aspectos neuropsicológicos dos transtornos de ansiedade na infância e adolescência: um estudo comparativo entre as fases pré e pós-tratamento medicamentoso
}

\author{
Dissertação apresentada à Faculdade de \\ Medicina da Universidade de São Paulo \\ para obtenção do título de Mestre em \\ Ciências \\ Programa de Psiquiatria \\ Orientador: Dr. Fernando Ramos Asbahr
}

São Paulo

2011 
Dados Internacionais de Catalogação na Publicação (CIP)

Preparada pela Biblioteca da

Faculdade de Medicina da Universidade de São Paulo

Creprodução autorizada pelo autor

\section{Rodrigues, Camila Luisi}

Aspectos neuropsicológicos dos transtornos de ansiedade na infância e adolescência : um estudo comparativo entre as fases pré e pós-tratamento medicamentoso / Camila Luisi Rodrigues. -- São Paulo, 2011.

Dissertação(mestrado)--Faculdade de Medicina da Universidade de São Paulo. Programa de Psiquiatria.

Orientador: Fernando Ramos Asbahr.

Descritores: 1.Transtornos de ansiedade 2.Criança 3.Adolescente 4.Neuropsicologia 5.Reavaliação 6.Medicamentos

USP/FM/DBD-208/11 
DEDICATÓRIA

Para meus pais e Cristiano, pelo amor e incentivo ao longo da minha vida. 
Ao prof. Dr Fernando Ramos Asbahr, orientador desta dissertação, por acreditar no tema da pesquisa, pelo exemplo de profissionalismo, conhecimento acadêmico, humildade, disponibilidade, atenção, dedicação, paciência nas correções e na orientação deste trabalho, assim como com toda equipe de trabalho.

À Dra Cristiana Castanho de Almeida Rocca, antes de tudo uma grande amiga, incentivadora, conselheira, companheira; agradeço pela ajuda indispensável para o desenvolvimento deste trabalho, em especial nas diversas noites de sextasfeiras, nos mutirões aos sábados e nas emendas de feriados.

À Dra Carolina Zadrozny Gouvêa da Costa, amiga e companheira acadêmica, além de psiquiatra responsável pela execução das avaliações clínicas e todo acompanhamento do tratamento medicamentoso das crianças e adolescentes do grupo com transtorno de ansiedade.

À Dra Rosa Magaly Campelo Borba de Morais, amiga e companheira acadêmica, sempre disponível e pela colaboração neste projeto.

À Eunice Monteiro Labbadia e Lilian Lerner Castro, amigas e companheiras, além de auxiliarem na randomização e distribuição da medicação.

À Sra. Cláudia Valéria Garcia, pela ajuda no processo de triagem dos pacientes.

A todos os profissionais que estiveram envolvidos no Programa de Transtorno de Ansiedade na Infância e Adolescência do Instituto de Psiquiatria do Hospital das Clínicas da Faculdade de Medicina da Universidade de São Paulo, pelo apoio, incentivo e companheirismo durante o desenvolvimento deste projeto, em especial: Márcia Morikawa, Mayra Helena Bonifacio Gaiato, Maria Carolina 
Mendes, Merylúcia M K e Silva, Milena M Spolon, Leandro Tadeu G Reveles, Gabriela Gorenstein, Renata Teixeira da Silva.

À Camila Tarif Ferreira Folquitto, grande amiga, companheira acadêmica, colega de consultório, sempre incentivando e auxiliando tanto nas avaliações das crianças e adolescentes do grupo controle, como na atualização de periódicos necessários para o desenvolvimento deste projeto.

À Maura Borges de Souza, auxiliar de enfermagem responsável pela recepção dos pacientes.

A Rafael Izbicki e Bernardo dos Santos, pela paciência, auxílio, orientações e preparo da análise estatística dos dados.

Ao Dr. Ennio Roberto Andrade, amigo e grande incentivador, sempre acreditando no meu trabalho, peça fundamental nesta conquista.

Ao Everton Duarte, amigo e companheiro de mutirões aos sábado, de aulas e principalmente das angústias do processo do desenvolvimento deste projeto.

Aos demais profissionais do Serviço de Psicologia do Instituto de Psiquiatria do Hospital das Clínicas da Faculdade de Medicina da Universidade de São Paulo, pelo apoio e motivação ao longo deste projeto, em especial Daniel Fuentes, Carolina Fuentes e Francy de Brito Ferreira Fernandes, que contribuíram de maneira mais próxima no meu projeto de pesquisa.

À Dra Jonia Lacerda Felicio, incentivadora no meu desenvolvimento acadêmico, tanto por meio de aulas, supervisões, como em proporcionar oportunidades em ministrar aulas na Universidade São Camilo, sempre acreditando no meu trabalho. 
À Dra Candida Helena Pires de Camargo, pelas discussões sobre o projeto, contribuindo no desenvolvimento do mesmo.

A todos os pacientes e seus familiares, por aceitarem participar deste estudo e possibilitar, assim, um maior conhecimento sobre o desempenho cognitivo nos transtornos ansiosos na infância e adolescência.

A todos os participantes que fizeram parte do grupo controle, por aceitarem participar deste estudo e possibilitarem, assim, um conhecimento sobre o funcionamento cognitivo em crianças e adolescentes que não apresentam transtornos psiquiátrico.

Ao grupo de pesquisa em transtorno bipolar da infância e adolescência, em especial a Dra Sheila Caetano e Dra Ana Kleinman, coordenadoras do ambulatório, que disponibilizaram algumas crianças e adolescentes do grupo controle para serem avaliadas.

À Eliza Fukushima, Isabel Ataide e Luciana Paula Ferreira, pelas orientações e apoio em relação aos assuntos burocráticos referentes a este estudo.

À banca da qualificação, pelas sugestões e correções fundamentais para o término da pesquisa.

À Mariana K Flaks, pelo interesse e atenção em fornecer as sugestões e correções realizadas no boneco dessa dissertação.

À Coordenação de Aperfeiçoamento de Pessoal de Nível Superior (Capes) e o Conselho Nacional de Desenvolvimento Científico e Tecnológico (CNPq) pelo suporte financeiro no início da pesquisa.

À FAPESP, pelo suporte financeiro que auxiliou na realização deste projeto de pesquisa. 
A todos meus familiares que me deram suporte durante todo o processo da pesquisa. Principalmente por esse período ter sido de intensas mudanças na minha vida pessoal. $\mathrm{O}$ apoio de todos foi fundamental.

A todos meus amigos pela compreensão e apoio durante todo este período. 


\section{"Alta Ansiedade - Cazuza"}

Se marco uma entrevista às 2

1:15 já fumei 10 cigarros

Se vou gravar uma faixa

A mesa do estúdio está quebrada

Não sei esperar, não sei esperar

E a minha vida é um engarrafamento

Se tenho uma festa às 10

8:30 já estou pronto

Fico balançando os pés

Sentado na beira da cama

O tempo não passa pra mim

Quero mais velocidade

Várias coisas ao mesmo tempo

Não quero esse bonde lento 


\section{Normalização adotada}

Esta dissertação ou tese está de acordo com as seguintes normas, em vigor no momento desta publicação:

Referências: adaptado de International Committee of Medical Journals Editors (Vancouver).

Universidade de São Paulo. Faculdade de Medicina. Divisão de Biblioteca e Documentação. Guia de apresentação de dissertações, teses e monografias. Elaborado por Anneliese Carneiro da Cunha, Maria Julia de A. L. Freddi, Maria F. Crestana, Marinalva de Souza Aragão, Suely Campos Cardoso, Valéria Vilhena. $3^{\circ}$. Edição. São Paulo: Divisão de Biblioteca e Documentação; 2011.

Abreviaturas dos títulos dos periódicos de acordo com List of Journals Indexed in Index Medicus. 
Lista de Abreviaturas, símbolos e siglas

Lista de Quadros

Lista de Tabelas

Lista de Figuras

Lista de Gráficos

Resumo

Summary

1. INTRODUÇÃO. .1

2. OBJETIVOS.

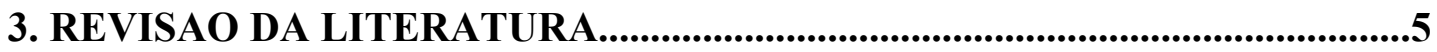

3.1. Desenvolvimento infantil: ansiedade normal ou patológica?.............................6

3.2. Transtorno de ansiedade na infância: aspectos clínicos....................................... 8

3.2.1. Transtorno de ansiedade de separação.................................................10

3.2.2. Transtorno de ansiedade generalizada.............................................12

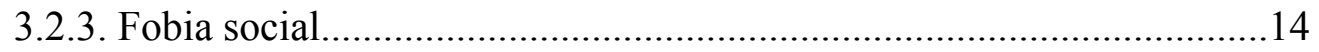

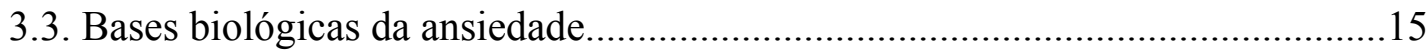

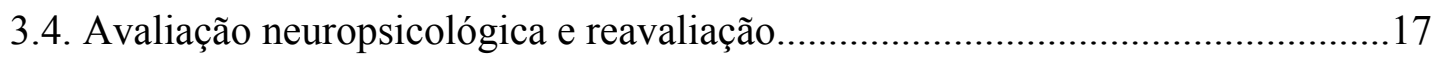

3.5. Transtorno de ansiedade na infância: aspectos neuropsicológicos......................20

3.5.1. Processos atencionais nos transtornos de ansiedade...........................22

3.5.2. Processos mnésticos nos transtornos de ansiedade.............................27

3.5.3. Funções executivas nos transtornos de ansiedade...................................33

3.6. Farmacologia nos transtornos de ansiedade........................................................40

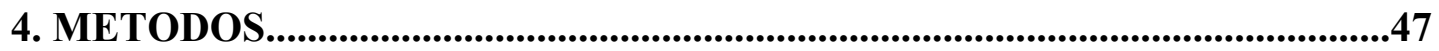

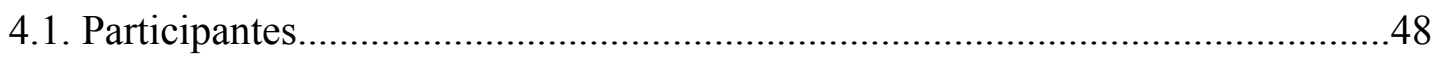

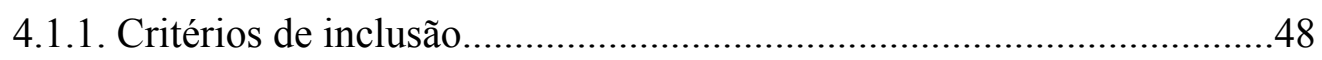

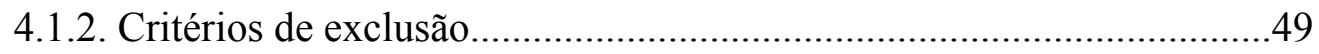

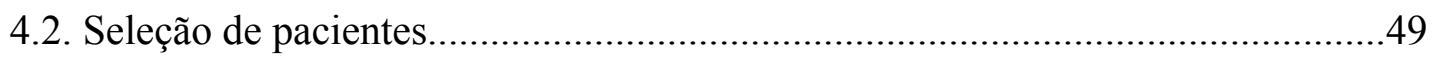




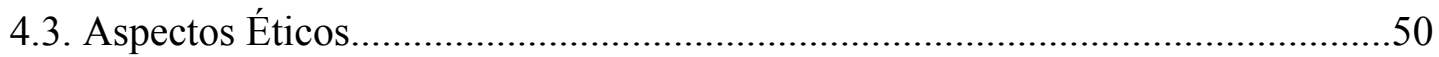

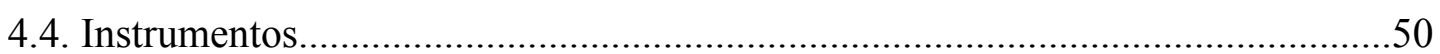

4.4.1. Avaliação neuropsicológica..............................................................

4.4.1.1. Provas cognitivas...............................................................51

4.4.2.2. Avaliação da ansiedade..........................................................53

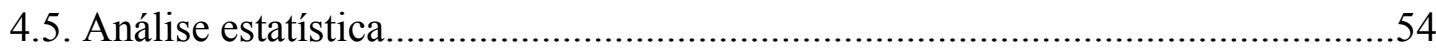

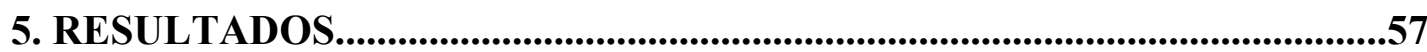

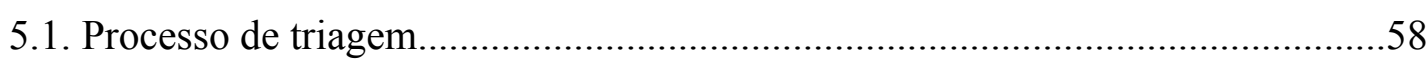

5.2. Características clínicas e demográficas................................................................6

5.3. Avaliação neuropsicológica..............................................................................64

5.3.1. Análise de covariância.....................................................................64

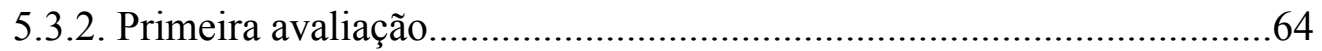

5.3.2.1. Eficiência intelectual..............................................................64

5.3.2.2. Funções atencionais e executivas.............................................65

5.3.2.3. Processos de memória e aprendizagem...................................67

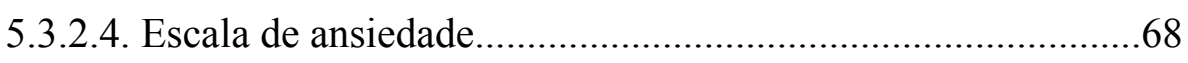

5.3.3. Segunda avaliação.............................................................................69

5.3.3.1. Eficiência intelectual.............................................................69

5.3.3.2. Funções atencionais e executivas..............................................71

5.3.3.3. Processos de memória e aprendizagem....................................78

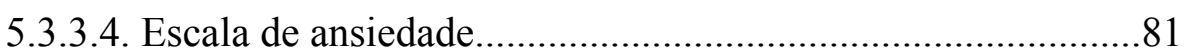

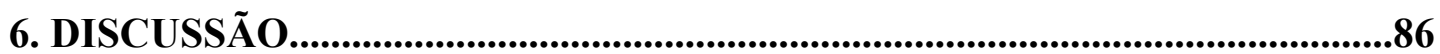

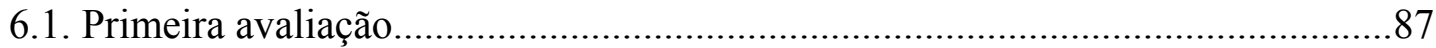

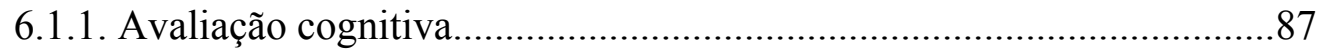

6.1.2. Manifestação da ansiedade.................................................................91

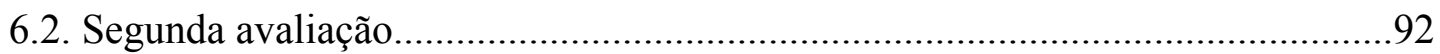

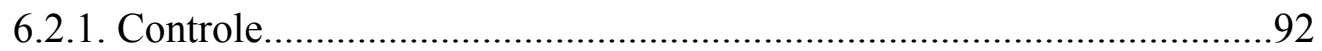

6.2.2. Diferentes tratamentos medicamentosos...............................................93

6.2.2.1. Ansiedade pré e pós tratamento medicamentoso (independentemente do tipo de tratamaneto) 


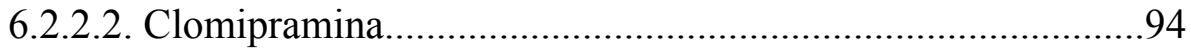

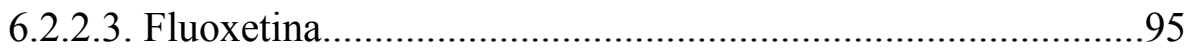

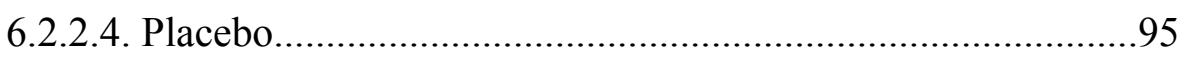

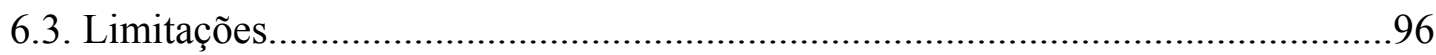

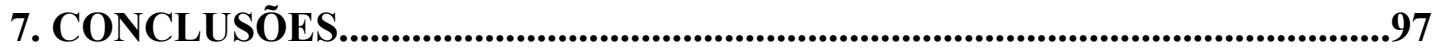

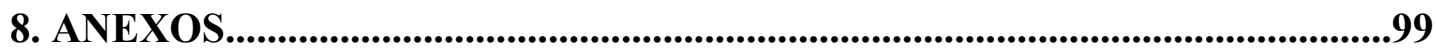

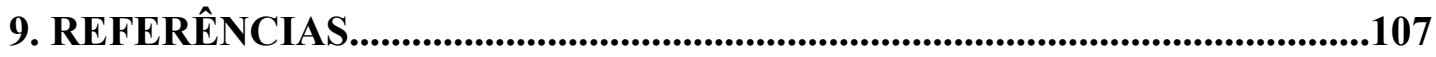

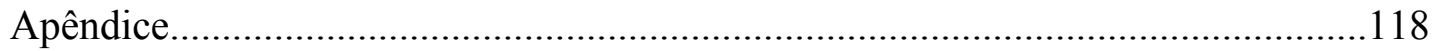




\section{Listas de Abreviaturas, Símbolos e Siglas}

TA

TAIA

TAS

TAE

TAG

FE

FS

TP

TDAH

TODO

DSM-III

DSM-IV-TR

WCST

FAS

RCFT

TASC

RCADS

CNCEQ

K-DIPS

CBCL

STAI-C

CDI

TAI- G

TEP

DISC
Transtornos de Ansiedade

Transtorno de Ansiedade na Infância e Adolescência

Transtorno de Ansiedade de Separação

Transtorno de Ansiedade Execessiva

Transtorno de Ansiedade Generalizada

Fobias Específicas

Fobia Social

Transtorno de Pânico

Transtorno de Déficit de Atenção e Hiperatividade

Transtorno Desafiador Opositor

Manual Diagnóstico e Estatístico de Transtornos Mentais terceira edição

Manual Diagnóstico e Estatístico de Transtornos Mentais -

quarta edição revisada

Wisconsin Card Sorting Test

Teste de Fluência Verbal para letras

Rey Complex Figure Test

Test Anxiety Scale for Children

Revised Child Reporto of Child Anxiety and Depression

Scales

Children's Negative Cognitive Error Questionnaire

Semi-Estructured Interview of the Children

Child Behavior Checklist

State-Trait Anxiety Inventory for Children and Adolescents

Children Depression Inventory

German Test Anxiety Inventory

Teoria da Eficiência do Processamento

Diagnostic Interview Schedule for Children 


\begin{tabular}{|c|c|}
\hline WISCIII & Wechsler Intelligence Scale for Children III \\
\hline WRAML & Wide Range Assement of Memory and Learning \\
\hline BDI & Beck Depression Inventory \\
\hline DRS & Dementia Ratting Scales \\
\hline CVLT & California Verbal Learning Test \\
\hline CVLT-C & California Verbal Learning Test-Children version \\
\hline DISC-R-P & Diagnostic Interview Schedule for Children- Revised Parent \\
\hline SCID & Structured Clinical Interview \\
\hline K-BIT & Kaufman Brief Intelligence \\
\hline K-SADS & Kiddie Schedule for Affective disorders and Schizophrenia \\
\hline CPT & Continuous Performance Test \\
\hline CBCL- TRF & Child Behavior Cheklist Teacher Report Form \\
\hline TCRS & Teacher-Child Rating Scale \\
\hline SCRS & Self-Control Rating Scale \\
\hline $\mathrm{CDM}$ & Child Depressed Mood \\
\hline SPQ-Y & $\begin{array}{l}\text { Seattle Personality Questionnaire for young school-age } \\
\text { children }\end{array}$ \\
\hline WISC-R & Wechsler Intelligence Scale for Children Revised \\
\hline CAT & California Achievement Test \\
\hline WRAT-R & Wide Range Achievement Test- Revised \\
\hline VADS & Visual Aural Digit Span Test \\
\hline TCS & Test of Cognitive Skills \\
\hline BGT & Bender Gestalt Test \\
\hline KEI & Kusché Emotional Inventory \\
\hline RCMAS & Revised Children's Manifest Anxiety Scale \\
\hline $\mathrm{SAC}$ & Cognitive Assessment System \\
\hline PISC-IV & Parent Interview for Child Symptoms \\
\hline TTI-IV & Teacher Telephone Interview \\
\hline CELF & Clinical Evaluation of Language Fundamentals \\
\hline SSP & Stop-Signal Paradigm \\
\hline MASC & Multidimensional Anxiety Scale for Children \\
\hline ADIS & Anxiety Disorder Interview Schedule \\
\hline
\end{tabular}


DANVA2

CHIPASAT

ISRS

ADT

TOC

COWAT

DSST

CT

SCT

IPQ HC FMUSP

ABIPEME

WASI

QI

MFFT-20

WRAML-2

SPSS

G TAIA

$\mathrm{G} \mathrm{CN}$

ANCOVA

TAIA 1

TAIA 2

$\mathrm{CN} 1$

$\mathrm{CN} 2$
Diagnostic Analysis of Nonverbal Accuracy 2

Children's Paced Auditory Serial Addition Test

Inibidores Seletivos da Recaptação da Serotonina

Antidepressivos Tricíclicos

Transtorno Obsessivo Compulsivo

Controlled Oral Word Association Test

Digit-Symbol Substitution Test

Cancellation Task

Symbol Copying Test

Instituto de Psiquiatria do Hospital das Clínicas da Faculdade de Medicina da Universidade de São Paulo

Associação Brasileira dos Institutos de Pesquisa de Mercado

Wechsler Abbreviated Scale of Intelligence

Quociente Intelectual

Matching Familiar Figures Test - 20

Wide Range Assement of Memory and Learning- 2

Statistical Package for Social Sciences

Grupo composto por todas as crianças e adolescentes com transtornos de ansiedade

Grupo composto por todas as crianças e adolescentes controles

Análise de covariância

Crianças e adolescentes do grupo com transtornos de ansiedade antes do tratamento medicamentoso e que foram reavaliadas

Crianças e adolescentes do grupo com transtornos de ansiedade depois do tratamento medicamentoso

Crianças e adolescentes do grupo controle na primeira avaliação e que foram reavaliadas

Crianças e adolescentes do grupo controle após seis meses da primeira avaliação 


CLO 1 Crianças e adolescentes do grupo com transtornos de ansiedade
que foram randomizadas para o tratamento medicamentoso
com clomipramina, antes do início do tratamento
medicamentoso
CLO 2
FLX 1
que foram submetidas ao tratamento com clomipramina
FLX 2
Crianças e adolescentes do grupo com transtornos de ansiedade
PLC 1
que foram submetidas ao tratamento com fluoxetina
PLC 2
\%




\section{Listas de Quadros}

Quadro 1 - Critérios diagnósticos para TAS, segundo o DSM-IV-TR 11

Quadro 2 - Critérios diagnósticos para TAG, segundo o DSM-IV-TR .13

Quadro 3 - Critérios diagnósticos para FS, segundo o DSM-TR .14

Quadro 4 - Estudos com crianças e adolescentes com transtornos de ansiedade e déficits de atencionais.

Quadro 5 - Estudos com crianças e adolescentes com transtornos de ansiedade e déficits de memória. 30

Quadro 6 - Estudos com crianças e adolescentes com transtornos de ansiedade e déficits nas funções executivas. .35

Quadro 7 - Comparação do desempenho no teste RCFT de uma criança com transtorno de ansiedade de 9 anos, com QI estimado na faixa média, antes e depois do tratamento medicamentoso - IPQ HC FMUSP - 2008 a 2011 121

Quadro 8 - Comparação do desempenho no teste RCFT de um adolescente com transtorno de ansiedade de 15 anos, com QI estimado na faixa limítrofe na primeira avaliação e na média na segunda, antes e depois do tratamento medicamentoso - IPQ HC FMUSP - 2008 a 2011 


\section{Listas de Tabelas}

Tabela 1 - Dados demográficos do grupo com transtornos de ansiedade e do grupo controle - IPQ HC FMUSP - 2008 a 2011

Tabela 2 - Análise de covariância dos itens que apresentaram uma diferença estatisticamente significativa em relação ao nível socioeconômico - IPQ HC FMUSP -2008 a 2011

Tabela 3 - Comparação do desempenho no teste de eficiência intelectual estimada dos grupos G TAIA e G CN - IPQ HC FMUSP - 2008 a 2011.

Tabela 4 - Comparação do desempenho nos testes de atenção e funções executivas dos sujeitos do grupo G TAIA e G CN - IPQ HC FMUSP - 2008 a 2011

Tabela 5 - Comparação do desempenho nos testes de memória e aprendizagem dos sujeitos dos grupos G TAIA e G CN - IPQ HC FMUSP - 2008 a 2011

Tabela 6 - Comparação do desempenho na escala de ansiedade de sujeitos do grupo

G TAIA e G CN - IPQ HC FMUSP - 2008 a 2011 .68

Tabela 7 - Comparação do desempenho das crianças e adolescentes dos grupos TAIA 1 e TAIA 2 e dos grupos CN1 e CN2, no teste de eficiência intelectual estimada IPQ HC FMUSP - 2008 a 2011

Tabela 8 - Comparação das crianças e adolescentes dos grupos CLO1 e CLO 2 e dos grupos FLX 1 e FLX 2, no teste de eficiência intelectual estimada - IPQ HC FMUSP -2008 a 2011

Tabela 9 - Comparação das crianças e adolescentes dos grupos PLC 1 e PLC 2 no teste de eficiência intelectual estimada - IPQ HC FMUSP - 2008 a 2011

Tabela 10 - Comparação do desempenho das crianças e adolescentes dos grupos TAIA 1 e TAIA 2 e dos grupos CN1 e CN2, nos testes de atenção e funções executivas - IPQ HC FMUSP - 2008 a 2011 
Tabela 11 - Comparação das crianças e adolescentes dos grupos CLO1 e CLO 2 e dos grupos FLX 1 e FLX 2, nos testes de atenção e funções executivas - IPQ HC FMUSP - 2008 a 2011

Tabela 12 - Comparação das crianças e adolescentes dos grupos PLC 1 e PLC 2, nos testes de atenção e funções executivas - IPQ HC FMUSP - 2008 a 2011. . .7

Tabela 13 - Comparação do desempenho das crianças e adolescentes dos grupos TAIA 1 e TAIA 2 e dos grupos CN1 e CN2, nos testes de memória e aprendizagem IPQ HC FMUSP - 2008 a 2011.

Tabela 14 - Comparação das crianças e adolescentes dos grupos CLO1 e CLO 2 e dos grupos FLX 1 E FLX 2, nos testes de memória e aprendizagem - IPQ HC FMUSP - 2008 a 2011

Tabela 15 - Comparação das crianças e adolescentes dos grupos PLC 1 e PLC 2, nos testes de memória e aprendizagem - IPQ HC FMUSP - 2008 a 2011 .81

Tabela 16 - Comparação do desempenho das crianças e adolescentes dos grupos TAIA 1 e TAIA 2 e dos grupos CN1 e CN2, na escala de ansiedade - IPQ HC FMUSP - 2008 a 2011

Tabela 17 - Comparação das crianças e adolescentes dos grupos CLO1 e CLO 2 e dos grupos FLX 1 e FLX 2, na escala de ansiedade - IPQ HC FMUSP - 2008 a 2011

Tabela 18 - Comparação das crianças e adolescentes dos grupos PLC 1 e PLC 2, na escala de ansiedade - IPQ HC FMUSP - 2008 a 2011

Tabela 19 - Comparação do valor do QI estimado entre as crianças e adolescentes do grupo de ansiedade nas fases pré e pós tratamento medicamentoso - IPQ HC FMUSP -2008 a 2011 


\section{Listas de Figuras}

Figura 1 - Processo de triagem dos participantes do estudo....................................58

Figura 2. Distribuição dos sujeitos da amostra clínica............................................59

Figura 3. Distribuição dos sujeitos submetidos a avaliações neuropsicológicas........60

Figura 4. Teste Figura Complexa de Rey..........................................................120 


\section{Lista de Gráficos}

Grafico 1. Frequência dos diagnósticos dos transtornos de ansiedade com e sem comorbidades com outros transtornos de ansiedade - IPQ HC FMUSP - 2008 a 2011 62

Grafico 2. Frequência dos transtornos de ansiedade sem comorbidade - IPQ HC FMUSP - 2008 a 2011 62

Grafico 3. Porcentagem da frequência dos diagnósticos de transtornos de ansiedade IPQ HC FMUSP - 2008 a 2011 63 
Rodrigues, Camila Luisi. Aspectos Neuropsicológicos dos Transtornos de Ansiedade na Infância e Adolescência: um estudo comparativo entre as fases pré e póstratamento medicamentoso [dissertação]. São Paulo: Faculdade de Medicina, Universidade de São Paulo; 2011.

O alto nível de ansiedade pode interferir no desempenho de diversas funções cognitivas. Nesse sentido, pessoas portadoras de transtorno de ansiedade são mais vulneráveis à presença de déficits cognitivos. Por meio de testagens neuropsicológicas, é possível mensurar o desempenho e, por conseguinte, descrever potenciais alterações de funções cognitivas. Estudos mostram déficits nos processos de atenção, memória e funções executivas. Uma vez que não existem dados suficientes na literatura sobre o funcionamento cognitivo de jovens com transtornos de ansiedade, objetivou-se com este estudo avaliar o funcionamento cognitivo em crianças e adolescentes com transtorno de ansiedade, pré e pós-tratamento medicamentoso. Para isso, foram estudados sujeitos (7 a 17 anos) diagnosticados com transtorno de ansiedade generalizada, transtorno de ansiedade de separação e/ou fobia social. Incluíram-se 30 portadores de ao menos um transtorno de ansiedade, avaliados antes do início do tratamento farmacológico, e 34 controles saudáveis. Dezoito sujeitos com transtornos de ansiedade foram reavaliados após terem sido aleatoriamente divididos (por meio de tabela de números aleatórios) em três grupos [clomipramina $(n=5)$, fluoxetina $(n=5)$ e placebo $(n=8)$ ] e submetidos a tratamento por um período de seis meses. Da mesma maneira, dez sujeitos do grupo controle foram reavaliados após o mesmo intervalo de tempo. Os instrumentos utilizados nas avaliações neuropsicológicas foram: "Wechsler Abbreviated Sacale of Intelligence", “Trail Making Test”, "Stroop Card Test”, "Matching Familiar Figures Test-20”, testes de fluência verbal para letras ("FAS") e para categoria ("animais"), "Wisconsin Card Sorting Test", "Torre de Hanói”, "Wide Range Assessment of Memory and Learning-2", "Figura Complexa de Rey". Para a avaliação de sintomas ansiosos, utilizou-se a "Escala Multidimensional de Ansiedade para Crianças". A partir dos dados obtidos, realizaram-se comparações estatísticas em dois momentos 
distintos: antes e depois do tratamento dos sujeitos diagnosticados com transtornos de ansiedade. Os resultados da avaliação pré-tratamento sugerem desempenho significativamente inferior nas atividades que medem atenção, memória visual, memória verbal e funções executivas entre sujeitos do grupo com transtorno de ansiedade em comparação ao do grupo controle. Em relação à sintomatologia ansiosa, conforme medida pela "Escala Multidimensional de Ansiedade para Crianças", o grupo com transtornos de ansiedade apresentou escores significativamente mais elevados que os observados entre os controles. Os resultados da avaliação pós-tratamento sugerem que, a partir de qualquer das intervenções realizadas (através de medicações ou placebo), o desempenho nos processos atencionais, mnésticos e executivos das crianças do grupo com transtorno de ansiedade melhora. Conclui-se, assim, que sintomas ansiosos nas crianças e adolescentes com transtorno de ansiedade interferem no desempenho das funções cognitivas.

Descritores: 1. Transtornos de ansiedade; 2. Criança; 3. Adolescente; 4. Neuropsicologia; 5. Reavaliação; 6. Medicamento. 
Rodrigues, Camila Luisi. Neuropsychological aspects of Anxiety Disorders in Children and Adolescents: a comparative study between the pre and postpharmacological treatment [dissertation]. São Paulo: "Faculdade de Medicina, Universidade de São Paulo"; 2011.

The high level of anxiety may interfere with the performance of various cognitive functions. Thus, people with anxiety disorders are more vulnerable to the presence of cognitive deficits. Through neuropsychological testings, it is possible to measure performance and, therefore, to describe potential changes in cognitive functions. Studies have pointed to deficits in attentional processes, memory and executive functions. Since there are insufficient data in the literature on the cognitive functioning of young people with anxiety disorders, the aim of this study is to evaluate cognitive functioning in children and adolescents with anxiety disorders, before and after pharmacological treatment. The sample consisted of subjects (7-17 years) diagnosed with generalized anxiety disorder, separation anxiety disorder and / or social phobia. Thirty subjects with at least one anxiety disorder, assessed before the beginning of pharmacological treatment, and 34 healthy controls. Eighteen subjects with anxiety disorders were reassessed after they have been randomly assigned (by table of random numbers) into three groups [clomipramine $(n=5)$, fluoxetine $(n=5)$ and placebo $(n=8)]$ and submitted to treatment for a period of six months. Likewise, ten subjects in the control group were evaluated after the same interval of time. The instruments used in the neuropsychological tests were "Wechsler Abbreviated Sacal of Intelligence," "Trail Making Test," "Card Stroop Test, Matching Familiar Figures Test-20", tests of verbal fluency for letters (FAS) and category (animals), "Wisconsin Card Sorting Test", "Tower of Hanoi", "Wide Range Assessment of Memory and Learning-2", "Rey Complex Figure". For the assessment of anxiety symptoms, the "Multidimensional Anxiety Scale for Children" was utilized. From the data observed, statistical comparisons were performed at two different times: before and after treatment of subjects with diagnoses of anxiety disorders. Results from the pre-treatment evaluation suggest that subjects from the 
anxiety disorder group when compared to the control group showed significantly lower performance in activities that measure attention, visual memory, verbal memory and executive function. In relation to anxiety symptoms, as measured by the "Multidimensional Anxiety Scale for Children", the group with anxiety disorders had significantly higher scores than those observed among controls. Results from the post-treatment evaluation suggest that, no matter which interventions have been used (either medications or placebo), performance on attentional, memory and executives processes of the group of children with anxiety disorder improved. We, therefore, conclude that anxious symptomatology in children and adolescents with anxiety disorder interferes with the performance of cognitive functions.

Words: 1. Anxiety disorders; 2. Child; 3. Adolescent; 4. Neuropsychology; 5. Reevaluation; 6. Medication. 


\section{INTRODUÇÃO}


Os Transtornos de Ansiedade (TA) são um dos quadros psiquiátricos mais comuns na infância (Asbahr, 2004). A ansiedade é de grande importância no campo da cognição e desempenho porque frequentemente está associada a efeitos adversos sobre o desempenho nas tarefas cognitivas (Eysenck et al., 2007). Quando excessiva, interfere negativamente no desempenho acadêmico (Monteiro, 1980; Rocha, 1976; Tobias, 1980; Wigfeld e Eccles, 1989).

Em situações de teste, indivíduos ansiosos sofrem com preocupações irrelevantes e inquietações sobre aspectos autoavaliativos. Tais ideias ocupam parcialmente sua capacidade de memória de trabalho, reduzindo sua capacidade de evocar as informações (Eysenck et al. apud Dutke e Stober, 2001).

As áreas cerebrais consideradas relacionadas à ansiedade são: a amígdala e o córtex pré-frontal (Lau e Pine, 2008). A amígdala parece estar relacionada à memória (Graeff, 2004) e o córtex pré-frontal às funções executivas (Santos, 2004).

Estudos neuropsicológicos sugerem que os indivíduos com Transtorno de Ansiedade na Infância e na Adolescência (TAIA) apresentam um desempenho prejudicado em diversas funções cognitivas: atenção, memória e funções executivas.

Em relação à memória, questiona-se se a dificuldade encontrada em crianças com TAIA estaria relacionada a uma disfunção primária da memória ou secundária à atenção (Vasa et al., 2007).

Nessa faixa etária, há escassez de estudos que relacionem transtornos ansiosos a alterações neuropsicológicas. Da mesma forma, há carência de ensaios clínicos que focalizem sobre os efeitos do tratamento medicamentoso desses pacientes com o desempenho cognitivo. Dessa maneira, faz-se necessário maior número de estudos que possam elucidar os déficits encontrados em pacientes com TAIA. 
1. Comparar o desempenho neuropsicológico de sujeitos portadores de transtorno de ansiedade na infância e adolescência sem tratamento prévio em relação ao dos controles normais;

2. Comparar o efeito do tratamento (com fluoxetina, clomipramina ou placebo) sobre o desempenho cognitivo entre os sujeitos com transtorno de ansiedade na infância e adolescência;

Hipotetiza-se que:

1. O grupo com transtorno de ansiedade apresente um desempenho inferior ao grupo controle nos processos atencionais, mnésticos e executivos;

2. O grupo com transtorno de ansiedade tratado com medicamento durante período de seis meses apresente um desempenho superior na segunda avaliação (póstratamento) em relação à primeira (pré-tratamento) nos processos atencionais, mnésticos e executivos;

3. O grupo placebo apresente desempenho inferior ao grupo que recebeu medicação nos processos atencionais, mnésticos e executivos. 
3 REVISÃO DA LITERATURA 
O levantamento bibliográfico para a revisão teórica desta dissertação foi realizado através de consultas às principais bases de dados eletrônicas, bem como em livros nacionais e internacionais a respeito dos transtornos de ansiedade. Os temas apresentados a seguir perfazem um conjunto de descrições e conceitos que fornecem sustentação teórica para a presente pesquisa.

\subsection{Desenvolvimento infantil: ansiedade normal ou patológica?}

Todas as pessoas em algum momento sentem ansiedade, não é um estado normal, mas é uma reação normal. Os animais também experimentam ansiedade, como meio de preservação (fugindo ou lutando). É um sinal de alerta, que adverte sobre perigos iminentes e possibilita a pessoa a tomar medidas para enfrentar ameaças e até mesmo disponibilizar recursos a fim de impedi-las (Kaplan et al., 1995). Desta maneira, seria uma resposta normal, adaptativa e positiva (Holmes, 1997).

A ansiedade natural é necessária para a sobrevivência e sem essa não lutaríamos para conquistar melhorias, não procuraríamos superar obstáculos, não fugiríamos em situações perigosas (Barbirato e Dias, 2009). É um acompanhamento normal do crescimento, da mudança, de experiência de algo novo (Gorenstein et al., 2000).

Também pode ser explicada como um estado afetivo penoso associado a uma atitude de expectativa de um acontecimento imprevisto, mas vivenciado como desagradável (Marcelli, 1998). Ou ainda como um estado emocional com aspectos psicológicos e fisiológicos, fazendo parte das experiências humanas (Gorenstein et al., 2000). Acompanhada de experiência subjetiva de medo ou outra emoção relacionada, como terror, horror, alarme e pânico. É desagradável, comparada a uma sensação de um perigo iminente, de colapso ou de morte. Direcionada ao futuro, de um modo geral não há um risco real, mas se houver, a emoção é desproporcionalmente intensa (Lewis, 1979, apud Gorenstein et al., 2000). 
Pode se diferenciar a ansiedade normal da patológica, avaliando se a reação ansiosa é de curta duração, autolimitada e/ou relacionada ao estímulo do momento ou não (Castilho et al., 2000). Na ansiedade patológica a característica adaptativa de alertar um perigo está excessiva, inapropriada e leva a um sofrimento intenso, podendo ser o sintoma inicial de um quadro psicopatológico (Marcelli, 1998). Essas reações exageradas frequentemente se desenvolvem quando há uma predisposição neurobiológica herdada (Asbahr, 2004).

Cada etapa do desenvolvimento infantil é influenciada por diversos aspectos como hereditários, ambientais, culturais, sociais entre outros. Há uma grande importância em se conhecer inicialmente o que é esperado para cada faixa etária, ou seja, o que é considerado um desenvolvimento saudável. Quanto maior o conhecimento do desenvolvimento infantil maior a distinção do que seria considerado saudável do patológico (Barbirato e Dias, 2009).

$\mathrm{Na}$ criança, o desenvolvimento emocional influencia as causas e as maneiras como os medos e preocupações se tornam aparentes. As crianças, especialmente as mais novas, podem ter dificuldade em reconhecer seus medos como exagerados ou irracionais (Asbahr, 2004).

À medida que essas crianças amadurecem, a maioria aumenta seu conhecimento sobre ferimentos e morte. Nas idades de 11 a 13 anos, algumas crianças podem evidenciar o que foi denominado de sensibilidade à ansiedade, que consiste em uma preocupação significativa em relação às mudanças nas funções corporais que fazem parte dos sintomas de ansiedade. Tal sensibilidade poderia interagir com a crescente habilidade cognitiva para elaborar e sentir medo de situações mais abstratas. A sensibilidade à ansiedade é um conceito mais pertinente aos adolescentes (Kissack e Léon, 2007).

Até a década de 80 havia a crença de que medos e preocupações durante a infância eram transitórios e benignos. Atualmente, reconhece-se que podem constituir quadros patológicos, quando excessivos (Souza et al., 2005).

A ansiedade considerada "patológica" relaciona-se à angústia antecipada e um comportamento de esquiva, ou seja, a criança sofre por antecipação e não faz nada que a amedronta. É um sentimento incômodo, uma preocupação com o fato de 
que algo inesperado pode, a qualquer momento, acontecer (Barbirato e Dias, 2009). Necessariamente implica prejuízos no dia-a-dia desses jovens.

\subsection{Transtorno de ansiedade na infância: aspectos clínicos}

A ansiedade tem sido uma das áreas mais difíceis de psicopatologia da infância para o estudo em amostras representativas da população. A avaliação é difícil porque muitas vezes as crianças e adolescentes têm dificuldade em falar sobre as preocupações, medos e pânicos. No entanto, os pais têm se mostrado confiáveis informantes sobre a ansiedade (Costello et al., 2005).

Crianças de 7 a 12 meses desenvolvem um medo de estranhos e expressam desconforto quando são separados de seus principais cuidadores. Esses medos apresentam um pico entre 9 e 18 meses de idade e diminuem aproximadamente com 2,5 anos. Aproximadamente $15 \%$ das crianças mostram medo mais intenso e persistente, timidez e retraimento social, em resposta a pessoas desconhecidas, situações ou objetos do que outras crianças (Costello et al., 2005).

Crianças com comportamentos mais inibidos exibem um padrão físiológico característico e são mais propensas a desenvolver um transtorno de ansiedade mais tarde (Costello et al., 2005).

Conforme a literatura de psicopatologia do desenvolvimento (Hinshaw, 1992), é possível identificar dois grandes grupos de problemas de comportamento: os externalizantes, que se expressam predominantemente em relação a outras pessoas e os internalizantes, que se expressam predominantemente em relação ao próprio indivíduo. Del Prette e Del Prette (2005) associam esses dois grupos a transtornos psicológicos específicos: (a) os problemas externalizantes, mais freqüentes, são os que envolvem agressividade física e/ou verbal, comportamentos opositores ou desafiantes, condutas anti-sociais como mentir e roubar e comportamentos de risco como uso de substâncias psicoativas; (b) os problemas internalizantes são mais prontamente identificáveis em transtornos como depressão, isolamento social, ansiedade e fobia social. 
Os transtornos de ansiedade encontram-se entre as doenças psiquiátricas mais comuns em crianças e adolescentes. Estima-se que até $10 \%$ das crianças e adolescentes sofrem de algum transtorno ansioso (Asbahr, 2004).

Os sintomas são em geral descritos como um sentimento de apreensão desagradável e vago, acompanhado de sensações físicas como: frio no estômago, aperto no peito, transpiração e falta de ar, dentre várias outras. Essas manifestações corporais involuntárias podem ser manifestadas como secura da boca, sudorese, arrepios, tremores, vômitos, palpitações, dores abdominais e outras, além do aumento da freqüência urinária (Gorenstein et al., 2000).

Crianças de 4 e 5 anos foram significativamente mais prováveis de apresentarem um transtorno de ansiedade do que as de 2 a 3 anos (11,9\% versus $7 \%)$. As meninas são mais prováveis do que meninos. A diferença tende a ser clinicamente e estatisticamente significativa duas vezes mais nas meninas (Costello et al., 2005).

$\mathrm{Na}$ infância, os transtornos ansiosos mais frequentes são: o Transtorno de Ansiedade de Separação (TAS) com prevalência em torno de 4\%, o Transtorno de Ansiedade Excessiva (TAE) ou o atual Transtorno de Ansiedade Generalizada (TAG) com prevalência de 2,7\% a 4,6\%, as Fobias Específicas (FE) com prevalência de $2,4 \%$ a $3,3 \%$, a Fobia Social (FS) com prevalência em torno de 1\% e o Transtorno de Pânico (TP) com 0,6\% (Asbahr, 2004).

A comorbidade é elevada, sendo que pelo menos $30 \%$ dos jovens portadores de um transtorno de ansiedade têm também outro transtorno ansioso associado. As possíveis explicações da presença frequente de transtornos múltiplos de ansiedade incluem a ocorrência de um transtorno de ansiedade que age como um fator de risco para outros, de tal maneira que diferentes transtornos de ansiedade têm a mesma etiologia ou sintomas sobrepostos, fato pelo qual os sujeitos atendem os critérios diagnósticos múltiplos (Kashani e Orvaschel, 1990). Mais da metade passará por um episódio depressivo como parte de sua síndrome ansiosa. Outras comorbidades com grande prevalência são os Transtornos de Déficit de Atenção e Hiperatividade (TDAH) e o transtorno de conduta (Bernstein et al., 1996; Williams e Miller, 2003).

Segundo estudo de Costello et al. (2005) a comorbidade mais comum não ansiosa seria a depressão, sendo 8,2 vezes mais prováveis em crianças com 
transtornos de ansiedade. Já em relação a outros transtornos, a comorbidade com transtorno de conduta ou com o Transtorno Desafiador Opositivo (TDO) seria 3,1 e com o TDAH seria 3,0 .

Além desse estudo, outros demonstraram que os problemas de ansiedade na infância são fatores de risco para outras formas de psicopatologia, como transtornos de conduta, transtornos de humor e para as tentativas e efetivação do suicídio (Silva e Figueiredo, 2005).

Estudos longitudinais indicam que as doenças psiquiátricas na infância são precursoras de uma gama de resultados negativos, ou seja, se uma criança sofre de uma doença psiquiátrica na infância e não é tratada, ela tem maior risco de desenvolver outros transtornos emocionais ao longo de sua vida adulta (Sourander et al., 2007).

Abaixo serão citados os três tipos de transtornos de ansiedade incluídos na amostra desse estudo.

\subsubsection{Transtorno de ansiedade de separação}

A ansiedade de separação se tornou uma categoria diagnóstica apenas em 1980, com a inclusão no Manual Diagnóstico e Estatístico de Transtornos Mentaisterceira edição (DSM-III) como um transtorno exclusivo da infância (Méndez et al., 2007).

O TAS é caracterizado por ansiedade excessiva acerca da separação de casa, pais ou seus substitutos, não adequada ao nível de desenvolvimento, que persiste por, no mínimo, quatro semanas, causando sofrimento intenso e prejuízos significativos em diferentes áreas da vida da criança ou adolescente (Asbahr, 2004).

Estas crianças temem que algo terrível aconteça a alguém próximo ou a elas próprias, quando afastadas das figuras de vinculação. Preocupações comuns envolvem a possibilidade de seus pais sofrerem um acidente, assalto ou ficarem doentes, assim como temor de se perderem ou serem seqüestradas e serem afastadas permanentemente dos pais (Kaplan, 1997). 
O TAS é considerado mais grave, aparece em idades mais precoces e o tempo requerido para o seu diagnóstico é menor (Méndez et al., 2007).

Quando a criança fica mais velha, a ansiedade de separação pode ser manifestada em sinais como os telefonemas repetidos que dá à mãe ou a outro adulto, como forma de se assegurar do bem-estar deles. Na pré-escola essas crianças têm forte medo de serem deixadas sozinhas (Barbirato e Dias, 2009).

O quadro 1 apresenta os critérios diagnósticos do TAS, segundo o Manual Diagnóstico e Estatístico de Transtornos Mentais- quarta edição revisada (DSM-IVTR) (American Psychiatric Association, 2000).

\section{Quando 1 - Critérios diagnósticos para TAS, segundo o DSM-IV-TR}

A. Ansiedade imprópria e excessiva em relação ao nível de desenvolvimento, envolvendo a separação do lar ou de figuras de vinculação, evidenciada por três (ou mais) dos seguintes aspectos: (1) sofrimento excessivo e recorrente frente à ocorrência ou previsão de afastamento de casa ou de figuras importantes de vinculação

(2) preocupação persistente e excessiva acerca da possível perda, ou perigos envolvendo figuras importantes de vinculação

(3) preocupação persistente e excessiva de que um evento indesejado leve à separação de uma figura importante de vinculação (por ex., perder-se ou ser sequestrado)

(4) relutância persistente ou recusa a ir para a escola ou a qualquer outro lugar, em virtude do medo da separação

(5) temor excessivo e persistente ou relutância em ficar sozinho ou sem as figuras importantes de vinculação em casa ou sem adultos significativos em outros contextos

(6) relutância ou recusa persistente a se recolher sem estar próximo a uma figura importante de vinculação ou a pernoitar longe de casa

(7) pesadelos repetidos envolvendo o tema da separação

(8) repetidas queixas de sintomas somáticos (tais como cefaleias, dores abdominais, náusea ou vômitos) quando a separação de figuras importantes de vinculação ocorre ou é prevista

B. A perturbação tem uma duração mínima de 4 semanas.

C. A perturbação inicia antes dos 18 anos.

D. A perturbação causa sofrimento clinicamente significativo ou prejuízo no funcionamento social, acadêmico (ocupacional) ou em outras áreas importantes da vida do indivíduo.

E. A perturbação não ocorre exclusivamente durante o curso de um Transtorno Global do Desenvolvimento, Esquizofrenia ou outro Transtorno Psicótico e, em adolescentes e adultos, não é mais bem explicada por Transtorno de Pânico com Agorafobia.

Especificar se:

Início Precoce: se o início ocorre antes dos 6 anos de idade. 


\subsubsection{Transtorno de ansiedade generalizada}

O TAG é a denominação dada pelo DSM-IV-TR à categoria diagnóstica que integra e modifica duas categorias que apareciam no DSM-III: o TAE e o TAG. Dessa maneira o TAE é enquadrado como uma variante do TAG (Kissack e León, 2007).

As crianças com TAG apresentam medo excessivo, preocupações ou sentimentos de pânico exagerados e irracionais a respeito de várias situações. Estão constantemente tensas e dão a impressão de que qualquer situação é ou pode ser provocadora de ansiedade. São crianças que estão sempre muito preocupadas com o julgamento de terceiros em relação a seu desempenho em diferentes áreas e necessitam exageradamente que lhes renovem a confiança, que as tranqüilizem (Asbahr, 2004).

O TAG é um dos transtornos de ansiedade de início na infância avançada (10,8 anos). Os sintomas devem se apresentar durante um período não inferior a seis meses em relação com duas ou mais circunstâncias da vida que não podem ser atribuídas a nenhum outro transtorno do Eixo I. Devem apresentar pelo menos seis sintomas físicos que reflitam tensão motora, hiper-reatividade autonômica, vigilância e escrutínio (Kissack e León, 2007).

A presença de sintomas somáticos muitas vezes leva os familiares a procurarem os pediatras, em primeira instância. Os sintomas somáticos mais comuns são cefaleia, náuseas e vômitos, taquicardia, sudorese, dispneia, formigamentos e dor muscular (Kendall e Pimentel, 2003). O pediatra investiga, mas não consegue descobrir nada (Barbirato e Dias, 2009).

$\mathrm{O}$ adulto deprimido normalmente tem um histórico de sintoma de ansiedade generalizada na infância. Essa ansiedade afeta até 4\% das crianças e é mais comum em meninas do que meninos. A criança pode ter uma necessidade extrema de agradar, pergunta várias vezes a mesma coisa e se preocupa demais com tarefas, lazer, relações. É uma aflição abrangente que também pode prejudicar o funcionamento social e acadêmico. Sofrem demais e levam seu sofrimento para a adolescência (Barbirato e Dias, 2009). 
O quadro 2 apresenta os critérios diagnósticos do TAG, segundo o DSM-IVTR (American Psychiatric Association, 2000).

\title{
Quando 2 - Critérios diagnósticos para TAG, segundo o DSM-IV-TR
}

\begin{abstract}
A. Ansiedade e preocupação excessivas (expectativa apreensiva), ocorrendo na maioria dos dias pelo período mínimo de 6 meses, com diversos eventos ou atividades (tais como desempenho escolar ou profissional).
\end{abstract}

B. O indivíduo considera difícil controlar a preocupação.

C. A ansiedade e a preocupação estão associadas com três (ou mais) dos seguintes seis sintomas (com pelo menos alguns deles presentes na maioria dos dias nos últimos 6 meses).

Nota: Apenas um item é exigido para crianças.

(1) inquietação ou sensação de estar com os nervos à flor da pele

(2) fatigabilidade

(3) dificuldade em concentrar-se ou sensações de "branco" na mente

(4) irritabilidade

(5) tensão muscular

(6) perturbação do sono (dificuldades em conciliar ou manter o sono, ou sono insatisfatório e inquieto)

D. O foco da ansiedade ou preocupação não está confinado a aspectos de um transtorno do Eixo I; por exemplo, a ansiedade ou preocupação não se refere a ter um Ataque de Pânico (como no Transtorno de Pânico), ser envergonhado em público (como na Fobia Social), ser contaminado (como no Transtorno Obsessivo-Compulsivo), ficar afastado de casa ou de parentes próximos (como no Transtorno de Ansiedade de Separação), ganhar peso (como na Anorexia Nervosa), ter múltiplas queixas físicas (como no Transtorno de Somatização) ou ter uma doença grave (como na Hipocondria), e a ansiedade ou preocupação não ocorre exclusivamente durante o Transtorno de Estresse Pós-Traumático.

E. A ansiedade, a preocupação ou os sintomas físicos causam sofrimento clinicamente significativo ou prejuízo no funcionamento social ou ocupacional ou em outras áreas importantes da vida do indivíduo.

F. A perturbação não se deve aos efeitos fisiológicos diretos de uma substância (droga de abuso, medicamento) ou de uma condição médica geral (por ex., hipertireoidismo) nem ocorre exclusivamente durante um Transtorno do Humor, Transtorno Psicótico ou Transtorno Global do Desenvolvimento. 


\subsubsection{Fobia social (FS)}

Para considerar um medo infantil fóbico são necessárias duas condições, que seja desproporcional às demandas da situação e que a elevada intensidade transforme o medo em um comportamento desadaptativo. Em alguns casos, os objetos temidos não constituem nenhuma ameaça objetiva ao bem-estar biopsicossocial do indivíduo, de modo que o medo é irracional. Em outras situações, existe a probabilidade, embora pequena, de receber estimulação aversiva, porém a resposta excessiva é considerada fóbica, como o fenômeno do "dar branco" em um aluno inteligente e estudioso que sofre de ansiedade em provas (Méndez et al., 2007).

Crianças com fobia social relatam desconforto em inúmeras situações: falar em sala de aula, comer na cantina próximo a outras crianças, ir a festas, escrever na frente de outros colegas, usar banheiros públicos, dirigir a palavra a figuras de autoridade como professores e treinadores, além de conversas/ brincadeiras com outras crianças. Nessas situações, comumente há a presença de sintomas físicos como: palpitações, tremores, calafrios e calores súbitos, sudorese e náusea (Asbahr, 2004).

O quadro 3 apresenta os critérios diagnósticos da FS, segundo o DSM-IV-TR, com suas especificidades na infância e adolescência (American Psychiatric Association, 2000).

Quadro 3. Critérios diagnósticos para FS, segundo o DSM-IV-TR

\footnotetext{
A. Medo acentuado e persistente de uma ou mais situações sociais ou de desempenho, nas quais o indivíduo é exposto a pessoas estranhas ou ao possível escrutínio por terceiros. O indivíduo teme agir de um modo (ou mostrar sintomas de ansiedade) que lhe seja humilhante e vergonhoso.

Nota: Em crianças, deve haver evidências de capacidade para relacionamentos sociais adequados à idade com pessoas que lhes são familiares, e a ansiedade deve ocorrer em contextos que envolvam seus pares, não somente em interações com adultos.

B. A exposição à situação social temida quase invariavelmente provoca ansiedade que, pode assumir a forma de um Ataque de Pânico ligado à situação ou predisposto por situação.

Nota: Em crianças, a ansiedade pode ser expressa por choro, ataques de raiva, imobilidade ou afastamento de situações sociais com pessoas estranhas.

C. A pessoa reconhece que o medo é excessivo ou irracional.

Nota: Em crianças, esta característica pode estar ausente.
} 
D. As situações sociais e de desempenho temidas são evitadas ou suportadas com intensa ansiedade e sofrimento.

E. A esquiva, a antecipação ansiosa ou o sofrimento na situação social ou de desempenho temida interferem significativamente na rotina, no funcionamento ocupacional (acadêmico), em atividades sociais ou relacionamentos do indivíduo, ou existe sofrimento acentuado por ter a fobia.

F. Em indivíduos com menos de 18 anos, a duração é de no mínimo 6 meses.

G. O temor ou esquiva não se deve aos efeitos fisiológicos diretos de uma substância (por ex., droga de abuso, medicamento) ou de uma condição médica geral, nem é mais bem explicado por outro transtorno mental (por ex., Transtorno de Pânico Com ou Sem Agorafobia, Transtorno de Ansiedade de Separação, Transtorno Dismórfico Corporal, Transtorno Global do Desenvolvimento ou Transtorno de Personalidade Esquizóide).

H. Em presença de uma condição médica geral ou outro transtorno mental, o medo no Critério A não tem relação com estes; por exemplo, o medo não diz respeito a Tartamudez, tremor na doença de Parkinson ou manifestação de um comportamento alimentar anormal na Anorexia Nervosa ou Bulimia Nervosa.

Especificar se:

Generalizada: se os temores incluem a maioria das situações sociais (considerar também o diagnóstico adicional de Transtorno da Personalidade Esquiva).

conclusão

\subsection{Bases biológicas da ansiedade}

Em um estudo recente, Lau e Pine (2008) analisaram o processamento de informações de ameaças e anomalias em circuitos do cérebro na expressão da ansiedade pediátrica. Apontaram que a relação entre riscos ambientais para os comportamentos ansiosos dependem das características genéticas. Assim, o meio ambiente poderia ser um gatilho para que os aspectos genéticos se desenvolvessem. Além disso, os riscos genéticos para a ansiedade pediátrica se manifestam através de uma maior sensibilidade aos ambientes estressores. Dessa maneira, enfatizam a importância de analisar as ligações entre genes, a função do cérebro e processamento de informações na infância e adolescência (Lau e Pine, 2008).

Alguns autores acreditam que as funções cerebrais mais relacionadas à ansiedade seriam a amígdala e o córtex pré-frontal. Ambos regulam as respostas às emoções e poderiam ser marcadores candidatos na mediação de risco genético (Lau e Pine, 2008).

Gray e Naughton (2007) estudaram a relação entre a teoria da neuropsicologia da ansiedade e do funcionamento do sistema septo-hipocampal. Tal 
sistema detectaria um conflito entre os objetivos simultaneamente disponíveis e para resolvê-lo, o sistema aumentaria o peso dado à informação negativa em áreas de processamento, sendo que esse aumento na informação afetivamente negativa produziria o aumento de ansiedade em algumas tarefas, reduzindo o efeito de interferência da memória em outras (Gray e Naughton, 2007).

O funcionamento do sistema septo-hipocampal seria facilitado por aferências nervosas mediadas pelos neurotransmissores noradrenalina e serotonina, provenientes do tronco cerebral, onde atuariam os medicamentos ansiolíticos. Há estudos que apontam que lesões do septo, do hipocampo dorsal, ou ambas as estruturas, têm efeitos semelhantes a esses medicamentos (Graeff, 2004).

Atualmente, acreditam que a estrutura cerebral chave subjacente à ansiedade seria a amígdala (Gray e Naughton, 2007). A amígdala avalia a natureza e intensidade da ameaça, atribuindo a ela conotação afetiva. Há uma grande importância no papel desempenhado pela amígdala no condicionamento da ansiedade e na memória emocional, havendo assim uma associação entre emoção e memória (Graeff, 2004). Também é conhecida por sua importância para o aprendizado e memória emocional e esse papel afeta uma variedade de comportamentos emocionais relacionados ao aprendizado implícito, à memória explícita, a respostas sociais e vigilância (Gazzaniga et al., 2006).

Jovens ansiosos, em relação aos não ansiosos, prestam mais atenção e são mais facilmente influenciados por estímulos ameaçadores e essa influência está associada à ou mediada por atividade excessiva da amígdala. Dessa maneira, a ativação da amígdala pode refletir os processos associados à ansiedade, enquanto que, no córtex, pode refletir processos associados à modulação tanto da atividade da amígdala como da resposta emocional associada (Pine et al., 2008).

Evidências clínicas comprovam a importância do córtex pré-frontal na ansiedade. A ansiedade cotidiana não é provocada por estímulos ameaçadores inatos e condicionados, ou ainda pela novidade, mas por sinais (verbais e não verbais) com significado simbólico. Nesse contexto as estruturas mais importantes são o córtex pré-frontal e as regiões frontais e temporais que permitem a compreensão verbal. Por 
meio delas, estímulos de natureza psicossocial passam a influir poderosamente sobre a ansiedade (Graeff, 2004).

O córtex pré-frontal é o local de armazenamento primário para a interação entre a informação perceptiva corrente e o conhecimento armazenado, constituindo um componente relevante do sistema de memória de trabalho (Gazzaniga et al., 2006).

O papel do córtex pré-frontal parece ser a análise de situações complexas e regulação das respostas afetivas a essas. Ele atua modulando a atividade do sistema septo-hipocampal. A hiperativação do córtex pré-frontal direito parece estar associada à ansiedade e afetos negativos (Phan et al., 2004).

A ansiedade poderia ser resultado de uma disfunção cognitiva relacionada à hiperatividade do hipocampo, estrutura que estaria relacionada à memória (Graeff, 2004) e à ansiedade (Mcnaughton, 1997).

\subsection{Avaliação neuropsicológica e reavaliação}

A avaliação neuropsicológica possibilita descrever uma função cerebral, além de fornecer informações sobre a cognição, características da personalidade, comportamento social, estado emocional e condições de ajustamento. Pode-se deduzir o potencial do indivíduo e descrever as funções deficitárias e preservadas. Envolve o estudo do comportamento utilizando entrevistas, questionários e testes que permitam mapear o desempenho do paciente de forma relativamente precisa (Lezak, 1995).

As áreas usualmente avaliadas nas baterias neuropsicológicas são: atenção, processamento visuoespacial, memória, linguagem compreensiva e expressiva, cálculo, funções executivas, formação de conceitos, habilidades motoras e características emocionais (Lezak, 1995).

$\mathrm{Na}$ avaliação neuropsicológica em crianças, os resultados devem ser analisados com cautela, considerando os fatores ambientais e de desenvolvimento. Outros métodos como: a observação clínica e o diagnóstico médico devem ser 
conjuntamente considerados para a interpretação dos resultados. A bateria de avaliação neuropsicológica infantil deve apresentar parâmetros de precisão e validade adequados (Golden,1991), com normas traçadas para diferentes idades ou níveis escolares (Lezak, 1995).

No Brasil, pesquisadores e clínicos que trabalham com avaliação neuropsicológica se deparam com o problema bastante grave da escassez de instrumentos validados disponíveis para pesquisa e diagnóstico (Capovila, 2007). Isso aumenta a necessidade da avaliação neuropsicológica em um grupo controle, ou seja, um grupo sem diagnósticos psiquiátricos.

É de fundamental importância a preparação do paciente para a avaliação, procurando obter sua cooperação e motivação para o processo, além de aliviar sentimentos de ansiedade, fator este a ser considerado devido à interferência no desempenho (Capovilla, 2007).

As repetições das avaliações neuropsicológicas são comuns na prática clínica. Os neuropsicólogos freqüentemente realizam a reavaliação para determinar sobre a doença e progressão das lesões ou recuperação. As avaliações são geralmente separadas por meses ou anos, as testagens com um intervalo rápido são ocasionalmente usadas em casos de lesão aguda e de recuperação (Beglinger et al., 2005).

Um estudo com pacientes com abuso e dependência de álcool, aponta para o benefício de reavaliações neuropsicológicas periódicas, que permitem a análise sistematizada das mudanças ocorridas no funcionamento cognitivo, indicando os benefícios de um tratamento ou a evolução do estado neuropsiquiátrico (Gruber e Yurgelun-todd, 2001).

Além disso, essas avaliações são utilizadas no desenvolvimento de novos tratamentos farmacêuticos verificando o quanto essas medicações afetam a cognição. Existem algumas limitações nessa fase inicial de ensaios de investigação da droga que incluem a utilização de voluntários saudáveis, pequenas amostras, o uso de escalas originalmente desenvolvido para pacientes com comprometimento da cognição, e re-teste em intervalos curtos (Beglinger et al., 2005). 
Esses fatores limitam o poder do estudo para detectar mudanças cognitivas em voluntários saudáveis, o que pode ser devido à aprendizagem que resulta da exposição repetida ao teste de materiais (isto é, os efeitos da "prática"). Variabilidade individual no desempenho do teste ao longo do tempo também pode limitar os resultados nesta fase (Beglinger et al., 2005).

Nestes estudos, a idade, doenças neurológicas, efeito da prática, intervalo entre os ensaios e tipo de teste de avaliação neuropsicológica afetam a estabilidade dos resultados ao longo do tempo. Formas alternativas têm sido mostradas para minimizar efeitos da prática (Beglinger et al., 2005).

Um estudo foi realizado com o objetivo de verificar a eficácia da medicação de antipsicóticos de segunda geração e os efeitos na cognição. Realizou-se uma análise dos efeitos da quetiapina na cognição de pacientes com esquizofrenia. As avaliações foram realizadas após 3, 6 e 12 meses do tratamento. Nesse estudo foram avaliadas as funções atencionais, produção verbal e funções executivas. Após 3 meses observou-se melhora no teste que media a atenção (Good et al., 2002). Dos testes utilizados nesse estudo, três foram utilizados na pesquisa: Wisconsin Card Sorting Test (WCST), Trail Making Test, Teste de Fluência Verbal para letras (FAS).

Outro estudo objetivou verificar as alterações na área de percepção visual e na memória imediata em 152 participantes masculinos com o diagnóstico de alcoolismo. Para a avaliação neurocognitiva foi utilizado o Rey Complex Figure Test (RCFT), aplicado em dois momentos com um intervalo de 3 meses entre os testes. Os resultados em relação à percepção visual não apresentaram diferenças estatisticamente significativas entre os dois momentos, já em relação à memória houve uma diferença, com uma melhora no segundo momento (Oliveira et al, 2002).

A confiabilidade nos resultados dos testes intelectuais tem sido investigada através de teste-re-teste com breves intervalos de tempo, questionando-se sua efetiva estabilidade diante das mudanças socioculturais das últimas décadas. Um estudo investigou a estabilidade temporal, após intervalo de seis meses entre teste-re-teste, do Teste de Goodenough e da Escala de Maturidade Mental Colúmbia. Os testes foram aplicados, individualmente. Os resultados apontaram razoável estabilidade dos 
dados, oferecendo confiabilidade técnica na avaliação cognitiva infantil (Marques et al., 2002).

Um instrumento de Avaliação Neuropsicológica Breve NEUPSILIN que mede: orientação têmporo-espacial, atenção, percepção, memória, habilidades aritméticas, linguagem, praxias, resolução de problemas e fluência verbal investigou novas evidências de validade e fidedignidade desse teste. Para isso alguns participantes foram retestados após um intervalo médio de 4 meses. Os resultados indicaram evidências de validade (Pawlowski et al., 2007).

\subsection{Transtorno de ansiedade na Infância: aspectos neuropsicológicos}

Crianças com desempenho escolar pobre freqüentemente apresentam problemas de comportamento externalizantes, caracterizados por impulsividade e atuação (Hinshaw, 1992). Manifestações internalizantes, como ansiedade e retraimento, também são comuns (Thompson et al., 1990).

Muitas vezes, alunos ansiosos têm também hábitos de estudo pobres e dificuldade em organizar o material. Há uma hipótese de que haja diferenças de desempenho entre indivíduos de alto e baixo nível de ansiedade e que essa diferença reflete na atenção para as tarefas que estão realizando. Dessa maneira, os indivíduos com alta ansiedade dividem a atenção entre a tarefa e suas ruminações sobre como eles estão fazendo, concentrando-se assim menos sobre o desempenho nas tarefas (Wigfeld e Eccles, 1989). Os sintomas comportamentais de ansiedade relativos ao desempenho escolar em crianças ansiosas incluem a agitação e dificuldade de concentração (American Psychological Association, 2000).

A ansiedade é de grande importância no campo da cognição e desempenho porque freqüentemente está associada a efeitos adversos sobre o desempenho nas tarefas cognitivas (Eysenck et al., 2007). Quando é excessiva interfere negativamente no desempenho acadêmico (Monteiro, 1980; Rocha, 1976;; Tobias, 1980; Wigfeld e Eccles, 1989) podendo ter um grande impacto na autoconfiança provocando o medo de errar (Spreen e Strauss, 1998). Parece haver uma relação entre nível elevado de 
ansiedade e baixo desempenho cognitivo em tarefas mais complexas (Dutke e Stober, 2001).

Em adultos, observam-se déficits na atenção, no reconhecimento visual, nas funções motoras e no tempo de reação em populações com ansiedade e depressão (Emerson et al., 2005).

Todo o funcionamento cognitivo do indivíduo pode ser afetado, visto que a atenção está alterada. Essa alteração no sistema atencional pode ser consequência de uma hiperatividade da amígdala, que também pode dificultar o planejamento e a execução de metas de longo prazo e aumentar a execução de comportamentos guiados por metas imediatas (Sapir e Aronson, 1990).

Sintomas de depressão ou ansiedade podem ser associados a prejuízos neuropsicológicos, crianças com esses sintomas são mais propensas a apresentarem prejuízos na memória de trabalho, na flexibilidade cognitiva, na velocidade de processamento e na memória verbal. Estes prejuízos podem resultar em criança que têm dificuldade em participar e completar de maneira eficiente suas tarefas escolares, de organizar e planejar projetos de longo alcance e memorizar informações aprendidas na escola (Micco et al, 2009).

Além dessas alterações cognitivas, observa-se que o estado de alerta, o estresse e a ansiedade são importantes moduladores das fases iniciais da formação da memória e sua evocação (Quevedo et al., 2003). Dessa maneira, a ansiedade pode prejudicar a capacidade de recordar ou recuperar um conteúdo aprendido em momento de tensão (Wigfeld e Eccles, 1989).

Abaixo se buscou separar didaticamente algumas funções cognitivas citadas em estudos relacionando crianças e adolescentes com ansiedade excessiva e os aspectos neuropsicológicos: processos atencionais, mnésticos e funções executivas. 


\subsubsection{Processos atencionais nos transtornos de ansiedade}

Toda atividade necessita de um direcionamento e de seletividade. Dos muitos estímulos que nos chegam apenas alguns são escolhidos como foco de nosso interesse ou são importantes para que possamos realizar determinada tarefa. A função cerebral responsável por esta atividade é a atenção (Silva, 1999).

O termo atenção é usado para se referir à capacidade de selecionar parte do estímulo que está entrando para um processamento mais intenso, e por vezes, é usado como sinônimo de concentração ou estado mental (Moray, 1969, apud Silva, 1999).

Sendo assim a atenção seria um sistema no qual ocorre um processo seqüencial numa série de estágios, com diferentes sistemas cerebrais envolvidos, pode variar de acordo com cada pessoa, em diferentes condições e grau de alerta (Silva, 1999).

Uma das maneiras de se dividir a atenção é a proposta pela Lezak em 1995:

- "Span” de Atenção ou Amplitude Atencional - quantidade de informação que pode ser processada de uma só vez. É um processo seletivo que tende a ser resistente aos efeitos da idade e de muitas doenças cerebrais;

- Atenção Seletiva ou Focalizada - capacidade de focalizar um ou dois estímulos importantes com supressão de estímulos distratores, geralmente é referido como concentração.

- Sustentação da Atenção ou Vigilância - capacidade de manter a atividade atencional por um período de tempo.

- Atenção dividida - habilidade de responder a mais de uma tarefa ao mesmo tempo ou a múltiplos elementos ou operações de uma tarefa mental complexa. É o aspecto mais sensível, e seu prejuízo reduz a capacidade atencional.

- Atenção Alternada - capacidade de seguir a mudança de foco de uma tarefa.

Esses aspectos podem ser demonstrados por diferentes exames cognitivos e um discreto dano envolvendo parte do sistema atencional pode criar alterações que afetam mais do que um aspecto da atenção.

Vários estudos demonstram como os adultos ansiosos prestam atenção desproporcional a estímulos emocionalmente ameaçadores, comparado com os que 
prestam a estímulos neutros. Ao contrário, os adultos não ansiosos parecem inibir a atenção a tais estímulos (Mclead e Mathews, 1988).

Os pacientes com transtorno de ansiedade apresentam dificuldade em focalizar objetos específicos ou mantê-los sob atenção sustentada por um período de tempo, bem como de concentração, devido à falta de habilidade de focalização. Em contrapartida parece haver um estreitamento da atenção, que pode levar à focalização excessiva nos pensamentos estressantes mais salientes, sem uma racionalização efetiva (Beck et al., 1985).

Em momentos de tensão, crianças da escola secundária, apresentam uma oscilação atencional, como, por exemplo, numa situação estressante de avaliação (Dutke e Stober, 2001). A atenção ficaria dividida entre as exigências da tarefa e os sentimentos de autodepreciação, diminuindo assim o nível de concentração, nesse estudo a ansiedade foi medida por meio da escala: Test Anxiety Scale for Children (TASC) (Wigfeld e eccles, 1989).

Em universitários, um estudo com uma amostra de 24 indivíduos, comparou escores em escalas de ansiedade e observou que aqueles que pontuavam maiores resultados também apresentavam desempenho lentificado na realização de tarefas que recrutavam a atenção, assim como mais falsas memórias. Para a avaliação da ansiedade nesse estudo foi utilizada a escala Sarason's Test Anxiety Scale e para a atenção foram utilizadas listas de palavras, o Stroop Task, em uma versão de seis listas com 15 palavras em cada uma delas, entre elas palavras relacionadas a exame e estresse (Sullivan, 2002).

Dessa maneira, pode-se observar que níveis elevados de ansiedade prejudicam o desempenho cognitivo em tarefas que exigem atenção. (Derakshan et al., 2009). Alto nível de ansiedade pode interferir na aprendizagem de tarefas complexas, dessa maneira a atenção seria afetada e reduzida (Contreras et al, 2005). Quando a ansiedade é excessiva interfere no controle atencional, no controle inibitório e na memória de trabalho. É importante fazer a seguinte distinção: embora a ansiedade possa afetar a eficiência (ou seja, a capacidade de ter um bom desempenho em uma tarefa), pode não afetar a eficácia (que seria o resultado esperado) (Derakshan et al., 2009). 
A preocupação seria um componente responsável pelos efeitos da ansiedade sobre a eficácia e eficiência do desempenho. Envolveria a interferência cognitiva antecipando a capacidade do processamento e armazenamento temporário da memória de trabalho. Os pensamentos preocupantes consumiriam os recursos limitados da atenção da memória de trabalho deixando menos disponível para o processamento de tarefas simultâneas (Eysenck et al., 2007).

$\mathrm{Na}$ busca por explicações entre os problemas de ansiedade e sua inter-relação com atenção seletiva, viés na memória, erros cognitivos, um estudo verificou uma correlação entre esses fatores, em uma amostra de 81 jovens (38 meninas e 43 meninos), com idades entre 9 e 17 anos, média de idade 12,8 anos. Uma escala foi utilizada para medir os sintomas de ansiedade e depressão: Revised Child Report of Child Anxiety and Depression Scales (RCADS). Para avaliação da atenção foi utilizada uma atividade de computador com palavras e figuras que eram apresentadas ao mesmo tempo como estímulos neutros e de ameaças, a memória dessas palavras também foi avaliada. E para verificar os erros cognitivos foi utilizado um questionário: Children's Negative Cognitive Error Questionnaire (CNCEQ) (Watts e Weems, 2006).

Eysenck e Calvo elaboraram uma teoria do controle da atenção relacionando com a ansiedade. Essa teoria se desenvolveu a partir da teoria anterior da eficiência da transformação dos mesmos autores. Os autores acreditam que a ansiedade prejudicaria no controle da atenção, reduzindo-o e aumentando a atenção para os estímulos ameaçadores (Eysenck et al., 2007).

O foco de atenção permaneceria normal, porém seria alterado quando houvesse estímulos ameaçadores. Esse controle atencional seria uma chave importante das funções executivas centrais envolvendo para isso:

- a inibição - a capacidade deliberada de inibir uma resposta automática dominante ou dominadora quando necessário. Envolve o uso do controle atencional para resistir à interferência de um estímulo ou resposta de tarefas irrelevantes e

- o deslocamento - a capacidade de deslocar para frente e para trás entre várias tarefas, operações ou séries mentais, envolvendo a mudança adaptativa do controle da atenção com base na demanda da tarefa (Eysenck et al., 2007). 
Sendo assim, a ansiedade prejudicaria a função de inibir, observando-se um aumento de distração nos indivíduos ansiosos quando comparados aos não ansiosos. Porém, essa alteração na atenção estaria relacionada ao tipo do estímulo (ameaça ou neutro), ou seja, a função de inibir um estímulo seria ineficiente na presença de um distrator relacionado à ameaça (Eysenck et al., 2007).

Abaixo serão citados dois estudos que compartilham dessa teoria do controle da atenção. No primeiro estudo, observou-se que a atenção de pessoas altamente ansiosas para palavras de ameaças e rostos zangados não eram mais influentes do que palavras positivas ou neutras. Em contrapartida, quando sugerido um estímulo de ameaça e posteriormente apresentado um alvo em outro local, os indivíduos com alto nível de ansiedade, levavam mais tempo para detectar o alvo em relação a um estímulo positivo ou neutro. Dessa maneira, conclui-se que os estímulos relacionados com ameaça afetam no tempo de permanência da atenção (Fox et al., 2001). No segundo estudo, Lau e Pine (2008) avaliaram a apresentação das ameaças em relação à atenção, com o uso da tarefa: Stroop emocional. Nessa tarefa era solicitado ao sujeito que nomeasse cores (em palavras ameaçadoras e não ameaçadoras). O tempo de reação para a nomeação dessas cores nos indivíduos ansiosos foi reduzido, indicando a existência de uma grande interferência associada com o conteúdo ameaçador das palavras estímulos entre este grupo. Pressupõe-se que os recursos atencionais foram capturados pela sugestão de ameaça, demonstrando um viés atencional para ameaças. Dessa maneira, conclui-se que elevados níveis de ansiedade aumentam a busca mais rápida para detectar ameaças (Lau e Pine, 2008).

Em um estudo com roedores objetivou-se mapear relação entre a função cerebral, processos psicológicos e as características clínicas, observaram que os estímulos ameaçadores manipulam o foco de atenção, alterando assim a orientação da atenção, sendo uma das características fundamentais da ansiedade a modulação anormal da atenção (Pine et al., 2008).

Abaixo no quadro 4 serão citados estudos que relacionam a ansiedade com a atenção em crianças e adolescentes. 
Quadro 4 - Estudos com crianças e adolescentes com transtornos de ansiedade e déficits de atencionais.

\begin{tabular}{|c|c|c|c|c|}
\hline $\begin{array}{c}\text { Autor (es) } \\
\text { e ano }\end{array}$ & Proposta & $\begin{array}{c}\text { População } \\
\text { Investigada }\end{array}$ & Instrumentos & $\begin{array}{c}\text { Principais } \\
\text { Achados }\end{array}$ \\
\hline $\begin{array}{l}\text { Vloet et al., } \\
2010\end{array}$ & $\begin{array}{l}\text { Avaliar aspectos } \\
\text { seletivos } \\
\text { intensidade da } \\
\text { atenção. }\end{array}$ & $\begin{array}{l}\text { Idade de } 8 \text { a } 15 \text { anos. } \\
102 \text { crianças: } \\
34 \text { TDAH } \\
34 \text { TDAH + Ansiedade } \\
34 \text { Controle } \\
\text { Sem Metilfenidato por } \\
\text { pelo menos } 2 \text { dias. }\end{array}$ & $\begin{array}{l}\text { Semi-Estructured } \\
\text { Interview of the } \\
\text { Children (K-DIPS); } \\
\text { Child Behavior } \\
\text { Checklist (CBCL); } \\
\text { Go no Go Task e } \\
\text { Visual set-shifting task. }\end{array}$ & $\begin{array}{l}\text { 1-Crianças com TDAH com } \\
\text { comorbidade com ansiedade } \\
\text { apresentam pior desempenho } \\
\text { quando comparadas com o grupo } \\
\text { controle. } \\
\text { 2- O desempenho da atenção dessas } \\
\text { crianças é melhor quando } \\
\text { comparadas aos das crianças que } \\
\text { foram diagnosticadas apenas com } \\
\text { TDAH. }\end{array}$ \\
\hline $\begin{array}{ll}\text { Castilho } & \text { et } \\
\text { al., } 2009 & \end{array}$ & $\begin{array}{l}\text { Verificar } \\
\text { associação entre } \\
\text { depressão, } \\
\text { ansiedade } \quad \text { e } \\
\text { desempenho } \\
\text { acadêmico. }\end{array}$ & $\begin{array}{l}\text { Idade de } 12 \text { a } 16 \text { anos } \\
\text { (média de } 13 \text { anos). } \\
98 \quad \text { estudantes } \\
\text { meninos) }\end{array}$ & $\begin{array}{l}\text { State-Trait Anxiety } \\
\text { Inventory for Children } \\
\text { and Adolescents (STAI- } \\
\text { C); } \\
\text { Children Depression } \\
\text { Inventory (CDI) e } \\
\text { Teste de atenção } \\
\text { seletiva e concentração } \\
\text { mental. }\end{array}$ & $\begin{array}{l}\text { 1-Moderado nível de ansiedade } \\
\text { associado a um melhor desempenho } \\
\text { acadêmico. } \\
\text { 2- Quanto maior nível de ansiedade } \\
\text { menor nível de atenção seletiva. } \\
\text { 3- Quanto menor nível de } \\
\text { ansiedade, maior a capacidade de } \\
\text { atenção. } \\
\text { 4- Não foi observado associação } \\
\text { entre ansiedade e atenção seletiva. }\end{array}$ \\
\hline
\end{tabular}

Os processos atencionais podem ter um papel muito importante na etiologia ou na manutenção da ansiedade infantil. Ainda não se sabe se essa distorção atencional é responsável pela ansiedade ou é resultado desta, independente disso pode ser um mecanismo para manter ou intensificar a ansiedade (Kissack e Léon, 2007). 


\subsection{Processos mnésticos nos transtornos de ansiedade}

A memória pode ser definida como um processo de armazenamento e evocação de experiências prévias adquiridas através dos órgãos dos sentidos. É uma função cerebral que possibilita mudanças no comportamento dos seres humanos e outros animais. Não há um modelo unitário de memória, nem um modelo geral aceito por todos que explique como a memória se desenvolve, funciona e é alterada (Silva, 1999).

Ela poderia ser considerada como um sistema de armazenagem dividido em uma série de estágios incluindo codificação, estocagem e evocação (Klatzky, 1980, apud Sheslow e Adams, 1990).

A informação sensorial é transferida seletivamente à estocagem de curto prazo ou memória operativa. A estocagem de curto prazo tem uma capacidade limitada, porém a informação pode ser retida através da repetição. Desta estrutura, a informação seletiva pode ser estabelecida de modo relativamente permanente na estocagem a longo prazo. (Krail e Hagan, 1982, apud Sheslow e Adams, 1990).

Há níveis de processamento em que a informação é analisada em uma série de estágios hierárquicos. Segundo este modelo, depois que um estímulo é reconhecido, ele pode sofrer uma análise cognitiva mais profunda de modo que a informação possa ser mais enriquecida, elaborada ou transformada por associações, imagens ou experiências passadas (Craik e Lockhart, 1972, apud Sheslow e Adams, 1990).

Conhecimento passado, regras aprendidas e outras operações de processamento de informação poderiam permitir que a informação fosse manejada e retida de modo mais eficiente. Assim, o indivíduo dentro dessa conceituação é visto como um diretor mais ativo do tipo de processamento de memória empregado na tarefa de lembrar (Boyd, 1987, apud Sheslow e Adams, 1990).

A manifestação patológica da ansiedade pode acarretar prejuízos na socialização, na aquisição de conhecimento e na memória do indivíduo (Cabrera e Sponholz, 2002).

Apesar dos dados sobre os déficits de memória na ansiedade de adultos, pesquisas sobre essa relação em crianças é escassa. Identificar alterações na memória 
de ansiedade na infância pode ajudar a caracterizar melhor o neuropsicológico e fornecer subsídios para novas intervenções terapêuticas (Vasa et al., 2007).

Observou-se que em situações de teste, indivíduos ansiosos ocupariam parcialmente a capacidade da memória de trabalho com pensamentos em tarefas irrelevantes, preocupações, autoavaliações e aspectos de fracasso. O que resultaria em uma redução na competência de evocar informações. Porém nas tarefas fáceis, o restante da capacidade de memória de trabalho seria suficiente para satisfazer as exigências da tarefa. Essas informações foram descritas a partir de dois estudos com estudantes. O primeiro com 24 estudantes (18 mulheres) com idade média de 27 anos e o segundo com 30 estudantes (25 mulheres) com idade média de 25,9 anos. Os instrumentos utilizados foram: German Test Anxiety Inventory (TAI-G) e uma tarefa de computador de lista de números (divididas em atividades de alta complexidade coordenativa e seqüencial) (Dutke e Stober, 2001).

Ao estudar o papel da memória de trabalho em relação à ansiedade, pode ser útil diferenciar a complexidade da tarefa, se a mesma é coordenativa ou sequencial. Nas tarefas sequenciais os ansiosos apresentam um efeito benéfico sobre o desempenho cognitivo. Nessas tarefas os indivíduos são solicitados a atualizar o conteúdo da memória de trabalho com muita frequência. Diferente das tarefas coordenativas que exige que as informações sejam processadas simultaneamente, armazenando o resultado das etapas anteriores (Dutke e Stober, 2001).

Avanços recentes na investigação da memória permitem cada vez mais uma análise da relação entre a ansiedade e processos mnésticos. Essa relação foi examinada em um estudo com uma amostra de 160 jovens ansiosos que cursavam a sexta e oitava séries. Os achados sugeriram que o funcionamento mnéstico de crianças sofre a interferência da complexidade e da multidimensionalidade das relações entre a ansiedade na infância, características dos estímulos emocionais, tipos de processamento cognitivos e os diversos sistemas de memória (Daleiden, 1998).

A fim de compreender a relação entre ansiedade e desempenho, Calvo et al. (1992) desenvolveram um modelo da Teoria da Eficiência do Processamento (TEP). Essa teoria afirma que há uma disfunção entre a eficácia do desempenho (qualidade) 
e a eficiência de transformação (utilização de recursos de processamento) e que a ansiedade prejudicaria a eficiência de processamento mais do que a eficácia do desempenho. Sendo assim, a eficácia da tarefa diz respeito a um nível individual da competência (por exemplo, a precisão) e a eficiência da tarefa refere-se a medições refletindo o grau de esforço despendido por um indivíduo para completar uma tarefa (por exemplo, o esforço de percepção subjetiva ou tempo necessário). Dessa maneira a ansiedade prejudicaria a eficiência do componente executivo central do sistema de memória de trabalho. (Hadwin et al., 2005).

Um exemplo disso seria os indivíduos com ansiedade generalizada por apresentarem tendências perfeccionistas, em que as preocupações sobre a competência e a avaliação dos outros os motivariam a entrar em um número de estratégias (por exemplo, a repetição de tarefas ou um maior esforço) para melhorar o desempenho do resultado. $\mathrm{O}$ modelo afirma que a preocupação motiva os indivíduos ansiosos para alocar recursos adicionais para as tarefas a fim de manter a eficácia da tarefa (Hadwin et al., 2005) .

A relação entre ansiedade e desempenho de tarefas no modelo sugere ser mediada pela memória de trabalho, em especial pelos seus componentes fonológicos e executivos. Dessa maneira, a ansiedade iria prejudicar a eficiência do tratamento, assim como a complexidade das tarefas prejudicaria a eficácia do desempenho de indivíduos ansiosos (Hadwin et al., 2005).

Um estudo compartilha dessa ideia e avaliou crianças com idades entre 9 e10 anos, divididas em alto e baixo nível de ansiedade. Para isso, utilizaram três tarefas de memória de trabalho. Para verificar o desempenho e eficácia na tarefa mediram a precisão da tarefa. As crianças no grupo com alto nível de ansiedade levaram mais tempo para completar uma das atividades e relataram um aumento do esforço mental em outra tarefa, indicando um efeito da ansiedade em relação à eficiência do desempenho (Hadwin et al., 2005).

Abaixo no quadro 5 serão citados estudos que relacionam a ansiedade com a memória em crianças e adolescentes: 
Quadro 5 - Estudos com crianças e adolescentes com transtornos de ansiedade e déficits de memória.

\begin{tabular}{|c|c|c|c|c|}
\hline $\begin{array}{c}\text { Autor (es) e } \\
\text { ano }\end{array}$ & Proposta & $\begin{array}{c}\text { População } \\
\text { Investigada }\end{array}$ & Instrumentos & $\begin{array}{c}\text { Principais } \\
\text { Achados }\end{array}$ \\
\hline $\begin{array}{lll}\text { Pine et al., } \\
1999 .\end{array}$ & $\begin{array}{l}\text { Examinar } \\
\text { associação entre } \\
\text { memória verbal e } \\
\text { visual com sintomas } \\
\text { de ansiedade em } \\
\text { jovens meninos. }\end{array}$ & $\begin{array}{l}\text { Idade de } 7 \text { a } 11 \\
\text { anos. } \\
111 \text { meninos } \\
\text { Com risco para } \\
\text { delinqüência. }\end{array}$ & $\begin{array}{l}\text { Diagnostic Interview } \\
\text { schedule for children } \\
\text { (DISC); } \\
\text { Wechsler Intelligence } \\
\text { Scale for Children III } \\
\text { (WISC III) e } \\
\text { Wide Range Assement of } \\
\text { Memory and Learning } \\
\text { (WRAML). }\end{array}$ & $\begin{array}{l}\text { 1 - Sintomas de ansiedade são mais } \\
\text { correlacionados com pobre } \\
\text { habilidade de memória do que com } \\
\text { redução intelectual. } \\
\text { 2- Sintomas de delinqüência são } \\
\text { mais correlacionados com redução } \\
\text { intelectual do que com a habilidade } \\
\text { de memória. }\end{array}$ \\
\hline $\begin{array}{l}\text { Gunther et al., } \\
2004 \text {. }\end{array}$ & $\begin{array}{l}\text { Avaliar a atenção e a } \\
\text { memória de crianças } \\
\text { virgens de tratamento } \\
\text { e adolescentes com } \\
\text { transtorno } \\
\text { ansiedade } \\
\text { depressivo e controle. }\end{array}$ & $\begin{array}{l}\text { Idade de } 6 \text { a } 17 \\
\text { anos. } \\
34 \text { crianças com } \\
\text { Transtorno de } \\
\text { Ansiedade, } \\
31 \text { crianças com } \\
\text { transtorno } \\
\text { depressivo } \\
33 \text { controles } \\
\text { Sem medicação. }\end{array}$ & $\begin{array}{l}\text { K-DIPS; } \\
\text { CDI; } \\
\text { Rey Auditory-Verbal } \\
\text { Learning Test; } \\
\text { Go No GO e } \\
\text { Sustained Attention } \\
\text { Task. }\end{array}$ & $\begin{array}{l}\text { 1-Diminuição da memória } \\
\text { associada ao grupo com depressão } \\
\text { na infância. } \\
\text { 2- Em relação à atenção, as crianças } \\
\text { com FS ou TAG não apresentaram } \\
\text { diferenças quando comparadas ao } \\
\text { grupo controle. }\end{array}$ \\
\hline
\end{tabular}


Continuação do quadro 5 - Estudos com crianças e adolescentes com transtornos de ansiedade e déficits de memória.

\begin{tabular}{|c|c|c|c|c|}
\hline $\begin{array}{c}\text { Autor (es) e } \\
\text { ano }\end{array}$ & Proposta & $\begin{array}{c}\text { População } \\
\text { Investigada }\end{array}$ & Instrumentos & $\begin{array}{c}\text { Principais } \\
\text { Achados }\end{array}$ \\
\hline $\begin{array}{l}\text { O'jile et al., }^{\prime} \text { en } \\
2004\end{array}$ & $\begin{array}{lll}\text { Observar } & & \text { o } \\
\text { impacto } & & \text { da } \\
\text { ansiedade } & \text { e } & \text { do } \\
\text { humor, } & & \text { na } \\
\text { memória. } & & \end{array}$ & $\begin{array}{l}\text { Idades de } 6 \text { a } 78 \\
\text { anos. } \\
\text { considerado de } 6 \text { a } \\
15 \text { anos. }\end{array}$ & $\begin{array}{l}\text { CDI; } \\
\text { STAI-C; } \\
\text { Beck Depression } \\
\text { Inventory (BDI); } \\
\text { Dementia Rating Scales } \\
\text { (DRS); } \\
\text { WISC-III e } \\
\text { Diversas versões do } \\
\text { California } \quad \text { Verbal } \\
\text { Learning Test (CVLT, } \\
\text { children version CVLT- } \\
\text { Cou CVLT-2). }\end{array}$ & $\begin{array}{l}\text { Os déficits de memória encontrados } \\
\text { nos relatos dos pacientes não estão } \\
\text { relacionados com os sintomas de } \\
\text { ansiedade ou depressão. }\end{array}$ \\
\hline Vasa et al., 2007 & $\begin{array}{l}\text { Avaliar a memória } \\
\text { de crianças e } \\
\text { adolescentes filhos } \\
\text { de pais com } \\
\text { história de pânico } \\
\text { ou depressão } \\
\text { unipolar. }\end{array}$ & $\begin{array}{l}\text { Idade de } 9 \text { a } 20 \\
\text { anos. } \\
160 \text { sujeitos: } \\
57 \text { com transtorno } \\
\text { de ansiedade (TAG, } \\
\text { FS e TAS) } \\
103 \text { sem transtorno } \\
\text { de ansiedade. }\end{array}$ & $\begin{array}{l}\text { Diagnostic Interview } \\
\text { Schedule for children- } \\
\text { Revised Parent Version } \\
\text { (DISC-R-P); } \\
\text { Structured Clinical } \\
\text { Interview (SCID); } \\
\text { WRAML e } \\
\text { Kaufman } \\
\text { Intelligence Test } \quad(K- \\
\text { Bit). }\end{array}$ & $\begin{array}{l}\text { 1-As crianças que tinham } \\
\text { diagnóstico de fobia social } \\
\text { apresentaram uma dificuldade } \\
\text { maior na memória visual. } \\
\text { 2- As crianças que tinham } \\
\text { transtorno de ansiedade no passado, } \\
\text { atualmente não apresentam } \\
\text { dificuldade na memória. }\end{array}$ \\
\hline
\end{tabular}


Continuação do quadro 5 - Estudos com crianças e adolescentes com transtornos de ansiedade e déficits de memória.

\begin{tabular}{|c|c|c|c|c|}
\hline $\begin{array}{c}\text { Autor (es) } \\
\text { e ano }\end{array}$ & Proposta & $\begin{array}{c}\text { População } \\
\text { Investigada }\end{array}$ & Instrumentos & $\begin{array}{c}\text { Principais } \\
\text { Achados }\end{array}$ \\
\hline $\begin{array}{l}\text { Micco et al., } \\
2009 \text {. }\end{array}$ & $\begin{array}{l}\text { Avaliação } \\
\text { neuropsicológica em } \\
\text { filhos de pais com } \\
\text { depressão maior, com } \\
\text { pânico e sem nenhum } \\
\text { transtorno. } \\
\text { Crianças com risco de } \\
\text { depressão e ansiedade. }\end{array}$ & $\begin{array}{l}\text { Idade de } 6 \text { a } 17 \\
\text { anos. } \\
147 \text { crianças: } \\
71 \text { filhos de pais } \\
\text { com depressão e } \\
\text { pânico } \\
12 \text { filhos de pais } \\
\text { com pânico } \\
31 \text { filhos de pais } \\
\text { com depressão } \\
33 \text { controle. }\end{array}$ & $\begin{array}{l}\text { SCID; } \\
\text { Kiddie Schedule for } \\
\text { Affective disorders and } \\
\text { schizophrenia (K-Sads- } \\
\text { E); } \\
\text { WISC-III; } \\
\text { WCST; } \\
\text { CVLT-C; } \\
\text { Stroop Card Word Test } \\
\text { e } \\
\text { Continuous Test } \\
\text { Performance } \\
\text { (CPT). }\end{array}$ & $\begin{array}{l}\text { 1- Não encontraram associação } \\
\text { entre os pais com transtornos e os } \\
\text { déficits neuropsicológicos. } \\
\text { 2- Depressão maior foi associada } \\
\text { com déficits de memória de } \\
\text { trabalho, velocidade de } \\
\text { processamento, e flexibilidade } \\
\text { cognitiva. } \\
\text { 3- Ansiedade foi associada com } \\
\text { deficiências na memória verbal (no } \\
\text { TAG) e atenção sustentada (na FS). }\end{array}$ \\
\hline
\end{tabular}

conclusão

Há necessidade de pesquisas futuras buscando esclarecer se a relação da dificuldade da memória em ansiedade pediátrica está relacionada a uma disfunção da memória primária ou secundária devido a desvios de atenção (Vasa et al., 2007). 


\subsubsection{Funções executivas nos transtornos de ansiedade}

De acordo com a definição do Dicionário de Neuropsicologia, função executiva são:

$$
\begin{aligned}
& \text { Aquelas habilidades cognitivas necessárias para um } \\
& \text { comportamento complexo dirigido para um objetivo e } \\
& \text { adaptado a uma variedade de mudanças e demandas } \\
& \text { ambientais. Função executiva inclui as habilidades de planejar } \\
& \text { e antecipar desfechos e de dirigir os recursos atencionais para } \\
& \text { resolver as demandas dos eventos não rotineiros. Muitas } \\
& \text { conceituações de função executiva incluem, também, } \\
& \text { automonitoramento e autoconsciência, já que estes são } \\
& \text { necessários para a flexibilidade comportamental (Loring, } \\
& \text { 1999) }
\end{aligned}
$$

Funções executivas podem ser definidas como um grupo de habilidades cognitivas do mais alto nível, que permitem aos indivíduos planejar e realizar atividades dirigidas para um objetivo. Tipos específicos de função executiva incluem abstração, iniciativa, planejamento, automonitoramento, inibição de comportamento incompatível com a meta escolhida e habilidade em organizar e dirigir as funções cognitivas mais básicas, tais como atenção e memória. (Velligan e Bow-Thomas, 1999).

O termo funções executivas definiria assim, um processo cognitivo complexo, que envolve a coordenação de vários subprocessos para a realização de uma meta. Nesse sentido, tal termo abrangeria vários processos cognitivos (Elliott, 2003). Seria um constructo multidimensional, o qual incluiria: iniciativa, planejamento, capacidade para formular hipóteses, flexibilidade mental, habilidade para tomar decisões, regulação, julgamento crítico, utilização de feedback e autopercepção. Estes processos são necessários para um comportamento apropriado a um contexto (Salthouse et al., 2003).

Dessa forma, as funções executivas possibilitam ao indivíduo a solução de problemas novos, através da modificação do comportamento baseada em novas 
informações, do estabelecimento de estratégias e da sequenciação de ações complexas (Elliott, 2003).

O funcionamento executivo pode ser compreendido através de quatro componentes básicos (Lezak, 1995):

1. Volição: compreendida como a capacidade para gerenciar comportamentos intencionais, formulando metas, o que requer motivação e autoconsciência;

2. Planejamento: a identificação e organização dos passos e elementos necessários para finalizar uma intenção ou alcançar uma meta envolvem um número considerável de capacidades. A pessoa deve ser capaz de conceitualizar mudanças das circunstâncias presentes, negociando objetivamente com o meio ambiente, o que requer pensamento abstrato. Também deve avaliar as alternativas a fim de fazer escolhas adequadas para chegar a seu objetivo. Soma-se a esse processo, a necessidade de encadear ideias sequenciais e hierárquicas, necessárias ao desenvolvimento de um esquema conceitual que possibilitará a realização do plano. Um bom controle dos impulsos, bem como raciocínio e memória intactas são necessários. Esta complexa atividade conceitual requer, também, a capacidade para sustentar a atenção;

3. Ação propositiva: referente à capacidade de traduzir uma intenção ou plano em atividade útil. A transposição de uma intenção ou plano para a sua execução requer que a pessoa mantenha e ordene sequências de comportamento de modo integrado e coordenado e

4. Desempenho efetivo: definido como a capacidade de automonitorização do comportamento e da ação.

Estes quatro componentes estão relacionados a, pelo menos, três funções básicas que interagem entre si e pertencem à esfera da cognição. São elas: a memória de trabalho, o esquema preparatório e o controle inibitório (Saboya et al., 2002).

A literatura neuropsicológica converge no sentido de considerar o desempenho adequado em testes de funcionamento executivo dependente da funcionalidade das estruturas do lobo frontal. Prova disso é que os termos funções executivas e funções de lobo frontal são, às vezes, utilizados como sinônimos (Elliott, 2003). 
Como descrito acima, quando há uma ansiedade excessiva, a atenção pode estar alterada, dificultando também o planejamento e a execução de metas de longo prazo e aumentando a execução de comportamentos guiados por metas imediatas (Sapir e Aronson, 1990).

Abaixo, são citados estudos que relacionam as funções executivas com a ansiedade (quadro 6).

Quadro 6 - Estudos com crianças e adolescentes com transtornos de ansiedade e déficits nas funções executivas.

\begin{tabular}{|c|c|c|c|c|}
\hline $\begin{array}{c}\text { Autor (es) e } \\
\text { ano }\end{array}$ & Proposta & $\begin{array}{l}\text { População } \\
\text { Investigada }\end{array}$ & Tarefa(s) & $\begin{array}{l}\text { Principais } \\
\text { Achados }\end{array}$ \\
\hline $\begin{array}{l}\text { Kusche et al., } \\
1993\end{array}$ & $\begin{array}{l}\text { Comparar } \\
\text { funcionamento baseados } \\
\text { em autorelatos e relatos } \\
\text { de professores sobre os } \\
\text { sintomas } \\
\text { psicopatológicos. }\end{array}$ & 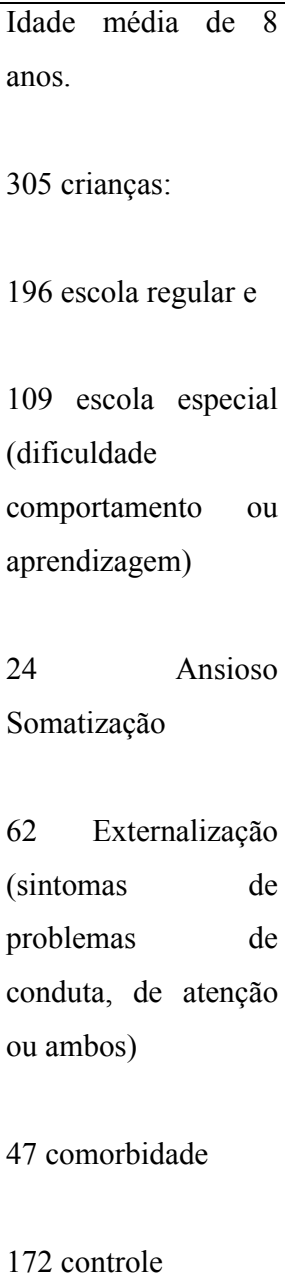 & $\begin{array}{l}\text { Child Behavior Checklist } \\
\text { Teacher Report Form } \\
\text { (CBCL-TRF) e Teacher- } \\
\text { Child Rating Scale } \\
\text { (TCRS); } \\
\text { Self-Control Rating Scale } \\
\text { (SCRS); } \\
\text { Child Depressed Mood } \\
\text { (CDM); } \\
\text { CDI; } \\
\text { Seattle Personality } \\
\text { Questionnaire for Young } \\
\text { scholl-age children } \\
\text { (SPQ-Y); } \\
\text { Test-Revised (WRAT-R); } \\
\text { Test (CAT); } \\
\text { Wchievement }\end{array}$ & $\begin{array}{l}\text { 1- Comparados aos controles, } \\
\text { todos os outros grupos } \\
\text { apresentaram déficits no } \\
\text { funcionamento intelectual, } \\
\text { nas funções executivas e, } \\
\text { consequentemente, nas } \\
\text { habilidades acadêmicas. } \\
\text { 2- Tanto no funcionamento } \\
\text { intelectual como nas } \\
\text { habilidades acadêmicas, os } \\
\text { resultados mais baixos foram } \\
\text { os apresentados pelo grupo } \\
\text { comorbidade. }\end{array}$ \\
\hline
\end{tabular}


Continuação do quadro 6 - Estudos com crianças e adolescentes com transtornos de ansiedade e déficits nas funções executivas.

\begin{tabular}{|c|c|c|c|c|}
\hline $\begin{array}{l}\text { Autor (es) e } \\
\text { ano }\end{array}$ & Proposta & $\begin{array}{l}\text { População } \\
\text { Investigada }\end{array}$ & Tarefa(s) & $\begin{array}{c}\text { Principais } \\
\text { Achados }\end{array}$ \\
\hline $\begin{array}{c}\text { Kusche et al., } \\
1993\end{array}$ & & & $\begin{array}{l}\text { WISC-R; } \\
\text { Scale of Children's } \\
\text { Abilities; } \\
\text { Visual Aural Digit Span } \\
\text { Test (VADS); } \\
\text { Test of Cognitve Skills } \\
\text { (TCS); } \\
\text { Bender Gestalt Test } \\
\text { (BGT); } \\
\text { McCarthy Scale; } \\
\text { Kusché Emotional } \\
\text { Inventory (KEI); } \\
\text { Halstead } \\
\text { Neuropsychological test } \\
\text { Battery for children; } \\
\text { The Stroop Color; } \\
\text { Halstead- Reitan Battery } \\
\text { Finger Tapping Test; } \\
\text { Harris Test of Lateral } \\
\text { Dominance - Grip } \\
\text { Stength, Name Writing e } \\
\text { lateral dominance test. }\end{array}$ & \\
\hline
\end{tabular}


Continuação do quadro 6 - Estudos com crianças e adolescentes com transtornos de ansiedade e déficits nas funções executivas.

\begin{tabular}{|c|c|c|c|c|}
\hline $\begin{array}{c}\text { Autor (es) e } \\
\text { ano }\end{array}$ & Proposta & $\begin{array}{l}\text { População } \\
\text { Investigada }\end{array}$ & Tarefa(s) & $\begin{array}{c}\text { Principais } \\
\text { Achados }\end{array}$ \\
\hline $\begin{array}{l}\text { Toren et al., } \\
2000\end{array}$ & $\begin{array}{l}\text { Avaliar os processos } \\
\text { neuropsicológicos de } \\
\text { crianças } \\
\text { adolescentes } \\
\text { transtornos } \\
\text { ansiedade, pareados } \\
\text { com de } \\
\text { saudáveis. }\end{array}$ & $\begin{array}{l}19 \text { crianças com } \\
\text { ansiedade } \\
\text { meninas) e } \\
14 \text { do grupo controle } \\
\text { (8 meninas). } \\
\text { Idades de } 6 \text { a } 18 \\
\text { anos. } \\
\text { Sem medicação. }\end{array}$ & $\begin{array}{l}\text { K-SADS; } \\
\text { Revised Children's } \\
\text { Manifest Anxiety Scale } \\
\text { (RCMAS); } \\
\text { CDI; } \\
\text { WISC-R; } \\
\text { CVLT; } \\
\text { RCFT e } \\
\text { WSCT. }\end{array}$ & $\begin{array}{l}\text { 1-Ambos os grupos com } \\
\text { resultados na normalidade no } \\
\text { WISC-R. } \\
\text { 2- O grupo com transtorno de } \\
\text { ansiedade teve desempenho } \\
\text { inferior no CVLT e no } \\
W C S T \text {. } \\
\text { 3- Transtorno de ansiedade } \\
\text { pode estar associado a } \\
\text { dificuldades lingüísticas, na } \\
\text { memória verbal e na } \\
\text { flexibilidade mental. }\end{array}$ \\
\hline $\begin{array}{l}\text { Naglieri et al., } \\
2003\end{array}$ & $\begin{array}{lr}\text { Examinou } & \text { as } \\
\text { diferenças } & \text { de } \\
\text { desempenho } & \\
\text { cognitivo entre } \\
\text { crianças com TDAH }\end{array}$ & $\begin{array}{l}25 \text { - TDAH } \\
\text { 25- Ansiedade e/ou } \\
\text { depressão } \\
\text { Idade média de } 10 \\
\text { anos. }\end{array}$ & $\begin{array}{l}\text { WISC-III e } \\
\text { Cognitive Assessment } \\
\text { System (SAC): } 4 \text { escalas } \\
\text { atenção, planejamento, } \\
\text { simultânea e sucessivos } \\
\text { processos cognitivos). }\end{array}$ & 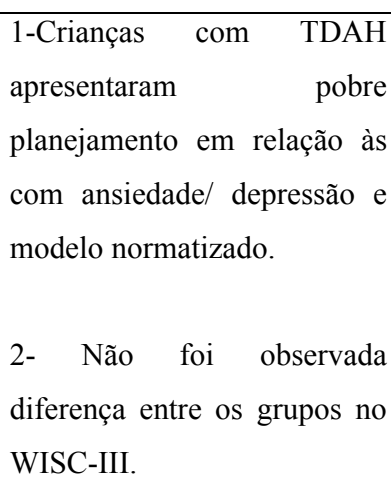 \\
\hline
\end{tabular}

continua 
Continuação do quadro 6 - Estudos com crianças e adolescentes com transtornos de ansiedade e déficits nas funções executivas.

\begin{tabular}{|c|c|c|c|c|}
\hline $\begin{array}{l}\text { Autor (es) } \\
\text { e ano }\end{array}$ & Proposta & $\begin{array}{l}\text { População } \\
\text { Investigada }\end{array}$ & Tarefa(s) & $\begin{array}{c}\text { Principais } \\
\text { Achados }\end{array}$ \\
\hline $\begin{array}{l}\text { Emerson, } \\
2005 .\end{array}$ & $\begin{array}{l}\text { Testar os efeitos da } \\
\text { ansiedade } \\
\text { depressão }\end{array}$ & $\begin{array}{l}\text { Idades de } 9 \text { a } 11 \\
\text { anos. } \\
38 \text { Meninos: } \\
19 \text { - Anisoso/ } \\
\text { depressivo } \\
19 \text { - não ansioso/não } \\
\text { depressivo }\end{array}$ & $\begin{array}{l}\text { STAI-C; } \\
\text { CDI; } \\
\text { WISC-III; } \\
\text { Lateral Preference Test; } \\
\text { Trail Making Test e } \\
\text { Woodcock Johnson Testo } \\
\text { Cognitive Abilities. }\end{array}$ & $\begin{array}{l}\text { 1-Meninos com elevados } \\
\text { níveis de ansiedade } \\
\text { depressão levaram mais } \\
\text { tempo para completar uma } \\
\text { atividade assim como } \\
\text { cometeram mais erros. } \\
\text { 2- Também apresentaram } \\
\text { dificuldades na mudança de } \\
\text { set, no teste de hipóteses e } \\
\text { categorias para resolver } \\
\text { problemas. } \\
\text { 3- A ansiedade e depressão } \\
\text { afetam as funções associadas } \\
\text { com o funcionamento do lobo } \\
\text { frontal. }\end{array}$ \\
\hline $\begin{array}{l}\text { Korenblum et } \\
\text { al., } 2007\end{array}$ & $\begin{array}{l}\text { Comparar medidas do } \\
\text { funcionamento } \\
\text { executivo (performance } \\
\text { de monitoramento e } \\
\text { inibição de resposta) }\end{array}$ & $\begin{array}{l}\text { Idades de } 6 \text { a } 14 \\
\text { anos. } \\
21 \text { com transtorno de } \\
\text { ansiedade, } \\
78 \text { com TDAH, } \\
38 \text { com transtorno de } \\
\text { ansiedade + TDAH } \\
40 \text { controle. }\end{array}$ & $\begin{array}{l}\text { Parent Interview for } \\
\text { Child Symptoms (PISC- } \\
\text { IV); } \\
\text { Teacher Telephone } \\
\text { Interview (TTI-IV); } \\
\text { WISC-III; } \\
\text { Clinical Evaluation of } \\
\text { Language } \\
\text { Fundamentals (CELF) e } \\
\text { Stop-Signal paradigm } \\
\text { (SSP) }\end{array}$ & $\begin{array}{l}\text { 1-Não foram observadas } \\
\text { diferenças na capacidade de } \\
\text { monitorar o comportamento } \\
\text { no grupo com ansiedade. } \\
\text { 2- Os três grupos clínicos } \\
\text { apresentaram déficits na } \\
\text { inibição. } \\
\text { 3- Os déficits no controle } \\
\text { inibitório e na monitorização } \\
\text { do desempenho estariam } \\
\text { relacionados à comorbidade } \\
\text { com TDAH. }\end{array}$ \\
\hline
\end{tabular}


Continuação do quadro 6 - Estudos com crianças e adolescentes com transtornos de ansiedade e déficits nas funções executivas.

\begin{tabular}{|c|c|c|c|c|}
\hline $\begin{array}{c}\text { Autor (es) } \\
\text { e ano }\end{array}$ & Proposta & $\begin{array}{c}\text { População } \\
\text { Investigada }\end{array}$ & Tarefa(s) & $\begin{array}{c}\text { Principais } \\
\text { Achados }\end{array}$ \\
\hline $\begin{array}{l}\text { Manassis et } \\
\text { al., } 2007\end{array}$ & $\begin{array}{l}\text { Avaliarar habilidades } \\
\text { acadêmicas, percepção } \\
\text { emocional e memória } \\
\text { de trabalho. }\end{array}$ & $\begin{array}{l}\text { Idade de } 8 \text { a } 12 \text { anos. } \\
108 \text { crianças: } \\
52 \text { Ansiedade } \\
21 \text { TDAH } \\
\text { Primeiro momento } \\
\text { sem medicação. }\end{array}$ & $\begin{array}{l}\text { Anxiety } \\
\text { Interview Schedule } \\
\text { (ADIS); } \\
\text { Parent Conner's } \\
\text { Questionnaire; } \\
\text { Conner's Questionaire; } \\
\text { Multidimensional } \\
\text { Anxiety Scale for } \\
\text { Children (MASC); } \\
\text { WRAT-R; } \\
\text { WISC III; } \\
\text { Auditory Serial Addition } \\
\text { Test (CHIPASAT)e } \\
\text { Donverbal Accuracy } \\
\text { (DANVA-2); } \\
\text { WRAML. }\end{array}$ & $\begin{array}{l}\text { 1 - O grupo com ansiedade }+ \\
\text { TDAH e o grupo TDAH } \\
\text { apresentaram pior } \\
\text { desempenho em relação aos } \\
\text { controles. } \\
\text { 2- Na atividade da percepção } \\
\text { auditiva para raiva, o grupo } \\
\text { com ansiedade }+ \text { TDAH } \\
\text { apresentou menor } \\
\text { sensibilidade do que as } \\
\text { crianças com ansiedade ou } \\
\text { com TDAH. }\end{array}$ \\
\hline
\end{tabular}




\subsection{Farmacologia nos transtornos de ansiedade}

O tratamento para TA é constituído por uma abordagem multimodal, incluindo orientação aos pais e à criança, intervenções familiares, terapia cognitivocomportamental, psicoterapia dinâmica e o uso de psicofármacos (Castilho et al., 2000).

A farmacoterapia deve ser considerada quando há presença de sintomas graves, causando comprometimento à vida do jovem (Birmaher et al., 1998). Devemse também considerar as diferenças dos estágios de desenvolvimento quando avaliar a necessidade do uso de medicação em pacientes pediátricos (Murphy et al., 2000).

As classes de medicações mais estudadas para manejo dos TAIA são os ansiolíticos e os antidepressivos. Entre os antidepressivos, destacam-se os Inibidores Seletivos da Recaptação da Serotonina (ISRS), a venlafaxina e os Antidepressivos Tricíclicos (ADT). Os ISRS são efetivos e seguros para tratamento agudo da ansiedade na infância e adolescência, sugeridos como medicamentos de primeira escolha (Pine, 2008). Já em relação aos ADT, há uma escassez de estudos, possivelmente devido aos possíveis efeitos colaterais destas medicações.

O número de estudos realizados com psicofármacos em crianças é infinitamente menor do que o realizado com adultos. No entanto, um volume considerável de evidências permite linhas gerais seguras, que regulam o manejo prático dessas substâncias em crianças e adolescentes (Mercadante e Scahill, 2005).

Existem várias substâncias que fazem a transmissão de um recado ao neurônio, sendo as mais famosas: a serotonina, a noradrenalina e a dopamina. Nas paredes dos neurônios, nessa região chamada sinapse, existem umas estruturas (proteína) chamadas receptores que são como nichos que acomodam, recebem e se ligam aos neurotransmissores, onde as mensagens vão sendo transmitidas, sendo que a grande maioria dos remédios agem nesse espaço. Existem mecanismos que bloqueiam a volta dessas mensagens (recaptação do neurotransmissor) e tem sido veiculado como o ponto principal da ação dos remédios (Mercadante e Scahill, 2005). 
Em algumas pessoas há um impedimento de comunicação entre dois sistemas de neurônios, implicando um mau funcionamento. Um estudo com ratos mostrou que a fluoxetina (um antidepresssivo ISRS) produz novos neurônios. O desempenho de aprendizado de novas tarefas foi muito melhor nos animais que estavam recebendo o medicamento, o que novamente sugere que a multiplicação dos novos neurônios estaria relacionada com a possibilidade de aprender (Mercadante e Scahill, 2005).

Evidências pré-clínicas indicam que os medicamentos utilizados no tratamento dos transtornos de ansiedade atuam, primariamente, em um ou mais passos do processo de neurotransmissão (Graeff, 2004).

Uma das maneiras mais aceitáveis para determinar se um remédio é realmente eficiente para tratar determinada doença, é pelos estudos comparativos entre a droga em questão e uma substância chamada placebo. O placebo é sempre uma substância inerte, sem ação. O que se espera com isso é saber se outro elemento, que não o remédio que está sendo estudado, pode diminuir ou eliminar os sintomas daquela doença (Mercadante e Scahill, 2005).

A revisão de literatura a seguir focaliza as duas medicações escolhidas para comparação de seu efeito nos sintomas ansiosos, seguindo a divisão de tratamento medicamentoso realizada nos participantes que eram acompanhados pela psiquiatra e pesquisadora responsável Carolina Zadrozny Gouvêa da Costa no estudo intitulado como: "Comparação entre Clomipramina e Fluoxetina para o Tratamento de Transtornos de Ansiedade em Crianças e Adolescentes" (Costa, 2010).

Outro ponto importante a ser considerado diz respeito ao efeito que alguns medicamentos podem causar sobre o funcionamento cognitivo, em alguns momentos prejudicando-o. Dessa maneira abaixo serão citados alguns estudos relacionando o uso dessas medicações e o placebo em relação às funções cognitivas.

Um estudo sobre a avaliação da memória e funções psicomotoras em voluntários saudáveis e pacientes com uso de ADT apresentou resultados inconsistentes, provavelmente devido às diferenças metodológicas, tais como drogas e doses empregadas, duração de tratamento, diagnóstico e tarefas (Thompson, 1991). O mesmo foi observado em um estudo com pacientes deprimidos tratados com antidepressivos (imipramina, clomipramina, fluoxetina e sertralina) comparados com 
controle, por pelo menos 6 meses. A avaliação da memória consistiu de testes de memória episódica, implícita e de trabalho, bem como a avaliação da metamemória. Nesse estudo, os resultados sugerem que os prejuízos no desempenho psicomotor e na memória, associado com estes antidepressivos, parecem ser de baixa intensidade e de relevância clínica questionável (Gorenstein et al, 2006).

\section{Fluoxetina}

Os ISRS têm poucos efeitos na cognição e no sistema psicomotor. Em certas circunstâncias, alguns ISRS estão associados a uma melhoria em medidas objetivas do funcionamento cognitivo, sem qualquer aumento na velocidade psicomotora. Além disso, por aumentar ligeiramente a capacidade cognitiva, em especial no processamento da informação, os ISRS podem exercer um efeito maior na "antiansiedade", possibilitando ao indivíduo melhor utilização de seus próprios processos cognitivos (Hindmarch, 1998).

Estudos sobre o impacto do uso de antidepressivos no desempenho cognitivo têm sido frequentemente realizados entre os idosos ou em voluntários saudáveis. Poucas pesquisas têm considerado o seu impacto em uma população relativamente jovem. Um estudo teve como objetivo analisar qualquer associação entre os ISRS e o desempenho cognitivo, humor e erros humanos no trabalho. A amostra foi um total de 34 participantes divididos em dois grupos: ISRS $(n=17)$ e controles $(n=17)$. Para isso utilizaram uma bateria de tarefas no computador medindo o humor, funções cognitivas pré e pós-trabalho no início e final de uma semana de trabalho. Eles também completaram diários relatando o desempenho no trabalho. Os resultados apontaram que a utilização de ISRS pode estar associada com comprometimento da memória, em especial a episódica, mas não com a memória de trabalho ou semântica. Os indivíduos que usam ISRS apresentaram uma pobre memória de reconhecimento e recordação tardia (Wadswoth et al., 2005).

A análise sugere que não foram encontrados efeitos prejudiciais do uso do ISRS na velocidade psicomotora, ineficiência momentânea, velocidade do foco de atenção, da velocidade e codificação de novas informações, da organização da 
resposta, humor ou desempenho profissional percebido. Isto está de acordo com trabalhos anteriores que sugerem que os ISRS são relativamente livres de efeitos psicomotores e cognitivos (Wadswoth et al., 2005).

Um estudo em ratos observou que quando são injetados benzodiazepinas ou ISRS, como a fluoxetina, ocorre uma diminuição da formação de memória aversiva. Os transtornos de ansiedade podem resultar de uma superexpressão de memórias aversivas. Nesse estudo, também se observou que a ablação do hipocampo diminui reações de medo e o desempenho cognitivo (Degroot e Nomikos, 2005).

Foi publicado um caso de um paciente com Transtorno Obsessivo Compulsivo (TOC) que desenvolveu uma síndrome frontal resultante do uso de fluoxetina, diversos estudos foram conduzidos com o objetivo de elucidar o real efeito desses medicamentos nas funções cognitivas de pacientes com TOC (Fontenelle et al., 2007).

Esse autor relata a diversidade de resultados em estudos sobre o tema. Alguns sugerem que o uso da medicação não apresenta diferenças significativas quando comparado com um grupo não medicado. Em contrapartida, há estudos que apontam para uma melhora no desempenho em tarefas neuropsicológicas com o uso de ISRS ou sugerem que essa medicação poderia proteger os pacientes dos efeitos deletérios de outros psicofármacos sobre algumas funções cognitivas, como as avaliadas pelo teste WCST. Porém em outras tarefas teriam lentificado o tempo de reação (Fontenelle et al., 2007).

Kim et al. (2002) estudaram pacientes com TOC e controles, após quatro meses de tratamento com ISRS, houve uma melhora no desempenho no Trail Making Test na parte A, no Block Design e no Controlled Oral Word Association Test (COWAT) para letras, mas mantiveram o comprometimento na evocação imediata e tardia do RCFT e no COWAT para categorias, apesar de terem apresentado uma melhora significativamente maior do que o grupo controle. Não diferenciaram no desempenho do WCST inicialmente, e ambos os grupos melhoraram seu desempenho na segunda avaliação.

Um estudo utilizou ISRS em doses elevadas por 10 semanas, observaram associação entre um pior desempenho em pacientes com TOC nos parâmetros erros 
perseverativos e categorias completadas do WCST, indicando comprometimento da capacidade de mudança do cenário cognitivo e uma melhor resposta ao tratamento. Eles sugeriram que os pacientes com TOC que exibiam comprometimento da capacidade de mudança do cenário cognitivo e o tônus serotoninérgico alterado, responderiam melhor ao tratamento com medicações serotoninérgicas (Fontenelle et al., 2001).

Estudo de Cavedini et al. (2002) comparou o desempenho de 34 pacientes com TOC, com 16 pacientes com transtorno do pânico e 34 saudáveis. Para isso, realizaram uma tarefa que simulava a tomada de decisões na vida real. Os pacientes com TOC respondedores aos ISRS foram comparados aos não respondedores. Observou-se que os respondedores alcançaram desempenho semelhante aos indivíduos saudáveis, enquanto os não respondedores tiveram maior comprometimento no desempenho da tarefa em comparação aos demais grupos (Cavedini et al., 2002).

Kang et al (2003) avaliaram o perfil cognitivo antes e após tratamento com ISRS, por quatro meses. Observaram melhora significativa do desempenho na evocação imediata e tardia da RCFT, manutenção dos escores no COWAT para letras e para categorias, no Trail Making Test na parte B e nos erros perseverativos do WCST (Kang et al, 2003).

Outro estudo comparou o desempenho de 19 pacientes com TOC ao de 24 indivíduos saudáveis. Para isso, utilizaram a Cambridge Neuropsychological Test Automated Battery e observaram que os pacientes não respondedores ao tratamento com fluoxetina por 12 semanas, foram aqueles que obtiveram mais erros de interferência no Stroop Test (Nielen e Den, 2004).

\section{Clomipramina}

Um estudo aponta que o uso de antidepressivos como a clomipramina pode prejudicar o funcionamento cognitivo em pacientes deprimidos tratados em um período médio de 9 meses (Hindmarch, 1998). 
Hindmarch (1998) sugere que esse prejuízo pode estar associado a efeitos colaterais anticolinérgicos e anti-histamínicos desses compostos. A atividade anticolinérgica pode prejudicar a memória e a habilidade de processar a informação e a anti-histamínica pode prejudicar a coordenação sensório-motora, um componente essencial para muitos comportamentos cognitivos (Hindmarch, 1998).

Allen (1991) estudou o efeito da administração de clomipramina por 10 dias e observou que a velocidade de reação foi lentificada pela clomipramina.

Prejuízo no desempenho da aprendizagem verbal foi associado com níveis plasmáticos elevados de clomipramina em pacientes deprimidos, após 3 semanas de tratamento com $150 \mathrm{mg}$ / dia (Bartfai et al., 1991, apud Carvalho et al., 2002).

A clomipramina, imipramina e placebo foram administrados durante um tratamento de 8 semanas em pacientes. Seu desempenho foi comparado com o de indivíduos normais. Não foram encontrados efeitos significativos do uso das drogas (Marcourakis et al., 1993, apud Carvalho et al., 2002).

Um estudo com 25 adultos (média de idade: 39,6) investigou o uso crônico de clomipramina no transtorno do pânico em remissão, para avaliar comprometimento de memória e funções psicomotoras. Os testes utilizados nesse estudo foram: DigitSymbol Substitution Test (DSST), Cancellation Task (CT), Symbol Copying Test (SCT), Tapping e Inserting pins (Vienna Test System). Foram encontradas associações significativas entre o tratamento a longo prazo de clomipramina e pobre desempenho na memória de trabalho. São necessárias novas investigações para confirmar esses resultados e determinar se o uso crônico de doses terapêuticas de ADT está associado com maior intensidade aos efeitos deletérios sobre a memória e funções psicomotoras (Carvalho et al., 2002).

\section{Placebo}

Khan e colaboradores sugeriram que a resposta ao placebo pode estar relacionada ao sofrimento subjetivo dos pacientes, e aqueles que têm maior insight sobre sua doença (como nos transtornos depressivos e ansiosos) teriam uma maior chance de resposta a tratamentos inespecíficos (Khan e colaboradores, 2005). 
Um estudo comparou 310 pacientes com transtorno depressivo maior, durante 8 semanas de tratamento (fluoxetina ou placebo), por meio de escalas. Esses sujeitos foram divididos em 134 respondedores à fluoxetina, 66 respondedores ao placebo e 110 não responderam. Foram comparados os fatores cognitivos antes e depois do tratamento e não foram observadas diferenças significativas. Esse resultado pode sugerir que o fator psicológico pode desempenhar um papel importante na melhora dos pacientes deprimidos tratados com placebo (Farabaugh et al., 2006).

As mudanças iniciais em medidas cognitivas, as quais refletem as expectativas dos pacientes da previsibilidade e da percepção do estresse, podem ser marcadores clínicos de resposta ao placebo (Farabaugh et al., 2006).

Outro estudo discutiu o efeito placebo, relatou que essa intervenção tem um efeito na esperança dos pais em achar algo que ajude seus filhos. A expectativa pela melhora parece ser um fator importante no efeito placebo. A participação em um ensaio clínico pode, por si só, ter efeito terapêutico, por meio da educação sobre o problema de saúde, dos encontros com profissionais de uma forma frequente e estruturada e da expectativa de um tratamento eficaz. A qualidade da relação médicopaciente, também, influencia o efeito placebo. Médicos que mostram confiança no tratamento e carinho pelos pacientes parecem com mais probabilidade de desencadear efeito placebo (Sandler, 2005). 


\subsection{Participantes}

Os participantes do estudo foram crianças e adolescentes, com idades de 7 a 17 anos, independentemente de raça ou sexo, que preencheram os critérios diagnósticos do DSM-IV para transtorno de ansiedade generalizada, transtorno de ansiedade de separação e/ou fobia social. Todos os sujeitos foram encaminhados pelo Ambulatório do Programa de Transtornos de Ansiedade na Infância e Adolescência do Instituto de Psiquiatria do Hospital das Clínicas da Faculdade de Medicina da Universidade de São Paulo (IPQ HC FMUSP).

\subsubsection{Critérios de inclusão}

Tanto os critérios de inclusão como os de exclusão seguiram o modelo utilizado no estudo entitulado "Comparação entre Clomipramina e Fluoxetina para o Tratamento de Transtorno de Ansiedade em Crianças e Adolescentes", conduzido pela psiquiatra e pesquisadora responsável Carolina Zadrozny Gouvêa da Costa, sob orientação do Dr. Fernando Ramos Asbahr (Costa, 2010).

Para compor o grupo com TA foram incluídos indivíduos com um ou mais diagnósticos de transtornos de ansiedade, uma vez que a comorbidade entre esses é frequente [ao menos $60 \%$ das crianças com diagnóstico de transtorno de ansiedade apresenta duas dessas condições, e 30\% apresenta três (RUPP Anxiety Study Group, 2001)].

Em relação ao grupo controle, foram incluídos indivíduos sem qualquer tipo de transtorno psiquiátrico. Todos os sujeitos tinham idade mínima de 7 anos e máxima de 17 anos.

Foram consideradas as características socioeconômicas a partir dos critérios da Associação Brasileira dos Institutos de Pesquisa de Mercado (ABIPEME), propostos por Almeida e Wickerhauser (1991, apud Mattar, 1995). 


\subsubsection{Critérios de exclusão}

Para o grupo com TA, foram excluídos os indivíduos que apresentaram: diagnóstico de episódio depressivo maior atual comórbido; diagnóstico de transtorno do déficit de atenção e hiperatividade como transtorno primário ou que necessitasse do uso de psicoestimulantes; doenças neurológicas; diagnóstico prévio ou atual de transtorno de humor bipolar, transtorno obsessivo-compulsivo, transtorno de estresse pós-traumático, transtornos alimentares, abuso de substâncias, transtornos psicóticos, transtornos de conduta, transtorno abrangente do desenvolvimento, retardo mental ou qualquer doença orgânica cerebral; ideação suicida, tratamento prévio para ansiedade (psicológico ou medicamentoso) ou uso de medicação que afete o sistema nervoso central e gravidez.

Em relação ao grupo controle, foram excluídos indivíduos que apresentaram faixa de eficiência intelectual inferior à limítrofe.

\subsection{Seleção de pacientes}

Os sujeitos foram avaliados e atendidos no Programa de Transtornos de Ansiedade na Infância e Adolescência do IPQ HC FMUSP.

Os participantes foram recrutados através de chamada na imprensa com referência a transtornos de ansiedade na infância e adolescência, além da inclusão dos indivíduos que procuraram espontaneamente ou foram encaminhados ao Programa de Transtornos de Ansiedade na Infância e Adolescência do IPQ HC FMUSP.

Quanto ao grupo controle, os participantes foram convidados a participar da pesquisa por meio de divulgação em escolas, assim como a parceria com outro ambulatório do mesmo instituto (transtorno de humor na infância) do qual necessitava também de crianças e adolescentes sem problemas psiquiátricos. 


\subsection{Aspectos Éticos}

Participaram do estudo apenas os indivíduos dos quais se obteve consentimento. O Consentimento Livre e Esclarecido (anexo A) foi assinado por responsável legal (todos os pacientes eram menores de idade), obtido após descrição dos procedimentos do estudo ao paciente e seus pais/responsáveis. Tal consentimento foi adquirido através de documentação.

$\mathrm{O}$ projeto de pesquisa relacionado a esta dissertação foi aprovado pela Comissão de Ética do Hospital das Clínicas da Faculdade de Medicina da Universidade de São Paulo.

\subsection{Instrumentos}

Todos os participantes foram submetidos a um protocolo de avaliação inicial de duas semanas conduzido pela pesquisadora responsável do estudo acima citado. Durante esse período, nenhum participante recebeu qualquer tipo de tratamento. Nesta etapa, tanto o grupo com transtornos ansiosos como o controle foram submetidos ao instrumento Schedule for Affective Disorders and Schizophrenia versão infantil para a avaliação de diagnósticos psiquiátricos no presente e ao longo da vida, de acordo com critérios diagnósticos do DSM-IV.

Os indivíduos que preencheram os critérios para o estudo foram encaminhados para avaliação neuropsicológica pré-tratamento. Nessa avaliação foram aplicadas provas neuropsicológicas com o objetivo de se investigar o desempenho cognitivo nas funções atencionais, mnésticas e executivas.

Após a primeira avaliação neuropsicológica, os participantes deste estudo foram divididos randomicamente em três grupos de tratamento (fluoxetina, clomipramina ou placebo) e receberam tratamento por um período de 6 meses.

Os pacientes foram acompanhados por quatro psiquiatras (nenhum deles teve qualquer conhecimento sobre a qual tratamento os pacientes estavam sendo submetidos; dois realizaram as avaliações clínicas e dois foram responsáveis pela administração das escalas de avaliação - avaliadores independentes). A 
randomização foi realizada por uma pessoa, sem qualquer outra participação no estudo, a qual tinha conhecimento sobre o tipo de tratamento dado a cada paciente. Para isso, foi realizada a randomização por meio de uma tabela de números aleatórios (anexo B).

Após um período de 6 meses, os participantes foram reavaliados com a utilização dos mesmos testes neuropsicológicos utilizados na primeira avaliação. Além disso, foi oferecido continuidade do tratamento ambulatorial vinculado ao Programa de Transtornos de Ansiedade na Infância e Adolescência do IPQ HC FMUSP para todos os pacientes para os quais houvesse necessidade.

\subsubsection{Avaliação neuropsicológica}

\subsubsection{Provas cognitivas}

A bateria de testes neuropsicológicos tem o objetivo de avaliar diversas funções cognitivas. Os testes foram selecionados a partir de compêndios de testes neuropsicológicos amplamente utilizados (Spreen e Strauss, 1991; Lezak, 1995).

a) Desempenho Intelectual

O teste utilizado para avaliar o desempenho intelectual foi o Wechsler Abbreviated Scale of Intelligence (WASI) (Wechsler, 1999). Os resultados ponderados de dois subtestes do WASI, quando somados fornecem a medida estimada de Quociente Intelectual (QI). Os subtestes usados nessa pesquisa foram:

- Vocabulário - WASI (Wechsler, 1999) - medida de estoque semântico e capacidade de definição de vocábulos.

- Matrizes de raciocínio - WASI (Wechsler, 1999) - medida de raciocínio lógico-abstrato não verbal. 
b) Funções atencionais e executivas

Foram utilizados diversos testes para medir o funcionamento das funções atencionais e executivas e serão descritos abaixo.

- Trail Making Test (Lezak, 1995) - mede o rastreamento visual e automonitorização para sequências simples e alternadas. Dividido em duas formas (A e B).

- Stroop Card Test (Stroop, 1935) - mede a capacidade de inibição da emissão de respostas a partir de estímulos visuo-verbais. Divido em três cartões (A, $\mathrm{B}$ e C).

- Matching Familiar Figures Test - 20 (MFFT- 20) (Cairns e Cammock, 2002) - avalia a reflexibilidade (tendência para considerar e deliberar sobre as soluções alternativas para os problemas) e a impulsividade (tendência a agir espontaneamente, sem deliberação, principalmente em situações de incerteza).

- Teste de Fluência verbal - para letras FA S e para animais (Spreen e Strauss, 1998) - mede a capacidade de fluência verbal sob condições delimitadas.

- Wisconsin Card Sorting Test (WCST) (Heaton et al, 2004) - mede a formação de conceitos, flexibilidade mental, planejamento e manutenção de metas.

- Torre de Hanoi (Lezak, 1995) - avalia a capacidade de resolver problema, de planejar e sequenciar as ações, além de antever os passos posteriores.

c) Processos de Memória e Aprendizagem

Os teste utilizados para avaliar os processos de memória e aprendizagem foram: 
- Rey Complex Figure Test (RCFT) (Lezak, 1995) - mede a capacidade de organização perceptivo-motora, a atenção e a memória visual imediata.

- Wide Range Assement of Memory and Learning - 2 (WRAML-2). Os subtestes usados nessa pesquisa foram:

- Memória para desenhos e Memória para cenas - medem a memória de curto e longo prazo para estímulos visuais;

- Memória para história - mede a memória de curto e longo prazo para estímulos visuais;

- Aprendizagem verbal - avalia a aprendizagem a curto e longo prazo para estímulos verbais;

-Memória de trabalho verbal e visual (apenas para as crianças com idades acima de 9 anos, de acordo com as normas do teste) - mede a memória de trabalho para estímulos verbais e visuais.

\subsubsection{Avaliação da ansiedade}

A manifestação da ansiedade e classificação dos sintomas das crianças e adolescentes (entre 8 a 17 anos) foram realizadas através da Multidimensional Anxiety Scale for Children (MASC) (March et al., 1997) (anexo C).

A escala é constituída de 39 perguntas as quais o examinado responde como tem se sentido nos últimos meses, para cada item ele pontua de 0 a 3 de acordo com a intensidade, sendo 0 nunca, $1=$ raramente, $2=$ algumas vezes e $3=$ frequentemente. As perguntas foram elaboradas baseadas nos sintomas do DSM IV para quatro transtornos: ansiedade: transtorno de ansiedade generalizada, fobia social, mutismo seletivo e transtorno de ansiedade de separação (March et al., 1997). 


\subsection{Análise Estatística}

A análise estatística foi realizada por meio do sofware Statistical Package for Social Sciences (SPSS) for Windows versão 14 (SPSS Inc., 2005). Para todas as análises adotou-se um valor de significância de 0,05.

Inicialmente foram realizadas análises descritivas para a obtenção dos valores de média e desvio padrão de cada uma das variáveis observadas. Foram descritas as características sociodemográficas da amostra divididas em casos e controles, em relação ao à idade e escolaridade (utilizando o teste t), assim como ao gênero, lateralidade e classificação socioeconômica (utilizando o teste qui-quadrado).

Posteriormente, verificou-se o tipo de distribuição das variáveis. A maioria delas apresentava uma distribuição normal e por conseguinte, foi utilizado o teste $\mathrm{t}$ (paramétrico). Para as outras variáveis (como os itens relacionados a erros), foi usado o teste Mann-Whitney (não paramétrico).

A análise dos dados foi dividida em dois eixos principais:

1 - Primeira avaliação: a análise foi realizada comparando o desempenho nos testes neuropsicológicos obtidos a partir da amostra clínica (grupo composto por todas as crianças e adolescentes com transtornos de ansiedade: G TAIA) e da amostra sem patologia (grupo composto por todas as crianças e adolescentes controles: $\mathrm{G} \mathrm{CN}$ ), na primeira avaliação. Dessa maneira, na comparação entre grupos no mesmo tempo (A = pré ou $\mathrm{B}=$ pós-tratamento), realizou-se o teste t ou o de Mann-Whitney.

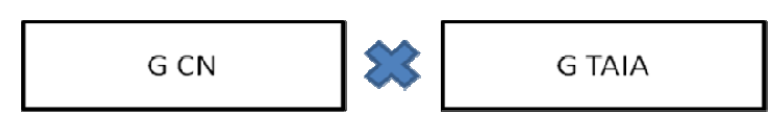

Após essa comparação, realizou-se uma análise de covariância (ANCOVA), para controlar possíveis efeitos do nível socioeconômico nos grupos. Essa análise foi necessária, devido à diferença estatisticamente significativa observada na comparação entre os grupos para o nível socioeconômico. 
2 - Segunda avaliação: a análise foi realizada comparando a primeira á segunda avaliação de cada grupo separadamente (intragrupo). Assim, foram comparados os tempos A e B (pré versus pós-tratamento), o teste utilizado foi o $\mathrm{t}$ pareado ou Wilcoxon sinalizado (de acordo com a distribuição das variáveis). Importante ressaltar que não foram todas as crianças e adolescentes que realizaram a reavaliação em ambos os grupos. Sendo assim, das 30 crianças e adolescentes que compunham o grupo com transtorno de ansiedade, apenas 18 foram reavaliadas e da mesma maneira, de 34 crianças e adolescentes que compunham o grupo controle, apenas 10 foram reavaliadas.

Sendo assim, as comparações realizadas foram:

- entre crianças e adolescentes do grupo com transtornos de ansiedade antes do tratamento medicamentoso e que foram reavaliadas (TAIA 1) com as crianças e adolescentes do grupo com transtornos de ansiedade depois do tratamento medicamentoso (TAIA 2) e

- entre crianças e adolescentes do grupo controle na primeira avaliação e que foram reavaliadas $(\mathrm{CN} 1)$ com as crianças e adolescentes do grupo controle após seis meses da primeira avaliação.

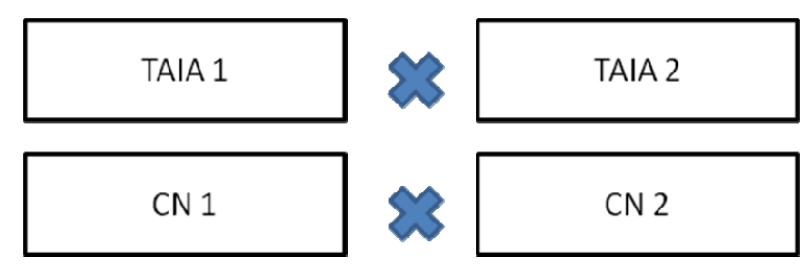

Além disso, foram realizadas comparações de acordo com os diferentes tratamentos medicamentosos (clomipramina, fluoxetina ou placebo):

- entre crianças e adolescentes do grupo com transtornos de ansiedade que foram randomizadas para o tratamento medicamentoso com clomipramina, antes e depois do início do tratamento medicamentoso (CLO 1 versus CLO 2);

- entre crianças e adolescentes do grupo com transtornos de ansiedade que foram randomizadas para o tratamento medicamentoso com fluoxetina, antes e depois do início do tratamento medicamentoso (FLX 1 versus FLX 2) e; 
- entre crianças e adolescentes do grupo com transtornos de ansiedade que foram randomizadas para o tratamento medicamentoso com placebo, antes e depois do início do tratamento (PLC 1 versus PCL 2).

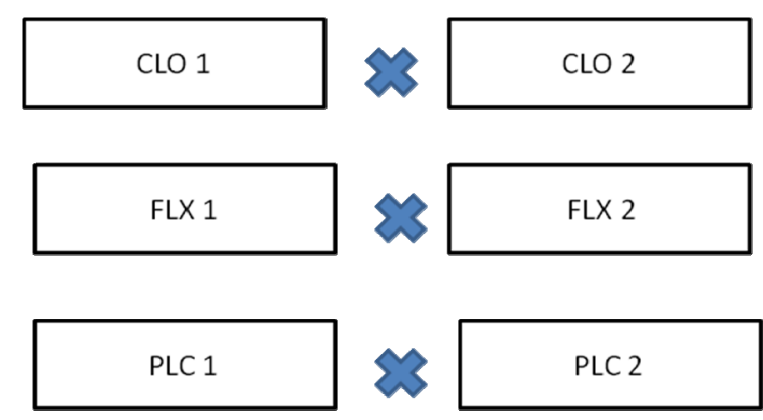


5 RESULTADOS 


\subsection{Processo de triagem}

Em relação ao grupo com transtornos de ansiedade, um total de 404 sujeitos foram entrevistados por telefone, dos quais 251 passaram em triagem com um psiquiatra da infância e adolescência. Destes, 94 foram incluídos, porém somente 37 foram randomizados e iniciaram tratamento. Os motivos das exclusões da pesquisa estão descritos em ordem de frequência de ocorrência na figura abaixo (figura 1).

Figura 1. Processo de triagem dos participantes do estudo.

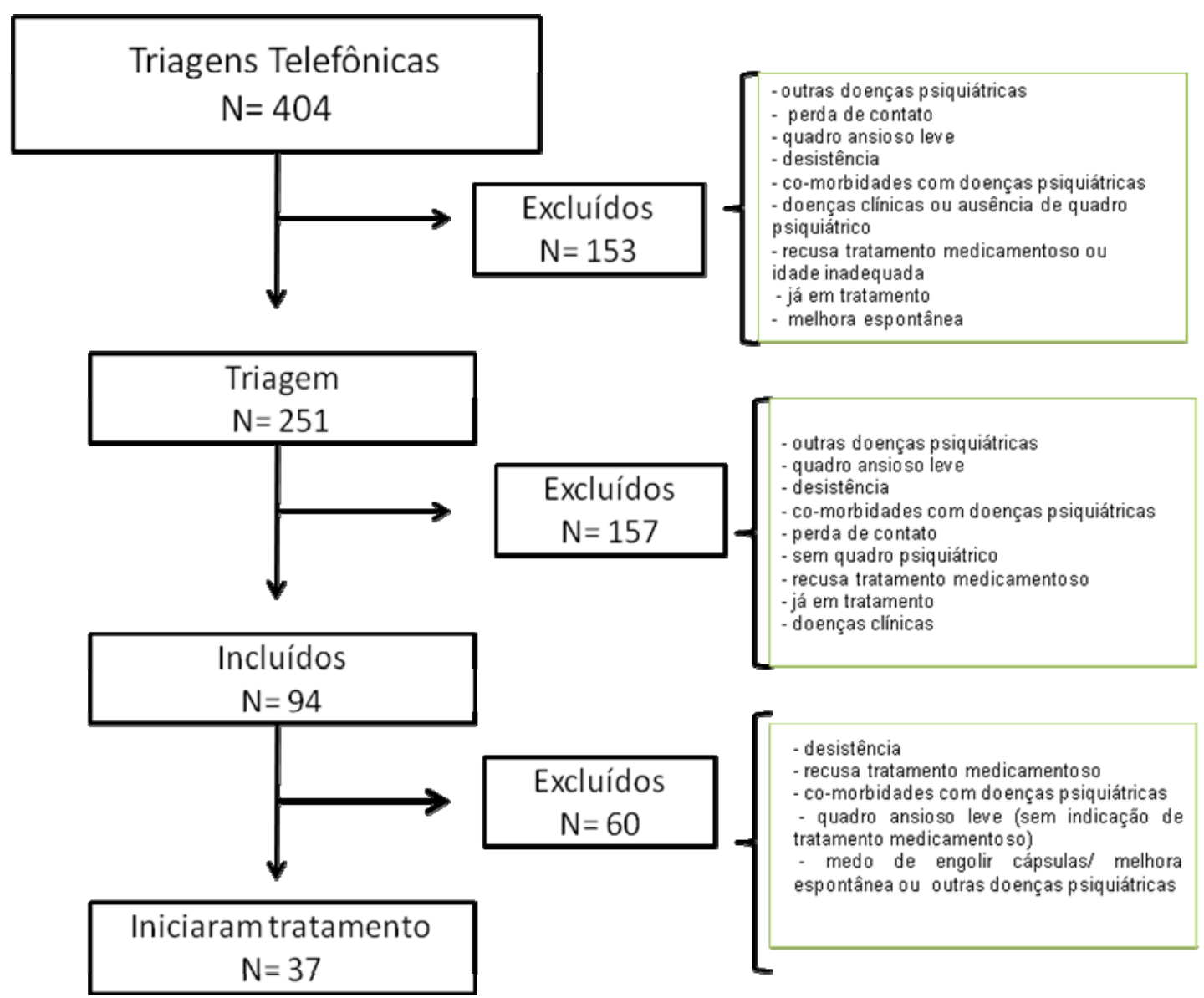

Após o início da pesquisa, 37 realizaram a primeira avaliação neuropsicológica, sendo 20 meninas e 17 meninos. Dessa amostra, sete sujeitos foram excluídos da pesquisa: três pela presença de sintomas depressivos 
clinicamente significativos, três por apresentarem eficiência intelectual na faixa deficiente mental e um por apresentar sintomas ansiosos leves (não justificando uso de medicação). Assim, 30 pacientes (12 meninas e 18 meninos) foram incluídos. Desses, 12 interromperam o estudo, cujos motivos foram: quatro abandonaram sem esclarecimentos, três por melhora espontânea, dois por efeitos colaterais, dois por medo de engolir a cápsula e um por dificuldade em comparecer às consultas. Foram reavaliadas 18 crianças (figura 2 ).

Figura 2. Distribuição dos sujeitos da amostra clínica.

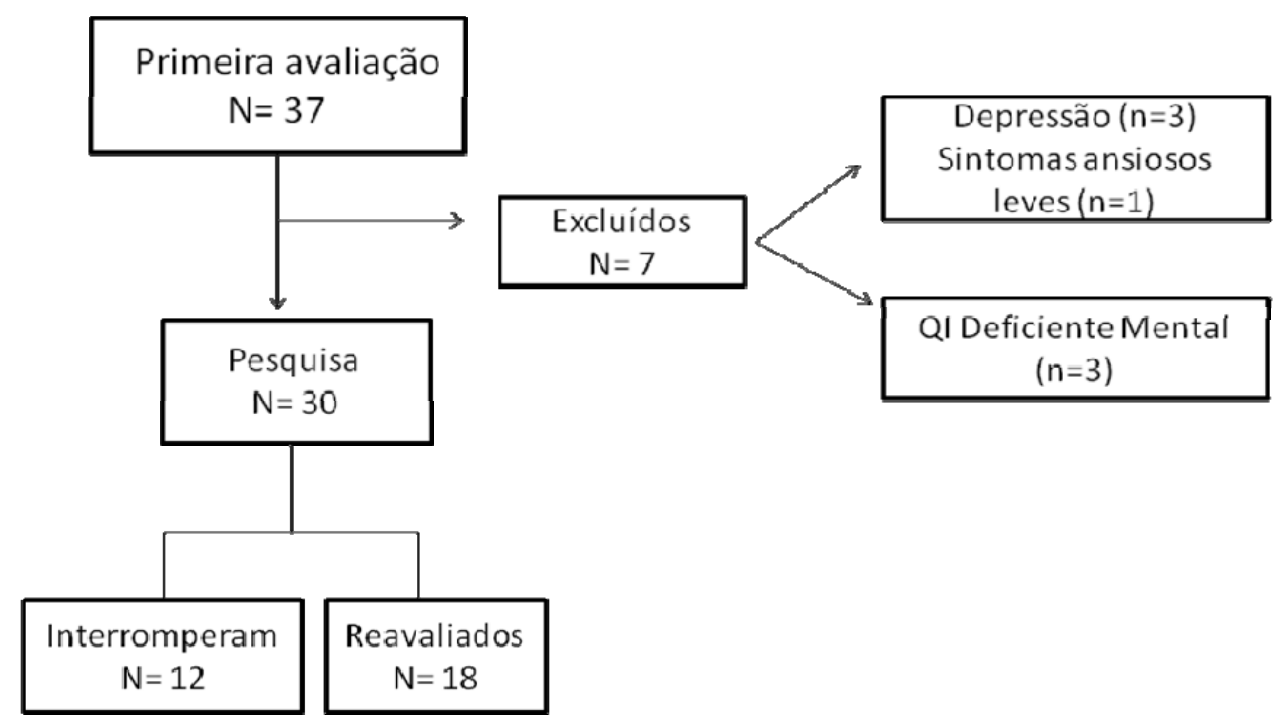

Em relação ao grupo sem transtornos psiquiátricos (grupo controle), um total de 34 sujeitos foram avaliados, sendo 21 meninas e 13 meninos, com o objetivo de comparar o desempenho desse grupo ao grupo com transtornos de ansiedade. Após 6 meses da primeira avaliação, dez sujeitos (4 meninos e 6 meninas) desse grupo foram reavaliados, com o objetivo de verificar o efeito aprendizagem (figura 3 ). 
Figura 3. Distribuição dos sujeitos submetidos a avaliações neuropsicológicas.

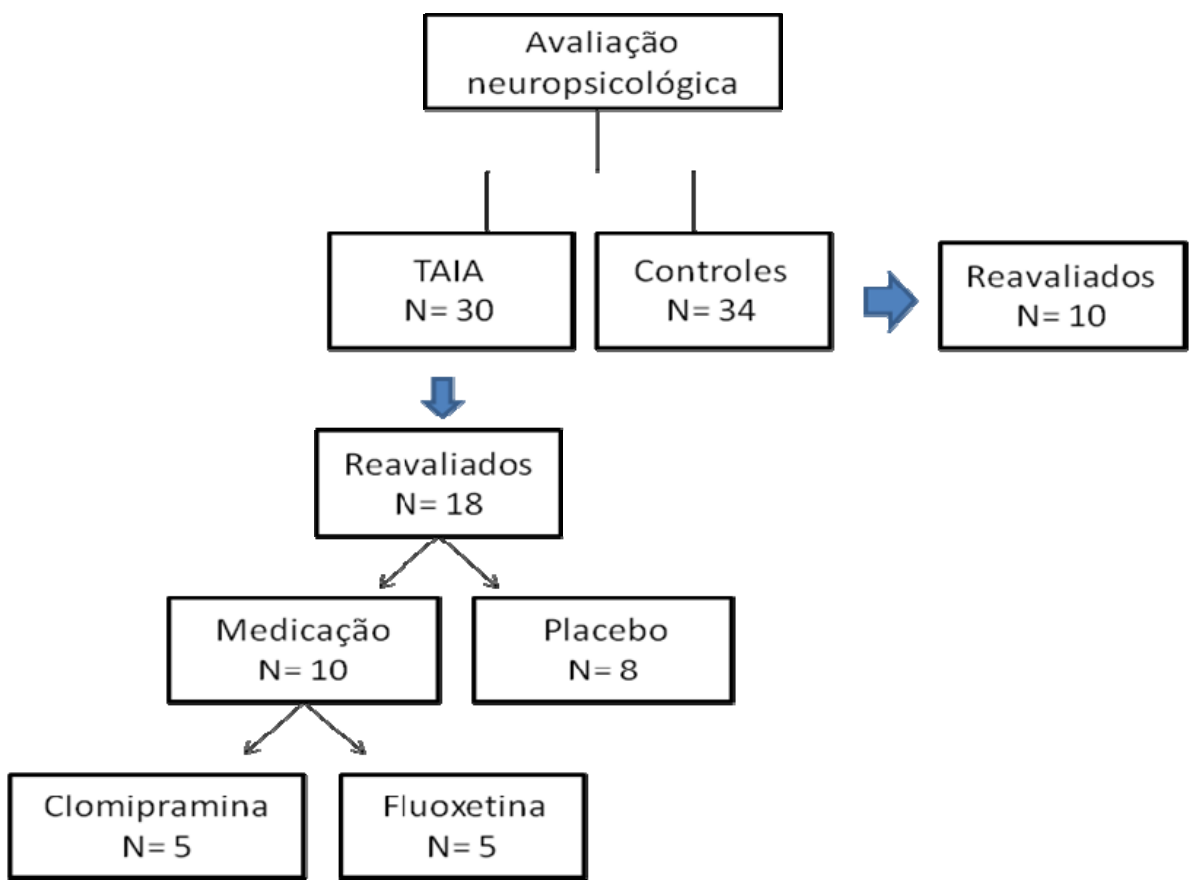

\subsection{Características clínicas e demográficas}

Os grupos de pacientes com TAIA (G TAIA) e o controle ( $\mathrm{G} \mathrm{CN}$ ) não diferiram em relação à idade $(p=0,530)$, escolaridade $(p=0,416)$, gênero $(p=0,082)$ e lateralidade $(\mathrm{p}=0,360)$. Já em relação ao nível socioeconômico, observou-se uma diferença estatisticamente significativa $(p=0,047)$ na comparação entre os grupos. $O$ grupo G TAIA apresentou uma porcentagem maior de pessoas com nível socioeconômico na faixa $\mathrm{C}$ e o grupo $\mathrm{G} \mathrm{CN}$ na faixa $\mathrm{B}$ (tabela 1 ).

Devido à diferença significativa relacionada aos dados socioeconômico, realizou-se, análise de covariância com outras variáveis (descrita posteriormente no capítulo). 
Tabela 1 - Dados demográficos do grupo com transtornos de ansiedade e do grupo controle - IPQ HC FMUSP - 2008 a 2011

\begin{tabular}{cccc}
\hline Caracterísitcas & $\begin{array}{c}\text { G TAIA (n=30) } \\
\mathbf{m ~ ( d p )}\end{array}$ & $\begin{array}{c}\text { G CN (n=34) } \\
\mathbf{m}(\mathbf{d p})\end{array}$ & Valor p \\
\hline Idade (anos) & $11,9(2,8)$ & $12,4(3,4)$ & $0,530^{*}$ \\
Escolaridade (anos) & $6,9(2,6)$ & $7,5(3,4)$ & $0,416^{*}$ \\
Gênero (\%) & & & \\
Feminino & 40 & 61,8 & \\
Masculino & 60 & 38,2 & $0,082^{* *}$ \\
Lateralidade (\%) & & & \\
Destro & 96,7 & 3,3 & \\
Canhoto & 88,2 & 11,8 & $0,360^{* *}$
\end{tabular}

Socioeconômico (\%)

\begin{tabular}{cccc} 
A & 6,7 & 3,2 & \\
B & 26,7 & 61,3 & \\
C & 63,3 & 35,5 & \\
D & 3,3 & 0 & $0,047 * *$ \\
\hline FONTE: Rodrigues, São Paulo, 2011 & & \\
*Teste t $/$ **Teste Qui-quadrado/ Legenda: $\mathrm{m}=$ média e dp = desvio padrão
\end{tabular}

Todos os pacientes apresentaram diagnósticos de TAG e/ou TAS e/ou FS na avaliação inicial. Foram incluídos sujeitos que apresentavam comorbidade com outros diagnósticos ansiosos (transtorno do pânico, agorafobia e fobia simples) e/ou com outros transtornos psiquiátricos (transtorno depressivo maior, TDAH e TOC), desde que as comorbidades não apresentassem uma gravidade superior ao do(s) transtorno(s) de ansiedade em avaliação, ou que necessitassem tratamento específico.

Dos 30 pacientes, seis apresentaram apenas um diagnóstico de transtorno de ansiedade (TAG: $\mathrm{N}=3$; TAS: $\mathrm{N}=2 ; \mathrm{FS}: \mathrm{N}=1$ ) (gráficos 1 e 2). 
Gráfico 1 - Frequência dos diagnósticos dos transtornos de ansiedade com e sem comorbidades com outros transtornos de ansiedade - IPQ HC FMUSP - 2008 a 2011

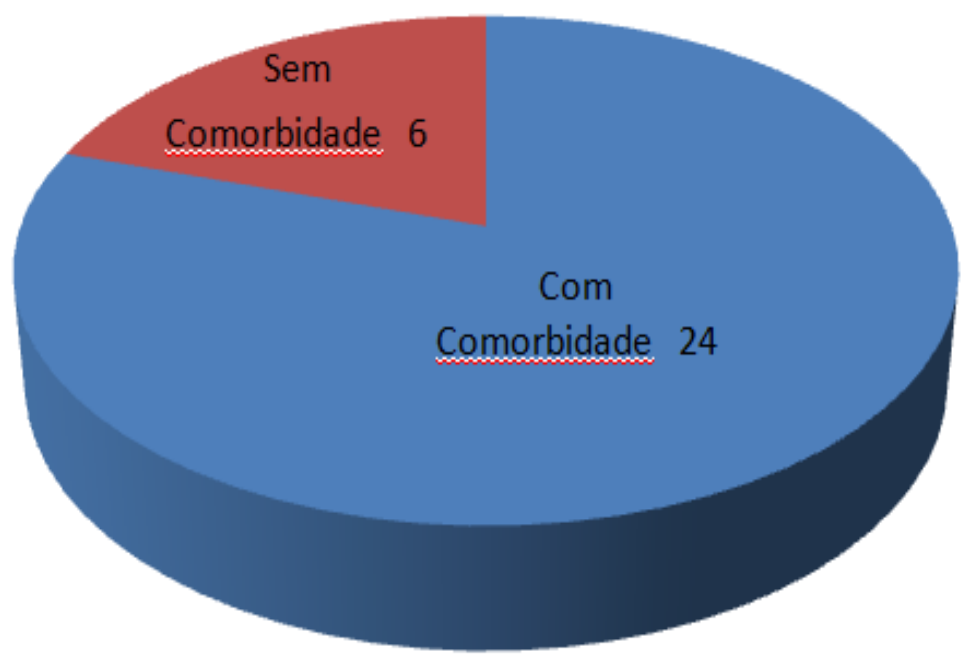

FONTE: Rodrigues, São Paulo, 2011

Grafico 2 - Frequência dos transtornos de ansiedade sem comorbidade - IPQ HC FMUSP - 2008 a 2011

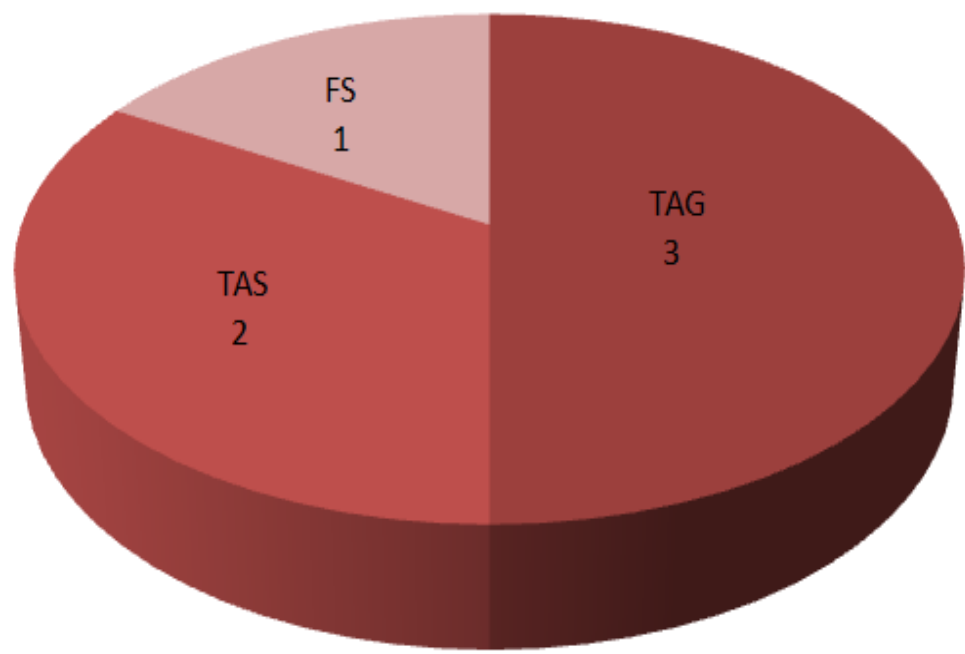

FONTE: Rodrigues, São Paulo, 2011 
Vinte e quatro pacientes apresentaram comorbidade com um ou mais TA (TAS: $60 \%$; FS: 50\%; TAG: 50\%; fobia simples: 50\%; agorafobia: 23,3\%, transtorno do pânico: 23,3\% e transtorno de evitação: 6,7\%) (gráfico 3).

Grafico 3 - Porcentagem da frequência dos diagnósticos de transtornos de ansiedade - IPQ HC FMUSP - 2008 a 2011

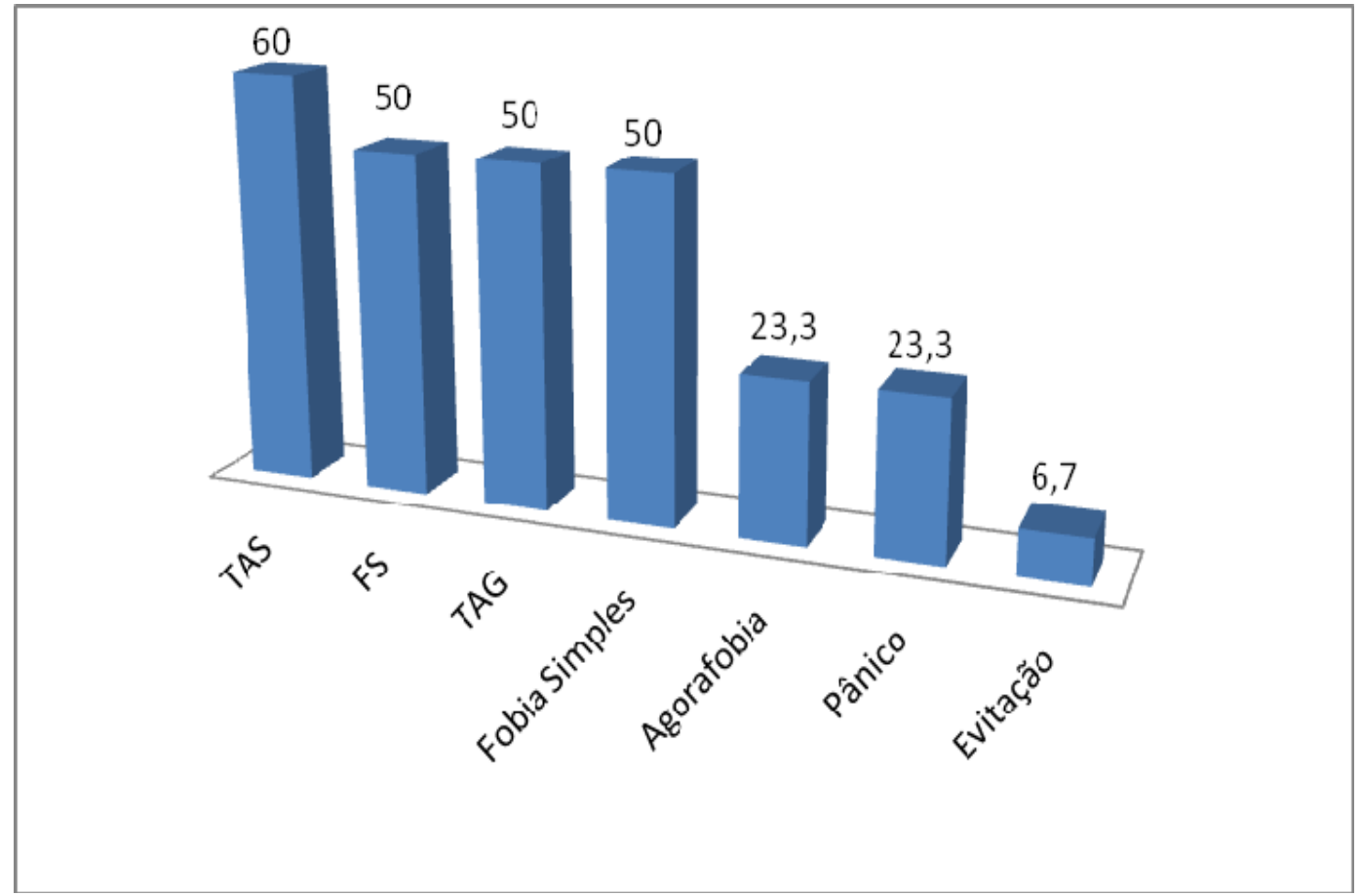

FONTE: Rodrigues, São Paulo, 2011

Em relação às comorbidades com outros transtornos psiquiátricos, sete crianças as apresentaram: cinco com o TDAH, uma com transtorno depressivo maior e uma com TOC. Conforme descrito acima, é importante ressaltar que todas essas comorbidades não apresentavam gravidade superior a do(s) transtorno(s) de ansiedade, dessa maneira não necessitaram de tratamento específico. 


\subsection{Avaliação neuropsicológica}

\subsubsection{Análise de covariância}

A partir da avaliação do desempenho das crianças e adolescentes dos grupos $\mathrm{G}$ TAIA e G CN observou-se que na comparação entre os dois grupos, a variável nível socioeconômico apresentou diferença estatisticamente significativa. Devido a esse dado, realizou-se uma análise de covariância para testar os efeitos dessa variável sobre os grupos (tabela 2).

Tabela 2 - Análise de covariância dos itens que apresentaram uma diferença estatisticamente significativa em relação ao nível socioeconômico - IPQ HC FMUSP -2008 a 2011

\begin{tabular}{ccl}
\hline $\begin{array}{c}\text { Diferença estatisticamente } \\
\text { Significativa }\end{array}$ & Valor P & \multicolumn{1}{c}{ Observação } \\
\hline Figura de Rey na memória & 0,044 & Nível C diferente do nível B \\
FAS & 0,045 & Nível C diferente do nível B \\
Animais & 0,028 & Nível C diferente do nível A e B \\
WCST erros perseverativos & 0,035 & Nível B diferente do nível C \\
Aprendizagem verbal evocação & 0,006 & Nível B diferente do nível C \\
\hline FONTE: Rodrigues, São Paulo, 2011 & &
\end{tabular}

\subsubsection{Primeira avaliação}

Grupo clínico sem tratamento medicamentoso prévio comparado ao grupo controle.

\subsubsection{Eficiência intelectual}

Nos testes que avaliaram a eficiência intelectual estimada, não foram observadas diferenças estatisticamente significativas entre o grupo G TAIA e o grupo G CN. (tabela 3). 
Tabela 3 - Comparação do desempenho no teste de eficiência intelectual estimada dos grupos G TAIA e G CN - IPQ HC FMUSP - 2008 a 2011

\begin{tabular}{cccc}
\hline Testes & $\begin{array}{c}\text { G TAIA (n=30) } \\
\text { m (dp) }\end{array}$ & $\begin{array}{c}\text { G CN (n=34) } \\
\text { m (dp) }\end{array}$ & Valor p* \\
\hline Vocabulário & $9,9(2,9)$ & $11,1(2,8)$ & 0,095 \\
Matrizes & $8,1(3,5)$ & $9,3(3,3)$ & 0,177 \\
QI estimado & $95,3(14,6)$ & $101,7(13,7)$ & 0,076 \\
FONTE: Rodrigues, São Paulo, 2011 \\
*Teste t / Legenda: $\mathrm{m}$ = média e dp = desvio padrão
\end{tabular}

\subsubsection{Funções atencionais e executivas}

A partir da avaliação do desempenho das crianças e adolescentes dos grupos $G$ TAIA e $\mathrm{G} \mathrm{CN}$ nos testes que avaliaram as funções atencionais e executivas, observou-se que o grupo G TAIA apresentou pior desempenho em comparação ao grupo G CN nos seguintes testes: Trail Making Test partes A e B em relação ao tempo $(p=0,018$ e $p=0,007$, respectivamente); Torre de Hanoi com 3 peças em relação ao tempo $(p=0,005)$ e em relação ao número de movimentos $(p=0,003)$, com 4 peças em relação ao tempo $(\mathrm{p}<0,001)$, ao número de movimento $(\mathrm{p}=0,014)$ e ao número de erros $(\mathrm{p}=0,08)$; WCST em relação ao número de categorias completas $(\mathrm{p}=0,021)$, ao número de acertos $(\mathrm{p}=0,029)$, ao número de erros $(\mathrm{p}=0,027)$ e em relação ao número de vezes em que combinaram as cartas com categoria diferente das consideradas (outros) $(\mathrm{p}=0,028)$ e $R C F T$ na cópia $(\mathrm{p}=0,016)$ (tabela 4).

Ressalta-se que, apesar do resultado dos testes de Fluência verbal para animais e para letras $F A S$ ter apresentado diferença estatisticamente significativa ( $\mathrm{p}=0,039$ e $\mathrm{p}=0,040$, respectivamente), esse resultado não deve ser considerado devido à análise de covariância realizada posteriormente em relação ao nível socioeconômico $(\mathrm{p}=0,028$ e $\mathrm{p}=0,045$, respectivamente) (tabela 2$)$. 
Tabela 4 - Comparação do desempenho nos testes de atenção e funções executivas dos sujeitos do grupo G TAIA e G CN - IPQ HC FMUSP - 2008 a 2011

\begin{tabular}{|c|c|c|c|}
\hline Testes & $\begin{array}{c}\text { G TAIA }(n=30) \\
\text { m (dp) }\end{array}$ & $\begin{array}{c}\text { G CN (n=34) } \\
\text { m (dp) }\end{array}$ & Valor $P^{*}$ \\
\hline \multicolumn{4}{|l|}{ Trail Making Test A } \\
\hline Tempo (segundos) & $55,4(26,8)$ & $40,6(20,2)$ & 0,018 \\
\hline Erros & $0,2(0,5)$ & $0,2(0,4)$ & $0,746 * *$ \\
\hline \multicolumn{4}{|l|}{ Trail Making Test B } \\
\hline Tempo (segundos) & $142,6(83,7)$ & $92,5(52,0)$ & 0,007 \\
\hline Erros & $0,7(1,1)$ & $0,3(0,4)$ & $0,081 * *$ \\
\hline \multicolumn{4}{|l|}{ Stroop 1} \\
\hline Tempo (segundos) & $19,4(6,5)$ & $17,2(7,3)$ & 0,227 \\
\hline Erros & $0,1(0,7)$ & $0,2(0,7)$ & $0,245 * *$ \\
\hline \multicolumn{4}{|l|}{ Stroop 2} \\
\hline Tempo (segundos) & $24,9(10,6)$ & $22,8(10,8)$ & 0,455 \\
\hline Erros & $0,2(0,6)$ & $0,3(0,9)$ & $0,856 * *$ \\
\hline \multicolumn{4}{|l|}{ Stroop 3} \\
\hline Tempo (segundos) & $36,6(15,6)$ & $35,1(16,6)$ & 0,709 \\
\hline Erros & $1,2(2,5)$ & $1,1(2,0)$ & $0,824 * *$ \\
\hline \multicolumn{4}{|l|}{ MFFT-20 } \\
\hline Tempo (segundos) & $409,1(215,1)$ & $344,4(171,0)$ & 0,189 \\
\hline Acertos & $10,6(4,3)$ & $12,3(4,6)$ & 0,116 \\
\hline Erros & $19,0(12,3)$ & $13,8(11,2)$ & 0,083 \\
\hline Impulsividade & $49,2(28,6)$ & $56,3(33,2)$ & 0,492 \\
\hline Ineficiência & $86,5(22,7)$ & $71,6(26,0)$ & 0,071 \\
\hline FAS & $21,6(11,3)$ & $28,3(14,0)$ & $0,040 * * *$ \\
\hline Animais & $12,8(5,2)$ & $15,5(5,0)$ & $0,039 * * *$ \\
\hline \multicolumn{4}{|l|}{ Torre de Hanoi 3} \\
\hline Tempo (segundos) & $42,1(35,8)$ & $21,3(10,6)$ & 0,005 \\
\hline Movimento & $12,9(6,6)$ & $8,9(2,1)$ & 0,003 \\
\hline Erros & $2,6(3,6)$ & $1,5(2,0)$ & $0,251 * *$ \\
\hline \multicolumn{4}{|l|}{ Torre de Hanoi 4} \\
\hline Tempo (segundos) & $85,9(31,2)$ & $57,4(24,0)$ & $<0,001$ \\
\hline Movimento & $30,5(8,6)$ & $24,9(8,9)$ & 0,014 \\
\hline Erros & $5,7(5,9)$ & $2,0(2,4)$ & $0,008 * *$ \\
\hline \multicolumn{4}{|l|}{ WCST } \\
\hline Categorias Completas & $2,5(1,4)$ & $3,3(1,2)$ & 0,021 \\
\hline Acertos & $40,5(11,3)$ & $46,3(9,4)$ & 0,029 \\
\hline Erros & $23,4(11,4)$ & $17,5(9,5)$ & $0,027 * *$ \\
\hline Erros Perseverativos & $10,6(7,4)$ & $8,5(4,6)$ & 0,188 \\
\hline Perdas & $0,6(0,7)$ & $0,4(0,6)$ & 0,235 \\
\hline Outros & $3,4(5,5)$ & $1,2(2,3)$ & $0,028 * *$ \\
\hline Rey cópia & $31,8(5,4)$ & $33,2(4,0)$ & $0,016 * *$ \\
\hline
\end{tabular}

FONTE: Rodrigues, São Paulo, 2011

*Teste $\mathrm{t} / * *$ Teste Mann-Whitney/*** não considerado devido `a análise de covariância

Legenda: $\mathrm{m}=$ média e $\mathrm{dp}=$ desvio padrão 


\subsubsection{Processos de memória e aprendizagem}

A partir da avaliação do desempenho das crianças e adolescentes dos grupos $\mathrm{G}$ TAIA e G CN nos testes que avaliaram a memória e a aprendizagem, observou-se que o grupo G TAIA teve pior desempenho em comparação ao grupo $\mathrm{G} C \mathrm{~N}$ nos seguintes subtestes do WRAML 2: memória para cenas $(\mathrm{p}=0,043)$ e reconhecimento $(0,026)$, memória para história $1(p<0,001)$, memória para história $2(p=0,003)$; aprendizagem verbal $(p=0,010)$ e memória de trabalho visual $(\mathrm{p}<0,001)$ (tabela 5).

Importante ressaltar que, apesar do resultado do subteste evocação da aprendizagem verbal ter sido estatisticamente significativo $(p=0,012)$, esse resultado não deve ser considerado devido à análise de covariância realizada posteriormente em relação ao nível socioeconômico $(\mathrm{p}=0,006)$ (tabela 2$)$.

Tabela 5 - Comparação do desempenho nos testes de memória e aprendizagem dos sujeitos dos grupos G TAIA e G CN - IPQ HC FMUSP - 2008 a 2011

\begin{tabular}{llll}
\hline Testes & $\begin{array}{c}\text { G TAIA (n=30) } \\
\text { m (dp) }\end{array}$ & $\begin{array}{c}\text { G CN (n=34) } \\
\text { m (dp) }\end{array}$ & Valor P* \\
\hline Memória Visual & & & \\
Rey (memória) & $16,2(6,3)$ & $20,6(7,8)$ & 0,195 \\
Memória cenas & $8,6(2,3)$ & $9,8(2,3)$ & 0,043 \\
Reconhecimento & $8,4(2,1)$ & $9,8(2,7)$ & 0,026 \\
Memória desenho & $9,7(3,1)$ & $10,5(3,1)$ & 0,271 \\
Recognition & $9,4(3,1)$ & $10,2(3,4)$ & 0,327 \\
Memória Verbal & & & \\
Memória História 1 & $10,3(2,6)$ & $12,9(3,1)$ & $<0,001$ \\
Memória História 2 & $10,1(2,8)$ & $12,3(3,0)$ & 0,003 \\
Reconhecimento & $11,4(2,8)$ & $12,8(2,4)$ & 0,052 \\
Aprendizagem Verbal & & & \\
Aprendizagem & $8,4(2,1)$ & $9,7(1,8)$ & 0,010 \\
Evoção & $8,5(2,2)$ & $10,0(2,6)$ & $0,012 * * *$ \\
Reconhecimento & $10,0(2,6)$ & $10,9(2,1)$ & 0,149 \\
Memória de Trabalho & & & \\
Visual & $9,5(3,2)$ & $12,6(3,1)$ & $<0,001$ \\
Verbal & $9,7(3,5)$ & $11,1(2,0)$ & 0,073 \\
\hline
\end{tabular}

FONTE: Rodrigues, São Paulo, 2011

*Teste $\mathrm{t} / * * *$ não considerado devido `a análise de covariância

Legenda: $\mathrm{m}=$ média e $\mathrm{dp}=$ desvio padrão 


\subsubsection{Escala de ansiedade}

A partir da avaliação do desempenho das crianças e adolescentes dos grupos $\mathrm{G}$ TAIA e G CN na escala de ansiedade, observou-se que o grupo G TAIA teve maiores escores de manifestação de ansiedade em comparação ao grupo $\mathrm{G} \mathrm{CN}$ nos seguintes itens: "MASC total" $(p=0,006)$, "tensão e inquietação" $(p<0,001)$, "somático" ( $p=0,001)$, "sintomas físicos" $(p<0,001)$, "humilhação e rejeição" ( $p=0,033)$, “desempenho público" $(p=0,020)$ e "ansiedade social” $(p=0,018)$ (tabela $6)$.

Tabela 6 - Comparação do desempenho na escala de ansiedade de sujeitos do grupo G TAIA e G CN - IPQ HC FMUSP - 2008 a 2011

\begin{tabular}{clll}
\hline Itens da escala & $\begin{array}{c}\text { G TAIA (n=30) } \\
\text { m (dp) }\end{array}$ & $\begin{array}{c}\text { G CN (n=34) } \\
\mathbf{m}(\mathbf{d p})\end{array}$ & Valor P* \\
\hline MASC Total & $51,8(9,8)$ & $44,3(10,2)$ & 0,006 \\
Inconsistencia & $7,0(3,5)$ & $5,9(3,1)$ & 0,201 \\
Tenso e Inquieto & $52,1(12,2)$ & $42,0(7,2)$ & $<0,001$ \\
Somático & $50,2(9,6)$ & $42,5(5,9)$ & 0,001 \\
Sintomas físicos & $51,3(11,2)$ & $41,4(6,3)$ & $<0,001$ \\
Perfeccionismo & $41,0(9,8)$ & $45,5(10,0)$ & 0,086 \\
Superar ans & $40,3(7,3)$ & $42,8(8,3)$ & 0,352 \\
Evitar danos & $38,9(8,3)$ & $42,3(9,3)$ & 0,150 \\
Humilhação e rej & $54,7(12,7)$ & $47,8(11,4)$ & 0,033 \\
Desempenho púb & $55,1(10,6)$ & $48,0(11,9)$ & 0,020 \\
Ansiedade social & $55,5(11,0)$ & $48,4(11,3)$ & 0,018 \\
Pânico e separação & $56,8(11,5)$ & $52,6(10,6)$ & 0,154 \\
Índice de ansiedade & $46,7(11,1)$ & $41,0(10,5)$ & 0,052 \\
\hline
\end{tabular}

FONTE: Rodrigues. São Paulo, 2011

*Teste $\mathrm{t} /$ Legenda: $\mathrm{m}=$ média/ $\mathrm{dp}=$ desvio padrão 


\subsubsection{Segunda avaliação}

Comparação da primeira avaliação com a segunda intra grupo.

\subsubsection{Eficiência intelectual}

\section{a) TAIA}

Na comparação dos sujeitos do grupo com transtornos de ansiedade na infância e na adolescência que foram avaliados, antes e depois do tratamento medicamentoso (TAIA 1 X TAIA 2), pode-se observar melhora do desempenho do grupo na segunda avaliação (após o tratamento). Observou-se assim, diferença estatisticamente significativa no subteste do teste WASI: Matrizes do raciocínio $(\mathrm{p}=0,016)$ assim como no QI estimado $(\mathrm{p}=0,009)$ (tabela 7$)$.

b) Controle

$\mathrm{Na}$ comparação dos sujeitos do grupo controle que foram avaliados, antes e depois de seis meses ( $\mathrm{CN} 1 \mathrm{X} \mathrm{CN} 2)$, mesmo intervalo de tempo usado para a segunda avaliação do grupo com TAIA, não foram observadas diferenças estatisticamente significativas (tabela 7).

Tabela 7 - Comparação do desempenho das crianças e adolescentes dos grupos TAIA 1 e TAIA 2 e dos grupos CN1 e CN2, no teste de eficiência intelectual estimada IPQ HC FMUSP - 2008 a 2011

\begin{tabular}{|c|c|c|c|c|c|c|}
\hline Testes & $\begin{array}{c}\text { TAIA } 1(n=18) \\
\text { m (dp) }\end{array}$ & $\begin{array}{c}\text { TAIA } 2(n=18) \\
\text { m (dp) }\end{array}$ & Valor p* & $\begin{array}{c}\text { CN1 (n=10) } \\
\text { m (dp) }\end{array}$ & $\begin{array}{c}\text { CN2 (n=10) } \\
\text { m (dp) }\end{array}$ & Valor p* \\
\hline Vocabulário & $9,6(2,7)$ & $9,9(2,4)$ & 0,384 & $12,6(2,6)$ & $12,2(1,3)$ & 0,462 \\
\hline Matrizes & $7,2(3,1)$ & $9,0(2,8)$ & 0,016 & $10,4(2,6)$ & $11,6(1,6)$ & 0,193 \\
\hline QI estimado & $91,7(12,4)$ & $97,1(11,7)$ & 0,009 & $108,7(12,1)$ & $110,2(7,6)$ & 0,559 \\
\hline
\end{tabular}


c) Tratamento Medicamentoso

Na comparação dos sujeitos do grupo com transtorno de ansiedade na infância e na adolescência que vieram a ser tratados com clomipramina nos momentos, antes e depois do tratamento medicamentoso (CLO 1 X CLO 2), não foram observadas diferenças estatisticamente significativas. Da mesma maneira, não foram observadas diferenças estatisticamente significativas na comparação dos sujeitos do grupo com transtorno de ansiedade na infância e na adolescência que vieram a ser tratados com fluoxetina (FLX 1 X FLX 2) (tabela 8).

Tabela 8 - Comparação das crianças e adolescentes dos grupos CLO1 e CLO 2 e dos grupos FLX 1 e FLX 2, no teste de eficiência intelectual estimada - IPQ HC FMUSP -2008 a 2011

\begin{tabular}{lcccccc}
\hline Testes & $\begin{array}{c}\text { CLO1 (n=5) } \\
\text { m (dp) }\end{array}$ & $\begin{array}{c}\text { CLO2 (n=5) } \\
\text { m (dp) }\end{array}$ & Valor p* & $\begin{array}{c}\text { FLX1 (n=5) } \\
\text { m (dp) }\end{array}$ & $\begin{array}{c}\text { FLX2 (n=5) } \\
\text { m (dp) }\end{array}$ & Valor p* \\
\hline Vocabulário & $9,2(3,8)$ & $9,8(3,0)$ & 0,501 & $10,2(2,2)$ & $10,2(1,8)$ & 1,000 \\
Matrizes & $5,8(2,7)$ & $7,4(3,6)$ & 0,160 & $7,2(4,8)$ & $8,6(2,1)$ & 0,575 \\
QI estimado & $87,4(14,7)$ & $92,8(15,9)$ & 0,167 & $92,6(13,0)$ & $96,0(5,6)$ & 0,540 \\
\hline FONTE: Rodrigues, São Paulo, 2011 & & & & & \\
*Teste t / Legenda: $\mathrm{m}=$ média e dp = desvio padrão & & & & &
\end{tabular}

Na comparação dos sujeitos do grupo com transtorno de ansiedade na infância e na adolescência que vieram a ser tratados com placebo nos momentos, antes e depois do tratamento medicamentoso (PLC 1 X PLC 2), pode-se observar que, após o período de 6 meses, o grupo melhorou seu desempenho na segunda avaliação. Dessa maneira, observou-se uma diferença estatisticamente significativa nos itens: Matrizes do raciocínio $(p=0,005)$ e QI estimado $(p=0,020)$ (tabela 9). 
Tabela 9 - Comparação das crianças e adolescentes dos grupos PLC 1 e PLC 2 no teste de eficiência intelectual estimada - IPQ HC FMUSP - 2008 a 2011

\begin{tabular}{cccc}
\hline Testes & $\begin{array}{c}\text { PLC 1 (n=8) } \\
\text { m (dp) }\end{array}$ & $\begin{array}{c}\text { PLC (n=8) } \\
\text { m (dp) }\end{array}$ & Valor p* \\
\hline Vocabulário & $9,5(2,7)$ & $9,8(2,6)$ & 0,563 \\
Matrizes & $8,1(2,0)$ & $10,4(2,4)$ & 0,005 \\
QI estimado & $93,9(11,3)$ & $100,5(12,0)$ & 0,020 \\
\hline
\end{tabular}

FONTE: Rodrigues, São Paulo, 2011

*Teste $\mathrm{t} /$ Legenda: $\mathrm{m}=$ média e $\mathrm{dp}=$ desvio padrão

5.3.3.2. Funções atencionais e executivas

a) TAIA

Na comparação dos sujeitos do grupo com transtorno de ansiedade na infância e na adolescência que foram avaliados, antes e depois do tratamento medicamentoso (TAIA 1 X TAIA 2), pode-se observar que o grupo melhorou seu desempenho na segunda avaliação em alguns testes. Observou-se diferença estatisticamente significativa nos seguintes itens: Trail Making Test parte B em relação ao tempo $(p=0,037)$; Torre de Hanoi com 3 peças em relação ao tempo $(p=0,004)$ e em relação aos movimentos $(0,037)$ e ao número de erros $(\mathrm{p}=0,006)$; Torre de Hanoi com 4 peças em relação ao tempo $(0,002)$ e ao número de erros $(\mathrm{p}=0,021)$ (tabela 10$)$.

b) Controle

$\mathrm{Na}$ comparação dos sujeitos do grupo controle que foram avaliados, antes e depois de seis meses (CN 1 X CN 2), pode-se observar que o grupo apresentou melhor desempenho em alguns testes na segunda avaliação. Observou-se diferenças estatisticamente significativas nos itens: Trail Making Test parte A em relação ao tempo ( $\mathrm{p}=0,040)$; Stroop 3 em relação ao tempo $(\mathrm{p}=0,013)$; MFFT-20 em relação ao tempo $(\mathrm{p}=0,015)($ tabela 10$)$. 
Salienta-se que, apesar do resultado do teste Trail Making Test A em relação ao tempo, na comparação do grupo TAIA 1 e TAIA 2 ter sido estatisticamente significativo $(\mathrm{p}=0,015)$, esse resultado não deve ser considerado devido à diferença significativa observada na comparação entre os grupos CN 1 e CN 2 (tabela 10). Outros resultados que não devem ser considerados são os dos itens: Fluência verbal para animais $(\mathrm{p}=0,045)$ e para letras $F A S(\mathrm{p}=0,001)$ devido à análise de covariância $(\mathrm{p}=0,028$ e $\mathrm{p}=0,045$ respectivamente) (tabela 2$)$.

Da mesma maneira, na comparação entre os sujeitos do grupo controle $(\mathrm{CN} 1 \mathrm{e}$ $\mathrm{CN}$ 2) não deve ser considerado o resultado do teste $W C S T$ em relação ao número de erros perseverativos $(\mathrm{p}=0,016)$ devido à análise de covariância $(\mathrm{p}=0,035)$ (tabela 2$)$. 
Tabela 10 - Comparação do desempenho das crianças e adolescentes dos grupos TAIA 1 e TAIA 2 e dos grupos CN1 e CN2, nos testes de atenção e funções executivas - IPQ HC FMUSP - 2008 a 2011

\begin{tabular}{|c|c|c|c|c|c|c|}
\hline Testes & $\begin{array}{c}\text { TAIA } 1(n=18) \\
\text { m (dp) }\end{array}$ & $\begin{array}{c}\text { TAIA } 2(n=18) \\
\text { m (dp) }\end{array}$ & Valor P* & $\begin{array}{c}\text { CN1 (n=10) } \\
\text { m (dp) }\end{array}$ & $\begin{array}{c}\text { CN2 (n=10) } \\
\text { m (dp) }\end{array}$ & Valor p* \\
\hline \multicolumn{7}{|l|}{ Trail Making Test A } \\
\hline Tempo (segundos) & $61,8(30,8)$ & $47,5(26,8)$ & $0,015 * * *$ & $48,9(23,0)$ & $33,5(11,6)$ & 0,040 \\
\hline Erros & $0,2(0,4)$ & $0,3(0,7)$ & $0,317 * *$ & $0,3(0,5)$ & $0,3(0,7)$ & $1,000 * *$ \\
\hline \multicolumn{7}{|l|}{ Trail Making Test B } \\
\hline Tempo (segundos) & $149,3(85,0)$ & $123,7(74,8)$ & 0,037 & $88,4(39,8)$ & $66,5(27,7)$ & 0,138 \\
\hline Erros & $0,6(0,8)$ & $0,5(0,8)$ & $1,000 * *$ & $0,1(0,3)$ & $1,0(2,0)$ & $0,180 * *$ \\
\hline \multicolumn{7}{|l|}{ Stroop 1} \\
\hline Tempo (segundos) & $20,5(7,2)$ & $18,0(5,5)$ & 0,054 & $18,5(9,9)$ & $15,4(5,2)$ & 0,193 \\
\hline Erros & $0,2(1,0)$ & $0,0(0,0)$ & $0,317 * *$ & $0,5(1,3)$ & $0,0(0,0)$ & $0,180 * *$ \\
\hline \multicolumn{7}{|l|}{ Stroop 2} \\
\hline Tempo (segundos) & $26,6(12,5)$ & $23,9(9,3)$ & 0,138 & $23,8(14,6)$ & $20,9(9,1)$ & 0,201 \\
\hline Erros & $0,3(0,8)$ & $0,0(0,0)$ & $0,102 * *$ & $0,3(0,9)$ & $0,0(0,0)$ & $0,317 * *$ \\
\hline \multicolumn{7}{|l|}{ Stroop 3} \\
\hline Tempo (segundos) & $38,2(16,2)$ & $32,8(10,9)$ & 0,059 & $36,8(19,1)$ & $28,5(13,1)$ & 0,013 \\
\hline Erros & $1,0(1,7)$ & $0,5(1,2)$ & $0,293 * *$ & $1,2(2,5)$ & $0,7(1,3)$ & $0,593 * *$ \\
\hline \multicolumn{7}{|l|}{ MFFT-20 } \\
\hline Tempo (segundos) & $391,2(204,6)$ & $363,4(192,9)$ & 0,418 & $379,2(181,5)$ & $281,8(130,5)$ & 0,015 \\
\hline Acertos & $10,1(4,6)$ & $11,2(4,6)$ & 0,256 & $13,0(3,6)$ & $10,8(5,2)$ & 0,084 \\
\hline Erros & $21,0(12,4)$ & $17,5(12,0)$ & 0,163 & $10,9(7,6)$ & $15,6(11,4)$ & 0,121 \\
\hline Impulsividade & $56,2(22,5)$ & $63,4(24,1)$ & 0,427 & $44,7(34,8)$ & $79,2(8,0)$ & 0,064 \\
\hline Ineficiência & $81,6(29,4)$ & $72,1(25,6)$ & 0,719 & $65,7(29,2)$ & $73,2(18,6)$ & 0,553 \\
\hline FAS & $19,9(10,9)$ & $23,7(9,8)$ & $0,001 * * *$ & $29,1(15,5)$ & $32,1(12,8)$ & 0,290 \\
\hline Animais & $12,0(5,0)$ & $14,1(4,1)$ & $0,045 * * *$ & $16,5(4,9)$ & $18,2(6,9)$ & 0,131 \\
\hline \multicolumn{7}{|l|}{ Torre de Hanoi 3} \\
\hline Tempo (segundos) & $50,3(42,8)$ & $19,7(10,4)$ & 0,004 & $19,4(12,5)$ & $14,9(4,3)$ & 0,259 \\
\hline Movimento & $14,1(7,6)$ & $10,5(3,2)$ & 0,037 & $8,2(1,6)$ & $9,2(2,2)$ & 0,187 \\
\hline Erros & $2,5(3,1)$ & $0,5(1,2)$ & $0,006 * *$ & $1,0(1,4)$ & $0,3(0,5)$ & $0,111 * *$ \\
\hline \multicolumn{7}{|l|}{ Torre de Hanoi 4} \\
\hline Tempo (segundos) & $86,8(34,3)$ & $56,0(23,6)$ & 0,002 & $47,1(15,2)$ & $43,1(17,0)$ & 0,424 \\
\hline Movimento & $29,3(8,7)$ & $26,8(6,0)$ & 0,321 & $21,0(5,7)$ & $23,6(5,0)$ & 0,205 \\
\hline Erros & $6,2(6,3)$ & $3,6(9,0)$ & $0,021 * *$ & $2,2(2,5)$ & $0,9(1,7)$ & $0,101 * *$ \\
\hline \multicolumn{7}{|l|}{ WCST } \\
\hline Categorias Completas & $2,3(1,5)$ & $2,7(1,7)$ & 0,248 & $3,4(1,1)$ & $3,5(1,5)$ & 0,726 \\
\hline Acertos & $39,4(11,2)$ & $44,4(10,9)$ & 0,119 & $47,5(8,4)$ & $51,1(6,6)$ & 0,090 \\
\hline Erros & $24,5(11,2)$ & $19,5(10,7)$ & $0,116^{* *}$ & $16,4(8,5)$ & $12,6(6,5)$ & $0,084 * *$ \\
\hline Erros Perseverativos & $10,7(6,8)$ & $8,3(4,5)$ & 0,222 & $7,6(3,8)$ & $4,2(1,7)$ & $0,016^{* * *}$ \\
\hline Perdas & $0,6(0,7)$ & $0,7(1,0)$ & 0,717 & $0,3(0,5)$ & $1,6(2,3)$ & 0,103 \\
\hline Outros & $4,7(6,7)$ & $3,4(5,2)$ & $0,706 * *$ & $1,8(3,3)$ & $1,7(3,2)$ & $0,498 * *$ \\
\hline Rey (cópia) & $31,6(5,0)$ & $33,1(4,4)$ & $0,095 * *$ & $33,0(4,5)$ & $34,9(1,7)$ & $0,099 * *$ \\
\hline
\end{tabular}


c) Tratamento Medicamentoso

Na comparação dos sujeitos do grupo com transtorno de ansiedade na infância e na adolescência que vieram a ser tratados com clomipramina nos momentos, antes e depois do tratamento medicamentoso (CLO 1 X CLO 2), foram observadas diferenças estatisticamente significativas nos testes: Torre de Hanoi com 4 peças em relação ao tempo $(p=0,006)$ e em relação ao número de erros $(p=0,042)$ (tabela 11).

Já na comparação dos sujeitos do grupo com transtorno de ansiedade na infância e na adolescência com fluoxetina nos momentos, antes e depois do uso da medicação (FLX 1 X FLX 2) foram observadas diferenças estatisticamente significativas nos testes: $M F F T-20$ em relação ao índice de ineficiência $(\mathrm{p}=0,011)$; Fluência verbal para animais $(p=0,045)$; Torre de Hanoi com 4 peças em relação ao tempo $(p=0,004)$ (tabela 11).

Salienta-se que, apesar do resultado do teste $F A S$, na comparação do grupo FLX 1 e FLX 2 ter sido estatisticamente significativo $(p=0,025)$, esse resultado não deve ser considerado devido à análise de covariância $(\mathrm{p}=0,045)$ (tabela 2$)$. 
Tabela 11 - Comparação das crianças e adolescentes dos grupos CLO1 e CLO 2 e dos grupos FLX 1 e FLX 2, nos testes de atenção e funções executivas - IPQ HC FMUSP - 2008 a 2011

\begin{tabular}{|c|c|c|c|c|c|c|}
\hline Testes & $\begin{array}{c}\text { CLO1 (n=5) } \\
\text { m (dp) }\end{array}$ & $\begin{array}{c}\text { CLO2 }(n=5) \\
\text { m (dp) }\end{array}$ & Valor p* & $\begin{array}{c}\text { FLX1 (n=5) } \\
\text { m (dp) }\end{array}$ & $\begin{array}{c}\text { FLX2 }(n=5) \\
\text { m (dp) }\end{array}$ & Valor p* \\
\hline \multicolumn{7}{|l|}{ Trail Making Test A } \\
\hline Tempo (segundos) & $85,2(44,0)$ & $60,6(44,6)$ & 0,189 & $45,4(11,4)$ & $43,4(17,4)$ & 0,811 \\
\hline Erros & $0,4(0,5)$ & $0,6(0,9)$ & $0,564 * *$ & $0,0(0,0)$ & $0,6(0,9)$ & $0,180 * *$ \\
\hline \multicolumn{7}{|l|}{ Trail Making Test B } \\
\hline Tempo (segundos) & $172,0(55,5)$ & $133,6(68,3)$ & 0,363 & $117,6(57,7)$ & $114,6(54,8)$ & 0,824 \\
\hline Erros & $0,8(0,8)$ & $0,4(0,5)$ & $0,414 * *$ & $0,5(0,5)$ & $0,2(0,4)$ & $0,564 * *$ \\
\hline \multicolumn{7}{|l|}{ Stroop 1} \\
\hline Tempo (segundos) & $19,7(5,0)$ & $22,0(5,0)$ & 0,255 & $21,6(6,4)$ & $18,2(5,1)$ & 0,077 \\
\hline Erros & $0,0(0,0)$ & $0,0(0,0)$ & $1,000 * *$ & $0,0(0,0)$ & $0,0(0,0)$ & $1,000 * *$ \\
\hline \multicolumn{7}{|l|}{ Stroop 2} \\
\hline Tempo (segundos) & $27,5(6,8)$ & $27,5(5,9)$ & 1,000 & $28,2(11,9)$ & $23,6(10,2)$ & 0,105 \\
\hline Erros & $0,2(0,5)$ & $0,0(0,0)$ & $0,317 * *$ & $0,2(0,4)$ & $0,0(0,0)$ & $0,317 * *$ \\
\hline \multicolumn{7}{|l|}{ Stroop 3} \\
\hline Tempo (segundos) & $45,0(8,7)$ & $39,0(7,8)$ & 0,225 & $40,6(23,0)$ & $31,2(10,3)$ & 0,210 \\
\hline Erros & $1,2(1,9)$ & $0,2(0,5)$ & $0,317 * *$ & $1,2(2,7)$ & $0,2(0,4)$ & $0,655 * *$ \\
\hline \multicolumn{7}{|l|}{ MFFT-20 } \\
\hline Tempo (segundos) & $306,6(138,6)$ & $277,2(93,4)$ & 0,243 & $421,2(153,0)$ & $300,2(132,4)$ & 0,229 \\
\hline Acertos & $5,8(1,6)$ & $9,6(4,1)$ & 0,102 & $12,4(4,0)$ & $11,2(2,7)$ & 0,178 \\
\hline Erros & $32,2(5,8)$ & $23,6(15,2)$ & 0,274 & $15,6(11,7)$ & $16,0(8,4)$ & 0,888 \\
\hline Impulsividade & $60(26,8)$ & $68,0(34,8)$ & 0,676 & $40,0(35,3)$ & $62,5(3,5)$ & 0,563 \\
\hline Ineficiência & $70,5(46,1)$ & $72,0(33,5)$ & 0,958 & $89,5(13,4)$ & $60,0(14,1)$ & 0,011 \\
\hline FAS & $13,0(7,6)$ & $18,2(11,3)$ & 0,071 & $21,2(6,5)$ & $24,8(6,9)$ & $0,025 * * *$ \\
\hline Animais & $10,0(6,4)$ & $11,8(4,1)$ & 0,605 & $12,2(4,1)$ & $15,0(2,5)$ & $0,045^{* * *}$ \\
\hline \multicolumn{7}{|l|}{ Torre de Hanoi 3} \\
\hline Tempo (segundos) & $79,8(67,4)$ & $20,3(8,3)$ & 0,094 & $39,1(18,1)$ & $21,5(7,7)$ & 0,077 \\
\hline Movimento & $20,0(11,6)$ & $10,6(2,8)$ & 0,078 & $12,4(4,0)$ & $11,3(3,3)$ & 0,623 \\
\hline Erros & $3,2(3,6)$ & $0,4(0,5)$ & $0,144 * *$ & $3,4(4,1)$ & $0,4(0,5)$ & $0,109 * *$ \\
\hline \multicolumn{7}{|l|}{ Torre de Hanoi 4} \\
\hline Tempo (segundos) & $97,0(25,5)$ & $54,3(14,6)$ & 0,006 & $75,2(13,2)$ & $53,0(8,1)$ & 0,004 \\
\hline Movimento & $37,0(12,3)$ & $25,1(5,4)$ & 0,082 & $25,4(4,1)$ & $25,8(1,9)$ & 0,835 \\
\hline Erros & $6,8(5,8)$ & $1,8(1,8)$ & $0,042 * *$ & $7,2(4,1)$ & $2(2,3)$ & $0,068 * *$ \\
\hline \multicolumn{7}{|l|}{ WCST } \\
\hline Categorias Completas & $1,2(1,3)$ & $1,4(1,5)$ & 0,847 & $2,8(1,1)$ & $3,4(1,5)$ & 0,426 \\
\hline Acertos & $33,2(13,6)$ & $33,6(10,7)$ & 0,966 & $39,4(9,7)$ & $49,8(7,3)$ & 0,125 \\
\hline Erros & $30,8(13,6)$ & $30,2(10,3)$ & $0,893 * *$ & $24,6(9,6)$ & $14,2(7,2)$ & $0,080 * *$ \\
\hline Erros Perseverativos & $14,2(8,0)$ & $12,4(5,9)$ & 0,755 & $12,6(8,3)$ & $6,8(2,5)$ & 0,227 \\
\hline Perdas & $0,8(0,8)$ & $0,4(0,5)$ & 0,374 & $0,4(0,5)$ & $1,2(1,6)$ & 0,405 \\
\hline Outros & $7,4(10,3)$ & $6,4(8,0)$ & 1,000 & $3,8(4,2)$ & $1,2(1,8)$ & $0,066 * *$ \\
\hline Rey (Cópia) & $30,6(5,2)$ & $33,6(2,6)$ & $0,176 * *$ & $32,0(4,0)$ & $33,6(2,6)$ & $0,414 * *$ \\
\hline
\end{tabular}


d) Placebo

Na comparação dos sujeitos do grupo com transtorno de ansiedade na infância e na adolescência que vieram a ser tratados com placebo nos momentos, antes e depois do tratamento medicamentoso (PLC 1 X PLC 2), foram observadas diferenças estatisticamente significativas no item: Trail Making Test na parte B em relação ao tempo $(\mathrm{p}=0,009)$ (tabela 12).

Importante ressaltar que, apesar do resultado do item Trail Making Test A em relação ao tempo ter sido estatisticamente significativo, na comparação do grupo PLC 1 e PLC 2 ( $\mathrm{p}=0,012)$, esse resultado não deve ser considerado devido à comparação do grupo $\mathrm{CN} 1$ e $\mathrm{CN} 2$ ter sido também estatisticamente significativa $(\mathrm{p}=0,040)($ tabela 10). 
Tabela 12 - Comparação das crianças e adolescentes dos grupos PLC 1 e PLC 2, nos testes de atenção e funções executivas - IPQ HC FMUSP - 2008 a 2011

\begin{tabular}{|c|c|c|c|}
\hline Testes & $\begin{array}{c}\operatorname{PLC} 1(\mathrm{n}=8) \\
\mathrm{m}(\mathrm{dp})\end{array}$ & $\begin{array}{c}\text { PLC 2(n=8) } \\
\text { m (dp) }\end{array}$ & Valor $\mathbf{p}^{*}$ \\
\hline \multicolumn{4}{|l|}{ Trail Making Test A } \\
\hline Tempo (segundos) & $57,5(22,8)$ & $41,9(16,4)$ & $0,012 * * *$ \\
\hline Erros & $0,1(0,3)$ & $0,0(0,0)$ & $0,317 * *$ \\
\hline \multicolumn{4}{|l|}{ Trail Making Test B } \\
\hline Tempo (segundos) & $154,9(122,8)$ & $123,2(95,2)$ & 0,009 \\
\hline Erros & $0,5(0,9)$ & $0,8(1,1)$ & $0,083 * *$ \\
\hline \multicolumn{4}{|l|}{ Stroop 1} \\
\hline Tempo (segundos) & $20,1(9,1)$ & $15,9(5,4)$ & 0,056 \\
\hline Erros & $0,5(1,4)$ & $0,0(0,0)$ & $0,317 * *$ \\
\hline \multicolumn{4}{|l|}{ Stroop 2} \\
\hline Tempo (segundos) & $25,1(15,9)$ & $22,2(10,7)$ & 0,429 \\
\hline Erros & $0,4(1,1)$ & $0,0(0,0)$ & $0,317 * *$ \\
\hline \multicolumn{4}{|l|}{ Stroop 3} \\
\hline Tempo (segundos) & $33,2(14,4)$ & $30,6(12,5)$ & 0,509 \\
\hline Erros & $0,7(1,0)$ & $0,7(1,9)$ & $1,000 * *$ \\
\hline \multicolumn{4}{|l|}{ MFFT-20 } \\
\hline Tempo (segundos) & $425,4(265,0)$ & $456,7(239,3)$ & 0,515 \\
\hline Acertos & $11,4(4,5)$ & $12,1(5,9)$ & 0,605 \\
\hline Erros & $17,3(12,4)$ & $14,6(11,9)$ & $0,384 * *$ \\
\hline Impulsividade & $57,5(10,6)$ & $55,0(14,1)$ & 0,910 \\
\hline Ineficiência & $78,5(2,1)$ & $84,5(20,5)$ & 0,772 \\
\hline FAS & $23,5(13,5)$ & $26,5(10,1)$ & 0,119 \\
\hline Animais & $13,1(4,9)$ & $14,9(4,6)$ & 0,099 \\
\hline \multicolumn{4}{|l|}{ Torre de Hanoi 3} \\
\hline Tempo (segundos) & $38,9(28,3)$ & $18,2(13,6)$ & 0,367 \\
\hline Movimento & $11,5(4,3)$ & $9,9(3,7)$ & 0,063 \\
\hline Erros & $1,5(2,1)$ & $0,6(1,9)$ & $0,066^{* *}$ \\
\hline \multicolumn{4}{|l|}{ Torre de Hanoi 4} \\
\hline Tempo (segundos) & $87,6(47,0)$ & $58,8(34,3)$ & 0,167 \\
\hline Movimento & $26,8(5,1)$ & $28,5(8,0)$ & 0,637 \\
\hline Erros & $5,2(8,1)$ & $5,7(14,3)$ & $0,931 * *$ \\
\hline \multicolumn{4}{|l|}{ WCST } \\
\hline Categorias Completas & $2,6(1,6)$ & $3,0(1,8)$ & 0,197 \\
\hline Acertos & $43,4(10,0)$ & $47,7(8,6)$ & 0,146 \\
\hline Erros & $20,6(10,1)$ & $16,2(8,6)$ & $0,160 * *$ \\
\hline Erros Perseverativos & $7,4(3,4)$ & $6,7(3,0)$ & 0,637 \\
\hline Perdas & $0,6(0,7)$ & $0,6(0,7)$ & 1,000 \\
\hline Outros & $3,6(5,5)$ & $3,0(4,3)$ & $0,752 * *$ \\
\hline Rey (cópia) & $32,0(6,0)$ & $32,5(6,1)$ & $0,577 * *$ \\
\hline
\end{tabular}




\subsubsection{Processos de memória e aprendizagem}

a) TAIA

Na comparação dos sujeitos do grupo com transtorno de ansiedade na infância e na adolescência que foram avaliados, antes e depois do tratamento medicamentoso (TAIA 1 X TAIA 2 ), pode-se observar que o grupo melhorou seu desempenho na segunda avaliação em alguns testes. Observou-se diferença estatisticamente significativa no item: memória para história $2(\mathrm{p}=0,009)$ (tabela 13).

\section{b) Controle}

$\mathrm{Na}$ comparação dos sujeitos do grupo controle que foram avaliados, antes e depois de seis meses (CN 1 X CN 2 ), pode-se observar diferenças estatisticamente significativas, demonstrando que o grupo apresentou pior desempenho no teste memória para história $1(\mathrm{p}=0,027)$ e melhor desempenho no teste aprendizagem verbal $(p=0,025)$ (tabela 13$)$.

Importante ressaltar que, apesar do resultado dos itens: RCFT na memória $(p=0,001)$ e na evocação da aprendizagem verbal $(p=0,003)$ ter sido estatisticamente significativo, na comparação do grupo TAIA 1 e TAIA 2, esse resultado não deve ser considerado devido à análise de covariância ( $\mathrm{p}=0,044 \mathrm{e} \mathrm{p}=0,006$, respectivamente) (tabela 2). Assim como, não deve ser considerado o item na aprendizagem verbal $(p=0,002)$ devido à diferença estatisticamente significativa encontrada na comparação dos grupos controle (CN 1 e CN 2) (tabela 13). 
Tabela 13 - Comparação do desempenho das crianças e adolescentes dos grupos TAIA 1 e TAIA 2 e dos grupos CN1 e CN2, nos testes de memória e aprendizagem IPQ HC FMUSP - 2008 a 2011

\begin{tabular}{|c|c|c|c|c|c|c|}
\hline Testes & $\begin{array}{c}\text { TAIA } 1(n=18) \\
\text { m (dp) }\end{array}$ & $\begin{array}{c}\text { TAIA } 2(n=18) \\
\text { m (dp) }\end{array}$ & Valor P* & $\begin{array}{c}\text { CN1 (n=10) } \\
\text { m (dp) }\end{array}$ & $\begin{array}{c}\text { CN2 (n=10) } \\
\text { m (dp) }\end{array}$ & Valor p* \\
\hline \multicolumn{7}{|l|}{ Memória Visual } \\
\hline Rey (memória) & $14,8(6,2)$ & $19,8(7,1)$ & $0,001 * * *$ & $19,8(10,1)$ & $23,3(8,0)$ & 0,548 \\
\hline Memória cenas & $8,7(2,1)$ & $9,3(2,4)$ & 0,327 & $10,6(1,6)$ & $10,9(2,0)$ & 0,468 \\
\hline Reconhecimento & $8,3(2,1)$ & $9,4(3,0)$ & 0,149 & $10,2(2,5)$ & $10,9(3,0)$ & 0,460 \\
\hline Memória desenho & $9,4(2,7)$ & $10,8(3,0)$ & 0,015 & $11,5(3,0)$ & $11,0(3,5)$ & 0,591 \\
\hline Reconhecimento & $9,2(3,2)$ & $9,6(3,0)$ & 0,675 & $9,8(3,4)$ & $10,7(4,0)$ & 0,442 \\
\hline \multicolumn{7}{|l|}{ Memória Verbal } \\
\hline Memória História 1 & $9,9(2,5)$ & $11,0(3,0)$ & 0,130 & $14,0(1,9)$ & $12,0(1,7)$ & 0,027 \\
\hline Memória História 2 & $9,7(2,5)$ & $11,3(3,0)$ & 0,009 & $12,6(1,1)$ & $12,0(1,9)$ & 0,343 \\
\hline Reconhecimento & $11,4(2,7)$ & $11,7(2,2)$ & 0,622 & $13,6(1,8)$ & $12,6(2,2)$ & 0,096 \\
\hline \multicolumn{7}{|l|}{ Aprendizagem Verbal } \\
\hline Aprendizagem & $8,4(2,0)$ & $10,4(2,7)$ & $0,002 * * *$ & $9,3(2,3)$ & $11,0(2,3)$ & 0,025 \\
\hline Evocação & $8,4(2,1)$ & $10,2(2,3)$ & $0,003 * * *$ & $9,9(2,5)$ & $10,5(2,7)$ & 0,260 \\
\hline Reconhecimento & $10,0(2,6)$ & $10,5(2,4)$ & 0,429 & $10,8(2,4)$ & $11,1(2,2)$ & 0,824 \\
\hline \multicolumn{7}{|l|}{ Memória de Trabalho } \\
\hline Visual & $9,4(3,4)$ & $10,0(2,5)$ & 0,405 & $11,0(3,9)$ & $12,7(2,7)$ & 0,122 \\
\hline Verbal & $9,0(3,1)$ & $9,6(2,1)$ & 0,513 & $10,6(2,7)$ & $11,9(3,1)$ & 0,118 \\
\hline
\end{tabular}

FONTE: Rodrigues, São Paulo, 2011

Teste $\mathrm{t} / * *$ Teste Wilcoxon Sinalizado/*** não conseiderar devido a análise de covariância ou na comparação do $\mathrm{CN}$ 1 e $\mathrm{CN} 2$

Legenda: $\mathrm{m}=$ média e $\mathrm{dp}=$ desvio padrão

c) Tratamento Medicamentoso

Na comparação dos sujeitos do grupo com transtorno de ansiedade na infância e na adolescência que vieram a ser tratados com clomipramina nos momentos, antes e depois do uso da medicação (CLO 1 X CLO 2), foi observada diferença estatisticamente significativa no item: memória para cenas $(\mathrm{p}=0,025)$ (tabela 13)

Já na comparação dos sujeitos do grupo com transtorno de ansiedade na infância e na adolescência que vieram a ser tratados com fluoxetina nos momentos, antes e depois do uso da medicação (FLX 1 X FLX 2), foram observadas diferenças estatisticamente significativas no teste: memória para história $2(\mathrm{p}=0,033)$. (tabela 14) 
Salienta-se que, apesar do resultado do item: $R C F T$ na memória $(\mathrm{p}=0,033)$ ter sido estatisticamente significativo, na comparação do grupo CLO 1 e CLO 2, esse resultado não deve ser considerado devido à análise de covariância $(\mathrm{p}=0,044)$ (tabela 2).

Tabela 14 - Comparação das crianças e adolescentes dos grupos CLO1 e CLO 2 e dos grupos FLX 1 E FLX 2, nos testes de memória e aprendizagem - IPQ HC FMUSP - 2008 a 2011

\begin{tabular}{|c|c|c|c|c|c|c|}
\hline Testes & $\begin{array}{c}\text { CLO1 (n=5) } \\
\text { m (dp) }\end{array}$ & $\begin{array}{c}\text { CLO2 (n=5) } \\
\text { m (dp) }\end{array}$ & Valor p* & $\begin{array}{c}\text { FLX1 }(n=5) \\
\text { m (dp) }\end{array}$ & $\begin{array}{c}\text { FLX2 }(n=5) \\
\text { m (dp) }\end{array}$ & Valor p* \\
\hline \multicolumn{7}{|l|}{ Memória Visual } \\
\hline Rey (memória) & $12,4(6,3)$ & $20,4(4,8)$ & $0,033 * * *$ & $16,0(4,2)$ & $19,0(2,9)$ & 0,284 \\
\hline Memória cenas & $7,0(2,7)$ & $9,8(2,3)$ & 0,025 & $9,492,2)$ & $9,0(3,1)$ & 0,688 \\
\hline Reconhecimento & $7,2(2,3)$ & $7,0(2,2)$ & 0,838 & $8,0(1,0)$ & $9,6(3,6)$ & 0,347 \\
\hline Memória desenho & $7,6(1,5)$ & $8,2(1,5)$ & 0,374 & $11,0(2,2)$ & $12,2(3,1)$ & 0,145 \\
\hline Reconhecimento & $8,4(4,7)$ & $9,4(2,7)$ & 0,692 & $9,0(0,7)$ & $9,2(4,0)$ & 0,911 \\
\hline \multicolumn{7}{|l|}{ Memória Verbal } \\
\hline Memória História 1 & $10,6(3,6)$ & $10,8(2,4)$ & 0,847 & $9,6(1,5)$ & $12,0(2,5)$ & 0,109 \\
\hline Memória História 2 & $9,6(3,0)$ & $11,4(2,4)$ & 0,088 & $9,4(2,8)$ & $12,0(2,2)$ & 0,033 \\
\hline Reconhecimento & $11,2(4,6)$ & $12,0(1,9)$ & 0,614 & $10,8(0,8)$ & $11,8(2,6)$ & 0,326 \\
\hline \multicolumn{7}{|l|}{ Aprendizagem Verbal } \\
\hline Aprendizagem & $7,4(2,8)$ & $9,6(2,9)$ & 0,171 & $8,4(0,9)$ & $10,2(2,2)$ & 0,221 \\
\hline Evocação & $7,2(1,3)$ & $8,8(1,5)$ & 0,140 & $8,2(2,7)$ & $10,0(2,6)$ & 0,195 \\
\hline Reconhecimento & $11,2(3,4)$ & $10,4(0,5)$ & 0,636 & $8,2(2,2)$ & $9,2(3,4)$ & 0,413 \\
\hline \multicolumn{7}{|l|}{ Memória de Trabalho } \\
\hline Visual & $8,6(3,7)$ & $9,8(1,9)$ & 0,516 & $9,6(2,3)$ & $9,0(2,0)$ & 0,208 \\
\hline Verbal & $8,4(2,1)$ & $9,2(1,5)$ & 0,495 & $9,0(3,4)$ & $10,6(2,5)$ & 0,472 \\
\hline
\end{tabular}

FONTE: Rodrigues, São Paulo, 2011

*Teste $\mathrm{t} / * *$ Teste Wilcoxon Sinalizado/ *** não conseiderar devido à análise de covariância Legenda: $\mathrm{m}=$ média $\mathrm{e} \mathrm{dp}=$ desvio padrão

d) Placebo

Na comparação dos sujeitos do grupo com transtorno de ansiedade na infância e na adolescência que foram tratados com placebo nos momentos, antes e depois do uso da medicação (PLC 1 X PLC 2), não foi observada diferença estatisticamente significativa (tabela 15). 
Ressalta-se que, apesar do resultado dos testes: no teste: RCFT na memória $(p=0,033)$ e a aprendizagem verbal $(p=0,021)$ terem sido estatisticamente significativos na comparação do grupo PLC 1 e PLC 2, esse resultado não deve ser considerado devido à análise de covariância $(\mathrm{p}=0,044)$ (tabela 2) e a diferença significativa entre o grupo controle $(\mathrm{CN} 1$ e $\mathrm{CN} 2)(\mathrm{p}=0,025)$ respectivamente (tabela $13)$.

Tabela 15 - Comparação das crianças e adolescentes dos grupos PLC 1 e PLC 2, nos testes de memória e aprendizagem - IPQ HC FMUSP - 2008 a 2011

\begin{tabular}{llll}
\hline Testes & $\begin{array}{c}\text { PLC 1 (n=8) } \\
\mathbf{m}(\mathbf{d p})\end{array}$ & $\begin{array}{c}\text { PLC (n=8) } \\
\mathbf{m}(\mathbf{d p})\end{array}$ & Valor p* \\
\hline Memória Visual & & & \\
Rey (memória) & $15,5(7,5)$ & $19,9(10,3)$ & $0,033^{* * *}$ \\
Memória cenas & $9,4(0,7)$ & $9,2(2,4)$ & 0,897 \\
Reconhecimento & $9,2(2,4)$ & $10,7(2,2)$ & 0,239 \\
Memória desenho & $9,6(3,0)$ & $11,5(3,0)$ & 0,095 \\
Reconhecimento & $9,9(3,3)$ & $10,0(2,3)$ & 0,922 \\
Memória Verbal & & & \\
Memória História 1 & $9,7(2,4)$ & $10,5(3,8)$ & 0,539 \\
Memória História 2 & $9,9(2,5)$ & $10,7(3,9)$ & 0,406 \\
Reconhecimento & $11,9(2,2)$ & $11,4(2,4)$ & 0,487 \\
Aprendizagem Verbal & & & \\
Aprendizagem & $9,0(1,8)$ & $11,1(2,9)$ & $0,021 * * *$ \\
Evocação & $9,4(2,0)$ & $11,2(2,3)$ & 0,059 \\
Reconhecimento & $10,5(1,9)$ & $11,5(2,1)$ & 0,227 \\
Memória de Trabalho & & & \\
Visual & $9,8(4,2)$ & $11,0(3,0)$ & 0,452 \\
Verbal & $9,6(3,9)$ & $9,1(2,3)$ & 0,718 \\
\hline
\end{tabular}

FONTE: Rodrigues, São Paulo, 2011

*Teste $\mathrm{t} /$ ** não considerar devido a comparação do $\mathrm{CN} 1$ e CN 2 e à análise de covariância Legenda: $\mathrm{m}=$ média e $\mathrm{dp}=$ desvio padrão

5.3.3.4. Escala de ansiedade

a) TAIA

Na comparação dos sujeitos do grupo com transtorno de ansiedade na infância e na adolescência que foram avaliados, antes e depois do tratamento medicamentoso 
(TAIA 1 X TAIA 2 ), pode-se observar que o grupo apresentou diminuição nos escores da manifestação da ansiedade na segunda avaliação em alguns itens. Observou-se diferença estatisticamente significativa nos itens: "MASC total" ( $p=0,004)$, “inconsistência" $(p=0,001)$, “tenso e inquieto" $(p=0,004)$, “sintomas físicos" ( $p=0,003)$, “desempenho público" $(p=0,001)$, “ansiedade social” $(p=0,019)$ e “índice de ansiedade" ( $p=0,013)$. (tabela 16)

\section{b) Controle}

Na comparação dos sujeitos do grupo controle que foram avaliados, antes e depois de seis meses (CN 1 X CN 2 ), pode-se observar diferença estatisticamente significativa nos itens: "somático" $(p=0,046)$ e "pânico e separação" $(p=0,045)$. Demonstrando que após a segunda avaliação o grupo apresentou diminuição nos escores de manifestação de ansiedade (tabela 16).

Salienta-se, que apesar do resultado do item: "somático" $(p=0,013)$, ter sido estatisticamente significativo na comparação do grupo TAIA 1 e TAIA 2, esse resultado não deve ser considerado devido à diferença significativa entre o grupo controle (CN 1 e CN 2) $(\mathrm{p}=0,046)$ (tabela 16). 
Tabela 16 - Comparação do desempenho das crianças e adolescentes dos grupos TAIA 1 e TAIA 2 e dos grupos CN1 e CN2, na escala de ansiedade - IPQ HC FMUSP - 2008 a 2011

\begin{tabular}{|c|c|c|c|c|c|c|}
\hline Itens da escala & $\begin{array}{c}\text { TAIA } 1(n=18) \\
\text { m (dp) }\end{array}$ & $\begin{array}{c}\text { TAIA } 2(n=18) \\
\text { m (dp) }\end{array}$ & Valor P* & $\begin{array}{c}\text { CN1 (n=10) } \\
\text { m (dp) }\end{array}$ & $\begin{array}{c}\text { CN2 (n=10) } \\
\text { m (dp) }\end{array}$ & Valor p* \\
\hline MASC Total & $49,9(11,0)$ & $39,4(12,4)$ & 0,004 & $39,4(8,8)$ & $36,7(8,1)$ & 0,513 \\
\hline Inconsistência & $5,8(2,8)$ & $3,0(1,5)$ & 0,001 & $6,9(4,4)$ & $6,8(2,8)$ & 0,811 \\
\hline Tenso e Inquieto & $50,4(12,7)$ & $41,3(8,9)$ & 0,004 & $41,1(8,3)$ & $38,9(5,0)$ & 0,588 \\
\hline Somático & $48,6(8,6)$ & $42,0(4,7)$ & $0,013 * * *$ & $40,4(2,1)$ & $44,5(3,9)$ & 0,046 \\
\hline Sintomas físicos & $49,5(11,0)$ & $40,5(6,8)$ & 0,003 & $39,7(4,8)$ & $41,2(3,9)$ & 0,217 \\
\hline Perfeccionismo & $40,8(9,8)$ & $37,2(11,6)$ & 0,150 & $39,6(8,4)$ & $35,5(8,5)$ & 0,411 \\
\hline Superar ans & $37,8(6,4)$ & $35,6(9,6)$ & 0,296 & $39,4(9,5)$ & $37,1(9,0)$ & 0,805 \\
\hline Evitar danos & $37,2(7,7)$ & $34,9(10,9)$ & 0,321 & $36,6(9,4)$ & $34,8(8,5)$ & 0,826 \\
\hline Humilhação e rej & $51,8(14,8)$ & $43,8(11,8)$ & 0,051 & $45,5(9,9)$ & $42,1(6,1)$ & 0,543 \\
\hline Desempenho pub & $56,4(11,9)$ & $45,0(13,0)$ & 0,001 & $45,5(9,8)$ & $42,2(10,4)$ & 0,528 \\
\hline Ansiedade social & $54,3(13,6)$ & $45,3(12,2)$ & 0,019 & $45,2(9,9)$ & $41,2(8,2)$ & 0,427 \\
\hline Pânico e separação & $55,0(12,0)$ & $49,1(12,7)$ & 0,107 & $52,6(10,6)$ & $45,7(6,4)$ & 0,045 \\
\hline Índice de ansiedade & $44,0(12,0)$ & $35,5(11,3)$ & 0,013 & $41(10,5)$ & $34,9(10,0)$ & 0,752 \\
\hline \multicolumn{7}{|c|}{ FONTE: Rodrigues, São Paulo, 2011} \\
\hline \multicolumn{7}{|c|}{ *Teste $\mathrm{t}$ / ** não considerar devido a comparação do CN 1 e CN 2} \\
\hline \multicolumn{7}{|c|}{ Legenda: $\mathrm{m}=$ média/ $\mathrm{dp}=$ desvio padrão } \\
\hline
\end{tabular}

Na comparação dos sujeitos do grupo com transtorno de ansiedade na infância e na adolescência que vieram a ser tratados com clomipramina nos momentos, antes e depois do tratamento medicamentoso (CLO 1 X CLO 2), foi observada diferença estatisticamente significativas no item: "desempenho em público" $(\mathrm{p}=0,044)$ (tabela 17). O mesmo foi observado na comparação dos sujeitos do grupo com transtorno de ansiedade na infância e na adolescência com fluoxetina nos momentos, antes e depois do uso da medicação (FLX 1 X FLX 2) $(p=0,043)$ (tabela 17). 
Tabela 17 - Comparação das crianças e adolescentes dos grupos CLO1 e CLO 2 e dos grupos FLX 1 e FLX 2, na escala de ansiedade - IPQ HC FMUSP - 2008 a 2011

\begin{tabular}{cllllll}
\hline Itens da escala & $\begin{array}{c}\text { CLO1 (n=5) } \\
\mathbf{m}(\mathbf{d p})\end{array}$ & $\begin{array}{c}\text { CLO2 (n=5) } \\
\mathbf{m}(\mathbf{d p})\end{array}$ & $\begin{array}{c}\text { Valor } \\
\mathbf{p}^{*}\end{array}$ & $\begin{array}{c}\text { FLX1 (n=5) } \\
\mathbf{m}(\mathbf{d p})\end{array}$ & $\begin{array}{c}\text { FLX2 (n=5) } \\
\mathbf{m}(\mathbf{d p})\end{array}$ & $\begin{array}{c}\text { Valor p* } \\
\end{array}$ \\
\hline MASC Total & $42,8(6,9)$ & $39,6(12,2)$ & 0,554 & $49,6(8,3)$ & $35,6(8)$, & 0,124 \\
Inconsistência & $6,6(2,5)$ & $4,0(1,9)$ & 0,073 & $6,6(3,4)$ & $2,6(1,9)$ & 0,065 \\
Tenso e Inquieto & $46,6(6,8)$ & $42,6(10,3)$ & 0,341 & $50,6(17,6)$ & $36,6(2,3)$ & 0,167 \\
$\quad$ Somático & $43,0(5,6)$ & $40,6(6,5)$ & 0,622 & $49,2(9,4)$ & $42,4(3,8)$ & 0,303 \\
Sintomas físicos & $44,4(5,0)$ & $40,8(8,3)$ & 0,371 & $50,2(14,7)$ & $38,4(2,2)$ & 0,191 \\
Perfeccionismo & $34,6(8,1)$ & $37,4(12,5)$ & 0,480 & $41,0(9,5)$ & $38,2(14,3)$ & 0,581 \\
Superar ans & $33,8(7,5)$ & $37,4(13,8)$ & 0,449 & $40,4(4,0)$ & $33,8(10,9)$ & 0,171 \\
Evitar danos & $32,0(7,7)$ & $36,0(13,9)$ & 0,423 & $33,8(10,9)$ & $39,0(7,5)$ & 0,561 \\
Humilhação e rej & $41,8(5,9)$ & $42,8(11,1)$ & 0,841 & $36,0(12,4)$ & $50,4(14,7)$ & 0,278 \\
Desempenho pub & $55,0(8,6)$ & $46,8(11,1)$ & 0,044 & $40,2(5,0)$ & $50,2(8,9)$ & 0,043 \\
Ansiedade social & $47,0(6,2)$ & $44,2(5,9)$ & 0,454 & $37,4(3,4)$ & $50,4(10,5)$ & 0,121 \\
Pânico e separação & $54,2(6,6)$ & $48,6(9,3)$ & 0,155 & $60,4(14,3)$ & $46,8(11,0)$ & 0,195 \\
Índice de ansiedade & $38,4(9,3)$ & $37,2(8,1)$ & 0,595 & $45,0(9,5)$ & $34,0(9,3)$ & 0,208 \\
\hline
\end{tabular}

FONTE: Rodrigues, São Paulo, 2011

*Teste $\mathrm{t} /$ Legenda: $\mathrm{m}=$ média/ $\mathrm{dp}=$ desvio padrão

d) Placebo

Na comparação dos sujeitos do grupo com transtorno de ansiedade na infância e na adolescência que vieram a ser tratados com placebo nos momentos, antes e depois do tratamento medicamentoso (PLC 1 X PLC 2) foram observadas diferenças estatisticamente significativas nos itens: "MASC Total" $(\mathrm{p}=0,023)$, "tenso e inquieto" ( $p=0,001)$, "sintomas físicos" ( $p=0,004)$, "perfeccionista" $(p=0,033)$, "evitar danos" $(\mathrm{p}=0,029)$ e "índice de ansiedade" $(\mathrm{p}=0,045)$. (tabela 18)

Salienta-se, que apesar do resultado do item: "somático" $(\mathrm{p}=0,013)$, ter sido estatisticamente significativo na comparação do grupo PLC 1 e PLC 2, esse resultado não deve ser considerado devido à diferença significativa entre o grupo controle (CN 1 e CN 2) $(\mathrm{p}=0,046)$ (tabela 16). 
Tabela 18 - Comparação das crianças e adolescentes dos grupos PLC 1 e PLC 2, na escala de ansiedade - IPQ HC FMUSP - 2008 a 2011

\begin{tabular}{clll}
\hline Itens da escala & $\begin{array}{c}\text { PLC 1 (n=8) } \\
\text { m (dp) }\end{array}$ & $\begin{array}{c}\text { PLC (n=8) } \\
\text { m (dp) }\end{array}$ & Valor P* \\
\hline MASC Total & $55,1(13,1)$ & $42,0(15,8)$ & 0,023 \\
Inconsistência & $4,7(2,5)$ & $2,7(0,5)$ & 0,074 \\
Tenso e Inquieto & $53,0(13,1)$ & $43,7(10,5)$ & 0,001 \\
Somático & $52,3(8,5)$ & $42,7(4,5)$ & $0,013 * * *$ \\
Sintomas físicos & $52,6(11,4)$ & $41,7(8,2)$ & 0,004 \\
Perfeccionismo & $45,0(10,1)$ & $36,4(10,9)$ & 0,033 \\
Superar ans & $38,7(6,4)$ & $35,6(5,7)$ & 0,148 \\
Evitar danos & $39,6(7,0)$ & $33,3(9,0)$ & 0,029 \\
Humilhação e rej & $59,9(16,0)$ & $47,0(15,8)$ & 0,080 \\
Desempenho púb & $61,8(14,4)$ & $49,1(17,1)$ & 0,080 \\
Ansiedade social & $62,4(16,2)$ & $51,4(16,5)$ & 0,160 \\
Pânico e separação & $51,8(11,6)$ & $51,1(16,9)$ & 0,892 \\
Índice de ansiedade & $45,8(13,7)$ & $35,3(15,4)$ & 0,045 \\
\hline
\end{tabular}

FONTE: Rodrigues, São Paulo, 2011

*Teste $\mathrm{t} /$ ** não considerar devido a comparação do CN 1 e CN 2

Legenda: $\mathrm{m}=$ média/ $\mathrm{dp}=$ desvio padrão 
Para o nosso conhecimento, trata-se do primeiro estudo realizado no Brasil a comparar o desempenho de pacientes com transtorno de ansiedade na infância e adolescência sem qualquer tratamento prévio.

\subsection{Primeira avaliação}

\subsubsection{Avaliação cognitiva}

Em relação à primeira avaliação (grupo de sujeitos com transtornos ansiosos prétratamento medicamentoso comparado ao grupo controle), observaram-se diferenças estatisticamente significativas entre os grupos em diversas provas neuropsicológicas. Esse fato corrobora a hipótese inicial de que o grupo com transtornos de ansiedade (sem tratamento prévio e sem outras comorbidades do que com o próprio transtorno de ansiedade) apresentariam um desempenho inferior ao grupo controle nos processos atencionais, mnésticos e executivos, sugerindo a interferência da ansiedade nesses processos.

Entre os processos cognitivos acima mencionados, ressalta-se o déficit atencional observado entre os pacientes com TAIA, uma vez que os mecanismos atencionais são apontados como componentes essenciais para os processos cognitivos e/ou de aprendizagem (Nabas e Xavier, 2004). Sem a capacidade seletiva da atenção, a quantidade de informações não selecionadas seria tão grande e desorganizada que nenhuma atividade seria possível (Luria, 1981). Todo o funcionamento cognitivo do indivíduo pode ser afetado, visto que a atenção está alterada (Sapir e Aronson, 1990). Dessa maneira, acredita-se que as outras dificuldades cognitivas observadas no grupo TAIA seriam secundárias à dificuldade atencional. De fato, Vasa e colaboradores, em estudo com crianças com transtornos de ansiedade, sugerem que déficits de memória (visual) observados nesses sujeitos seriam secundários aos processos atencionais (Vasa et al., 2007).

Observou-se que as crianças e adolescentes com TAIA necessitaram de um tempo maior para executar as atividades quando comparadas ao grupo controle. Esse resultado revela que esses jovens apresentaram uma menor velocidade de resposta 
quando foi necessário mudar a atenção entre dois estímulos (Trail Making Test forma B). Derakshan et al (2009) afirmam que a ansiedade pode afetar a eficiência na tarefa, em relação à capacidade de ter um bom desempenho. De forma semelhante Emerson et al., utilizando o Trail Making Test para medir os efeitos da ansiedade e da depressão, observaram diferença significativa na parte B desse teste em relação ao tempo, ou seja, indivíduos com ansiedade ou depressão diminuíram a velocidade em comparação aos não ansiosos (Emerson et al., 2005). Sendo assim, a diminuição na velocidade do tempo poderia ocorrer devido à redução do funcionamento neuropsicológico em geral, sugerindo um funcionamento frontal prejudicado (influência da ansiedade ou depressão), conforme proposto por Kusche et al. (1993) e Emerson et al. (2005).

Além dessa diminuição da velocidade do tempo, observou-se diferença significativa no desempenho das crianças diagnosticadas com TAIA em relação ao grupo controle em testes de funcionamento executivo que medem o planejamento e a flexibilidade mental. De fato sujeitos do grupo com TAIA tiveram dificuldades para realizar o teste da Torre de Hanoi. Eles precisaram de mais movimentos e mais tempo para executar a tarefa, em comparação ao grupo controle. Além disso, cometeram mais erros na fase mais complexa da tarefa (4 peças). Nossos achados reforçam dados existentes na literatura. De acordo com Dutke e Stober (2001), indivíduos com ansiedade apresentam melhor desempenho em tarefas mais fáceis, uma vez que a capacidade de memória restante pode ser suficiente para satisfazer as exigências de tais tarefas. O mesmo não ocorreria na execução de tarefas complexas, tais como as presentes no teste da Torre de Hanoi (tarefas de solução de problemas complexos relacionada à função executiva, que tem sido definida como a capacidade de manter adequada a solução de um problema para a realização de um objetivo futuro). As dificuldades citadas acima estariam relacionadas à tarefa que envolve processos de execução, tais como: planejamento, memória de trabalho, inibição e inteligência fluida (Welsh e Huizinga, 2005).

Quanto à flexibilidade mental, o grupo com TAIA apresentou maior dificuldade no desempenho do teste WCST (em relação ao número de categorias completadas, ao número de acertos, erros e categorias outros) quando comparados ao 
grupo controle. Os resultados do presente estudo corroboram os achados por Emerson et al (2005), que avaliaram meninos com ansiedade e depressão por meio de um teste de formação de conceito (Woodcock Johnson Teste de Habilidades Cognitivas). Os autores relataram que indivíduos ansiosos ou deprimidos apresentavam dificuldade na mudança do set (mudar o curso da resposta), no teste de hipóteses e na resolução de problemas, aspectos relacionados à flexibilidade mental (Emerson et al, 2005).

Ainda em relação à flexibilidade mental, Toren et al (2000) observaram que indivíduos com ansiedade cometiam mais erros e respostas perseverativas do que os indivíduos não ansiosos em um teste que avaliou a flexibilidade cognitiva e habilidades organizacionais (WCST). Os autores também relataram que os jovens ansiosos não aproveitavam o feedback negativo dado pelo avaliador (uma resposta negativa após o erro induzia a criança a repetir o erro) (Toren et al, 2000). Estes resultados sugerem que crianças e adolescentes com transtornos de ansiedade exibem uma adesão rígida a um determinado padrão e uma diminuição da capacidade de mudar o foco para outra atividade, fatos relacionados à quantidade limitada de recursos cognitivos para investir em uma tarefa. Além disso, ansiedade e preocupação tendem a prejudicar o desempenho em tarefas com alta demanda de memória de trabalho (Dutke e Stober, 2001)

No presente estudo, o grupo diagnosticado com TAIA cometeu mais erros simples, mas não erros perseverativos ou respostas perseverativas, sugerindo que tentaram encontrar outra forma de resolver a tarefa, mas foram ineficientes para a resolução. De fato, Watts e Weems (2006) observaram que os ansiosos e deprimidos, quando comparados aos controles, apresentavam mais erros em testes que avaliam a atenção, sugerindo que tal funcionamento ocorre devido à percepção pobre existente no funcionamento frontal prejudicado (Hadwin et al., 2005).

Além das dificuldades acima citadas, as crianças e adolescentes com TAIA apresentaram pior desempenho em relação aos controles nos testes que avaliaram memória visual e verbal, memória de trabalho visual e processos de aprendizagem verbal. Dados da literatura confirmam esses achados, indicando que haja uma forte correlação entre a ansiedade e a memória. Em estudo com meninos ente 7 e 11 anos 
com risco para delinquência, Pine et al. (1999) verificaram escores baixos na memória verbal e de desenho por meio do WRAML. De forma semelhante, Vasa relatou dificuldade tanto na memória verbal quanto na visual (Vasa, 2007).

As associações mais importantes encontradas no WRAML no estudo de Pine et al (1999) foram em relação ao subteste memória de desenho, embora tenha havido alguma inconsistência nas análises dos dados, que poderiam relacionar-se a limitações de poder estatístico. Observaram-se também déficits na habilidade desses jovens em memorizar uma lista de palavras. Tais achados sugerem uma relação com a região temporal esquerda nos transtornos de ansiedade. Além disso, a dificuldade de memória de trabalho estaria relacionada a déficits no córtex pré-frontal dorsolateral e à dificuldade na codificação da memória ou recordação relacionada a disfunções mais específicas no hipocampo e outras estruturas límbicas, incluindo a amígdala (localizada na região temporal medial) (Pine, 1999).

Segundo Pine (1999), três mecanismos poderiam explicar as associações entre a ansiedade e a memória. Primeiramente, a ansiedade pode levar a déficits de memória interrompendo processos cognitivos básicos (tais como a atenção) que facilitam a memória. $O$ segundo mecanismo relaciona a ansiedade como consequência do déficit de memória, fato ligado ao estresse associado ao déficit na capacidade cognitiva fundamental. Como exemplo, crianças com um déficit de memória podem ir mal na escola ou encontrar dificuldades em situações sociais. $\mathrm{O}$ estresse associado a essas situações poderia, assim, levar à ansiedade. Finalmente, os déficits de memória e a ansiedade podem surgir a partir do mesmo substrato, influenciados por estruturas temporais mediais (Pine, 1999).

Outro estudo sugere que dificuldades de memória poderiam ocorrer devido ao fato que indivíduos ansiosos ocupariam parcialmente a capacidade da memória de trabalho em tarefas irrelevantes com pensamentos, preocupações, autoavaliações e aspectos de fracasso. Resultaria, assim, em uma redução na competência de evocar informações. Dessa maneira, em tarefas coordenativas que exigem que as informações sejam processadas simultaneamente (armazenando o resultado das etapas anteriores), os indivíduos ansiosos apresentariam um desempenho inferior 
(Dutke e Stober, 2001). Ou seja, a complexidade da tarefa prejudicaria a eficácia do desempenho de indivíduos ansiosos (Hadwin et al., 2005).

Outra explicação para a dificuldade em recordar ou recuperar um conteúdo aprendido nos indivíduos ansiosos poderia relacionar-se a um momento de tensão (Wigfeld e Eccles, 1989). Em contrapartida, um estudo que avaliou crianças e adolescentes (com idades de 6 a 17 anos) diagnosticados com transtorno de ansiedade ou depressão, associou a dificuldade de memória apenas ao grupo com depressão e não ao grupo com ansiedade (Gunther et al., 2004).

De um modo geral, pode-se dizer que as dificuldades cognitivas estão associadas a deficiências do funcionamento do lobo frontal, como demonstrado, por exemplo, no desempenho na tarefa do teste da Torre de Hanoi. Tal tarefa tem demonstrado sensibilidade para a função e disfunção do lobo pré-frontal (Kusche et al, 1993; Emerson, 2005; Hadwin, 2005).

\subsubsection{Manifestação da ansiedade}

Os diagnósticos mais encontrados nesse estudo foram: transtorno de ansiedade de separação, fobia social, transtorno de ansiedade generalizada, fobia simples. Além disso, observou-se taxa elevada de comorbidades entre os vários diagnósticos de transtornos de ansiedade (80\%). Esses resultados estão de acordo com aqueles encontrados na literatura (Asbahr, 2004; Kashani e Orvaschel, 1990). Assim, optouse por avaliar a percepção da criança sobre seus sintomas, através da utilização da escala $M A S C$, para a avaliação das diversas formas de manifestação de ansiedade.

Quando comparados o grupo com TAIA e o grupo controle, observaram-se diferenças estatisticamente significativas em vários itens do referido instrumento ("escore total", "tenso e inquieto", "somático", "sintomas físicos", "humilhação e rejeição", "desempenho público" e "ansiedade social"). Tais resultados estão de acordo com a literatura, que aponta para a associação de sintomas físicos a quadros de TAIA (Gorenstein et al., 2000). 


\subsection{Segunda avaliação}

Após a primeira avaliação, foi realizada a comparação entre os dois momentos (pré e pós-tratamento) em cada grupo separadamente, o que permitiu a comparação do desempenho daqueles sujeitos que foram reavaliados após o período de seis meses. A segunda avaliação foi realizada em cinco subgrupos: ansiedade (todos os reavaliados independentemente do tratamento), controle, fluoxetina, clomipramina e placebo. Essa comparação possibilitou a análise conjunta dos dados para a verificação tanto do efeito da aprendizagem (por meio do re-teste nos controles), quanto do efeito do tratamento medicamentoso sobre o desempenho cognitivo.

\subsubsection{Controle}

Para a reavaliação de sujeitos submetidos a avaliações repetidas após breve intervalo de tempo e que utilizam os mesmos instrumentos (re-testagem), faz-se necessário considerar a existência de possível efeito aprendizagem (Beglinger et al., 2005). A re-testagem permite a análise das mudanças ocorridas no funcionamento cognitivo, possibilitando verificar os benefícios de um tratamento (Gruber e Yurgelun-todd, 2001).

No presente estudo, quando comparados os desempenhos das duas avaliações do grupo controle, encontraram-se diferenças estatisticamente significativas nas atividades que avaliaram:

a) a atenção em relação ao tempo necessário para desempenhar algumas atividades (nos testes: Trail Making Test forma A; Stroop Card Test 3 e MFFT-20);

b) a memória verbal de curto prazo e a aprendizagem verbal (nos subtestes do WRAML 2) e

c) a manifestação da ansiedade (pela escala MASC nos itens: "somático"; “pânico e separação”).

De um modo geral, apresentaram um melhor desempenho na segunda avaliação, com exceção da atividade que avaliava memória verbal a curto prazo 
(“memória para história 1" do subteste WRAML 2) nessa as crianças e adolescentes apresentaram um pior desempenho. Esses dados sugerem que a melhora do desempenho pelo aprendizado ocorreu mesmo após um intervalo de seis meses, razão pela qual essas atividades não foram consideradas na comparação com os outros grupos. Para o nosso conhecimento, esse é o primeiro estudo a apresentar dados de re-testagem com um grupo controle.

Importante considerar que alguns testes são mais sensíveis à presença de sintomas de ansiedade (Cunha et al, 2000). Além disso, em situações desconhecidas, tais com aplicações de testes neuropsicológicos, a pessoa pode demonstrar certo grau de reserva, falta de espontaneidade, certa apreensão ou ansiedade, como modos adaptativos frente a essas situações (Cunha et al., 2000). Assim, é de fundamental importância a preparação do paciente para a avaliação, procurando aliviar sentimentos de ansiedade, que podem vir a interferir no desempenho (Capovilla, 2007). Dessa maneira, mesmo não sendo patológicos, sintomas de ansiedade podem ter ocorrido quando da primeira avaliação (situação desconhecida). Essa ansiedade pode ter sido reduzida na segunda avaliação (situação conhecida).

\subsubsection{Diferentes tratamentos medicamentosos}

\subsubsection{Ansiedade pré e pós-tratamento medicamentoso (independentemente do tipo de tratamento)}

Fizeram-se duas hipóteses para segunda avaliação:

1) o grupo com transtorno de ansiedade tratado com medicamento durante período de seis meses apresentaria um desempenho superior na segunda avaliação (pós-tratamento) em relação à primeira (pré-tratamento) nos processos atencionais, mnésticos e executivos e;

2) o grupo placebo apresentaria desempenho inferior ao grupo que recebeu medicação nos mesmos processos. 
Em relação à primeira hipótese, quando comparados os desempenhos nas duas avaliações dos sujeitos do grupo TAIA, encontrou-se diferença significativa nas atividades que avaliavam:

a) eficiência intelectual estimada (no subteste "matrizes do raciocínio" do WASI e no valor do QI);

b) atenção e função executiva em relação ao tempo e número de movimentos e erros necessários para desempenhar uma atividade (nos testes Trail Making Test forma B e Torre de Hanoi com 3 e 4 peças);

c) na memória verbal a longo prazo (no subteste “memória para história 2" do WRAML 2) e

d) manifestação da ansiedade (em alguns itens da escala MASC), demonstrando uma melhora do desempenho na segunda avaliação.

Esses resultados estão de acordo com a nossa primeira hipótese sobre a segunda avaliação, o que sugere que após o tratamento, o grupo com TAIA apresentou um melhor funcionamento cognitivo.

\subsubsection{Clomipramina}

Quando comparados os grupos (clomipramina, fluoxetina e placebo) separadamente nos dois momentos (pré e pós-tratamento medicamentoso), pode-se observar que o grupo que foi tratado com clomipramina apresentou melhora na segunda avaliação, em três variáveis: duas relacionada à atenção e funções executivas (Torre de Hanoi com 4 peças em relação ao tempo e ao número de erros) e a outra relacionada à memória visual a curto prazo (subteste "memória para cenas" do WRAML 2). Além disso, apresentaram melhora no item "desempenho público" da escala MASC. Os dados da literatura são inconsistentes, alguns apontam para um prejuízo no funcionamento cognitivo, o que não foi observado no presente estudo (Hindmarch, 1998; Allen, 1991; Bartfai et al., 1991 apud Carvalho et al., 2002). 


\subsubsection{Fluoxetina}

O grupo que foi tratado com fluoxetina, quando comparados os desempenhos nas duas avaliações, apresentou uma melhora na segunda avaliação, em três variáveis: duas relacionadas à atenção e funções executivas (MFFT-20 índice de ineficiência e Torre de Hanoi com 4 peças em relação ao tempo) e memória verbal a longo prazo (subteste "memória para história 2" do WRAML 2). Além disso, apresentaram melhora no item "desempenho público" da escala MASC. De fato, alguns estudos sugerem que a fluoxetina poderia melhorar o desempenho de novas tarefas, levando à melhora da capacidade cognitiva (Hindmarch, 1998; Kim et al, 2002; Kang et al., 2003; Fontenelle et al., 2007).

\subsubsection{Placebo}

$\mathrm{Na}$ comparação do desempenho nas duas avaliações do grupo que tomou placebo, observou-se melhora na segunda avaliação, em três variáveis: duas relacionadas (subteste matrizes do raciocínio do WASI e valor do QI) e uma a atenção e funções executivas (Trail Making Test forma B em relação ao tempo). Além disso, apresentou melhora nos seguintes itens da escala MASC: "MASC total", "tenso e inquieto", "sintomas físicos", "perfeccionismo", “evitar danos" e "índice de ansiedade". Tais resultados são contrários à segunda hipótese, sugerindo que o grupo que tomou placebo não apresentou desempenho inferior ao grupo que recebeu medicação. A explicação para essa melhora pode relacionar-se a fatores psicológicos (Khan et al., 2005; Sandler, 2005; Farabaugh et al.,2006). 


\subsection{Limitações}

Ressalta-se primeiramente, que tal análise foi realizada com uma amostra pequena, o que limita as conclusões do estudo. Os resultados obtidos mostram tendências que, com a ampliação da amostra, poderão ser confirmadas.

Pela mesma razão amostral, não foi possível realizar análises separadas por faixas etárias e gêneros. Não se pode, assim, avaliar se houve alguma diferença de resposta entre crianças e adolescentes, tampouco entre meninos e meninas. Da mesma maneira, não foi possível realizar análises separadas por diagnósticos específicos de transtornos de ansiedade.

Possivelmente, a razão do pequeno número da presente amostra relaciona-se ao número substancial de exclusões, intimamente ligado a critérios bastantes rigorosos adotados no estudo.

Realizaram-se 404 triagens telefônicas e somente 30 pacientes foram incluídos no estudo. Esse fato deveu-se à dificuldade em se incluir sujeitos com algum TAIA sem comorbidades (associação a outros transtornos psiquiátricos). No caso dos TAIA, a presença de comorbidades é a regra e não, a exceção. De fato, dados da literatura apontam para a existência de altas prevalências de transtornos ansiosos com os quadros de Depressão (Costello et al., 2005), de TDAH e Transtorno de conduta (Bernstein et al., 1996; Williams e Miller, 2003).

Outra limitação relaciona-se aos instrumentos utilizados para as avaliações neuropsicológicas, não padronizadas para a população brasileira. Esse fato dificulta a comparação desse estudo a outros encontrados na literatura. A inclusão de um controle submetido às mesmas avaliações procurou reduzir a influência desse possível viés metodológico. 


\section{CONCLUSÕES}


Com base nos resultados obtidos, conclui-se que:

1. O presente estudo sugere que a ansiedade excessiva interfere no desempenho cognitivo de crianças e adolescentes, em especial na atenção, funções executivas e memória.

2. O funcionamento cognitivo de crianças e adolescentes com transtornos de ansiedade pode ser afetado devido à alteração da atenção.

3. As dificuldades cognitivas encontradas na população estudada são compatíveis com um funcionamento frontal prejudicado.

4. Após período de tratamento, as crianças e adolescentes apresentam melhora no desempenho em diversas funções cognitivas, em especial: eficiência intelectual estimada, atenção, funções executivas, memória verbal a longo prazo e sintomas de ansiedade.

5. Após período de tratamento, as crianças e adolescentes não apresentaram diferença em relação ao desempenho cognitivo, independentemente do tipo de tratamento.

6. O grupo tratado com placebo apresentou melhora semelhante aos grupos tratados com medicação. 
8 ANEXOS

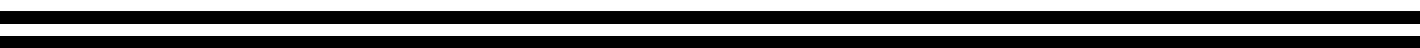


ANEXO A - TERMO DE CONSENTIMENTO

HOSPITAL DAS CLÍNICAS DA FACULDADE DE MEDICINA

DA UNIVERSIDADE DE SÃO PAULO-HCFMUSP

MODELO DE TERMO DE CONSENTIMENTO LIVRE E ESCLARECIDO

DADOS DE IDENTIFICAÇÃO DO SUJEITO DA PESQUISA OU RESPONSÁVEL LEGAL

1. NOME:

DOCUMENTO DE IDENTIDADE $\mathrm{N}^{\circ}$ : SEXO : .M $\square \mathrm{F} \square$ DATA NASCIMENTO: $\mathrm{N}^{\circ}$ APTO:

ENDEREÇ CIDADE

BAIRRO

CEP:. TELEFONE: DDD ( ...)

\section{RESPONSÁVEL LEGAL}

NATUREZA (grau de parentesco, tutor, curador etc.)

DOCUMENTO DE IDENTIDADE : SEXO: M $\square \mathrm{F} \square$

DATA NASCIMENTO.: $\mathrm{N}^{\mathrm{o}}$ APTO:

ENDEREÇO: CIDADE:

BAIRRO:

CEP: TELEFONE: DDD ( ...).

\section{DADOS SOBRE A PESQUISA}

1. TÍTULO DO PROTOCOLO DE PESQUISA Aspectos Neuropsicológicos dos Transtornos de Ansiedade na infância e na Adolescência: um estudo comparativo entre as fases de pré e pós-tratamento medicamentoso.

PESQUISADOR: Camila Luisi Rodrigues

CARGO/FUNÇÃO: Pesquisadora executante/ Psicóloga INSCRIÇÃO CONSELHO REGIONAL N $06 / 69150$

UNIDADE DO HCFMUSP: Instituto de Psiquiatria 


\title{
3. AVALIAÇÃO DO RISCO DA PESQUISA:
}

\author{
RISCO MÍNIMO $\square$ \\ RISCO MÉDIO 口 \\ RISCO BAIXO \\ RISCO MAIOR $\square$
}

\section{DURAÇÃO DA PESQUISA : 24 meses}

Você procurou tratamento médico por estar percebendo em seu filho (a) sinais de ansiedade. Você e seu(sua) filho(a) passaram por uma avaliação inicial de duas semanas com uma médica que está como pesquisadora responsável de um outro estudo chamado: "Comparação entre Clomipramina e Fluoxetina para o Tratamento de Transtorno de Ansiedade em Crianças e Adolescentes". Sua médica the explicou que este tipo de comportamentos que seu(sua) filho(a) apresenta recebe o nome de Transtorno de Ansiedade e que seria necessário iniciar o tratamento medicamentoso, o qual tem por objetivo aliviar os sintomas desta doença. Entretanto, a literatura científica mostra que pacientes com Transtorno de Ansiedade podem apresentar dificuldades no seu desempenho nas atividades escolares diárias e certamente lhe trazem grande desconforto.

Você está sendo convidado a participar de um estudo, o qual consta de uma aplicação de testes neuropsicológicos. Estes testes são tarefas simples, que irão verificar a capacidade de atenção, de memória e a habilidade para tomar decisões importantes de seu(sua) filho(a) em dois momentos. A primeira avaliação será realizada no início do tratamento sem que seu(sua) filho(a) esteja fazendo uso de medicação. Após essa avaliação seu(sua) filho(a) receberá um tratamento por um período de 12 semanas e nesse tratamento será utilizada alguma das três medicações: fluoxetina, clomipramina ou placebo. A segunda avaliação será aproximadamente após um período de 6 meses da avaliação inicial.

O objetivo principal desta pesquisa será comparar o desempenho de seu(sua) filho(a) na primeira avaliação em algumas tarefas com a segunda avaliação e verificar se existe alguma diferença nesses dois momentos. Além disso, esses resultados serão comparados com os de outras crianças e adolescentes com sintomas parecidos aos do(a) seu(sua) filho(a) com o objetivo de verificar se existe diferença entre as três formas de tratamento citadas acima.

Procedimentos do Estudo: Para participar deste estudo seu(sua) filho(a) precisa ter entre 7 e 17 anos e estar participando da pesquisa citada acima, recebendo acompanhamento ambulatorial no SEPIA -Serviço de Psiquiatria da criança e do adolescente do Instituto de Psiquiatria. A médica que lhe atende fará o encaminhamento para a psicóloga caso você concorde em realizar os testes. Sua participação será em sessão individual, na qual he serão apresentadas tarefas diferentes. O tempo estimado para a conclusão destas tarefas é de aproximadamente duas horas e meia em apenas uma sessão, nos dois momentos citados acima (antes e depois da medicação).

Riscos e desconfortos: Não existe nenhum risco em relação à realização dos testes, mas um possível desconforto é o cansaço que, pode acontecer antes de seu(sua) filho(a) concluir todas as atividades; se isto ocorrer seu(sua) filho(a) poderá levar mais tempo para realizá-la, poderá realizar mais intervalos ou intervalos maiores ou ainda suspender os testes e retomar em um outro dia. 
Benefícios que poderão ser obtidos: De imediato o benefício que está diretamente ligado a você diz respeito ao conhecimento de seu desempenho nas atividades propostas, como suas habilidades e dificuldades. Caso haja necessidade, esses dados poderão servir como orientação aos pais, professores e equipe médica. Além disso, os dados obtidos nesta pesquisa possibilitarão um maior conhecimento a respeito do que ocorre com os pacientes que sofrem com este transtorno em termos cognitivos e sua comparação nos dois momentos da avaliação (antes e depois da medicação), assim como entre os grupos três grupos de tratamento. Estes dados irão favorecer, posteriormente, o planejamento e a elaboração de programas de reabilitação, com a finalidade de reduzir ou adaptar o impacto que estes prejuízos podem ocasionar na vida cotidiana e na adaptação social.

Quanto a sua participação: Sua participação é voluntária. Se aceitar participar, você deverá assinar este termo de consentimento e a partir daí estará fazendo parte de um grupo de pacientes, que sofrem com o mesmo problema e que também estarão contribuindo para um melhor conhecimento a respeito de possíveis dificuldades cognitivas. Caso você queira desistir de participar do estudo, isto não lhe trará prejuízos em relação ao seu acompanhamento médico. Você terá direito de ser mantido atualizado sobre os resultados parciais das pesquisas, quando em estudos abertos, ou de resultados que sejam do conhecimento dos pesquisadores;

Confidencialidade: Sua identidade será preservada. Durante o estudo você será identificado por um número específico e o mesmo ocorrerá no caso de publicações ou apresentação deste estudo em eventos científicos.

Despesas e compensações: não há despesas pessoais para o participante em qualquer fase do estudo, incluindo exames e consultas. Também não há compensação financeira relacionada à sua participação. Se existir qualquer despesa adicional, ela será absorvida pelo orçamento da pesquisa.

O pesquisador se compromete em utilizar os dados e o material coletado somente para esta pesquisa.

Em qualquer etapa do estudo, você terá acesso aos profissionais responsáveis pela pesquisa para esclarecimento de eventuais dúvidas. A principal investigadora é a Dra Cristiana Castanho de Almeida Rocca que pode ser encontrada no endereço Dr Ovídio Pires de Campos, 785, telefone 30696274. Se você tiver alguma consideração ou dúvida sobre a ética da pesquisa, entre em contato com o Comite de Ética em Pesquisa (CEP) - Rua Ovídio Pires de Campos, 225 - 5º andar - tel: 3069-6442 ramais 16, 17, 18 ou 20, FAX: 3069-6442 ramal 26 - E-mail: cappesq@hcnet.usp.br.

Acredito ter sido suficientemente informado a respeito das informações que li ou que foram lidas para mim, descrevendo o estudo "Aspectos Neuropsicológicos dos Transtornos de Ansiedade da Infância e Adolescência: um estudo comparativo entre a fase pré e pós-tratamento medicamentoso".

Discuti com a pesquisadora sobre a minha decisão em participar nesse estudo. Ficaram claros para mim quais são os propósitos do estudo, os procedimentos a serem realizados, seus desconfortos e riscos, as garantias de confidencialidade e de esclarecimentos permanentes.

Ficou claro também que minha participação é isenta de despesas e que tenho garantia do acesso a tratamento hospitalar quando necessário. Concordo voluntariamente em participar deste estudo e poderei 
retirar o meu consentimento a qualquer momento, antes ou durante o mesmo, sem penalidades ou prejuízo ou perda de qualquer benefício que eu possa ter adquirido, ou no meu atendimento neste Serviço.

Para casos de pacientes menores de 18 anos, analfabetos, semi-analfabetos ou portadores de deficiência auditiva ou visual.

\section{(Somente para o responsável do projeto)}

Declaro que obtive de forma apropriada e voluntária o Consentimento Livre e Esclarecido deste paciente ou representante legal para a participação neste estudo. 


\section{Anexo B - Tabela de números aleatórios para randomização}

TABELA 13 Números aleatôrios

\begin{tabular}{|c|c|c|c|c|c|c|c|c|c|}
\hline 14835 & 07362 & 26733 & 66337 & 20020 & 46848 & 24360 & 67813 & 17531 & 96160 \\
\hline 84156 & 22328 & 08704 & 06439 & 64789 & 19606 & 74597 & 42899 & 36235 & 91089 \\
\hline 07439 & 84935 & 67799 & 78493 & 03976 & 72783 & 31131 & 60452 & 23680 & 88212 \\
\hline 60562 & 06499 & 56274 & 89528 & 77248 & 82823 & 29149 & 02415 & 46849 & 34372 \\
\hline 92554 & 02182 & 58212 & 23811 & 74399 & 01856 & 50828 & 05868 & 60178 & 36120 \\
\hline 57154 & 33430 & 44547 & 19479 & 28029 & 98735 & 02523 & 07352 & 26115 & 05784 \\
\hline 33592 & 35545 & 09878 & 39291 & 05498 & 20618 & 13325 & 88848 & 05151 & 10298 \\
\hline 63113 & 59196 & 90890 & 52945 & 95027 & 82655 & 76150 & 00102 & 23247 & 38135 \\
\hline 53456 & 15261 & 00582 & 37612 & 11971 & 92844 & 44112 & 48161 & 15426 & 26704 \\
\hline 89202 & 77388 & 51468 & 91049 & 19894 & 02188 & 13318 & 22280 & 34959 & 55245 \\
\hline 88891 & 23578 & 84958 & 96820 & 99600 & 94748 & 42738 & 57576 & 79063 & 07765 \\
\hline 84885 & 80345 & 96016 & 01251 & 09348 & 28560 & 11147 & 01657 & 00755 & 43642 \\
\hline 38697 & 69389 & 98345 & 73048 & 29507 & 18526 & 67736 & 56657 & 49748 & 02160 \\
\hline 39871 & 02677 & 13729 & 60302 & 49365 & 36310 & 29226 & 52028 & 93731 & 58365 \\
\hline 33006 & 74668 & 41831 & 49768 & 95000 & 21495 & 32144 & 0.9647 & 64404 & 36257 \\
\hline 07154 & 82834 & 40799 & 10422 & 81214 & 26325 & 65495 & 48346 & 27304 & 76266 \\
\hline 31432 & 17859 & 22968 & 94194 & 06884 & 34888 & 65166 & 25467 & 35774 & 61056 \\
\hline 56960 & 26638 & 36632 & 91651 & 29180 & 98155 & 01805 & 51464 & 49138 & 05710 \\
\hline 02355 & 56388 & 09067 & 75695 & 25493 & 97169 & 22686 & 21475 & 31110 & 53045 \\
\hline 82103 & 63195 & 65527 & 66243 & 96807 & 69165 & 95289 & 62930 & 66343 & 83711 \\
\hline 50825 & 82955 & 24147 & 75012 & 20103 & 60267 & 04051 & 11654 & 81456 & 02920 \\
\hline 03628 & 55427 & 72771 & 11270 & 13391 & 42267 & 25646 & 96957 & 39640 & 34334 \\
\hline 15891 & 95262 & 89450 & 10087 & 92371 & 99885 & 94941 & 46284 & 77397 & 40100 \\
\hline 50811 & 44401 & 92573 & 84821 & 49314 & 34342 & 01290 & 91163 & 37248 & 35041 \\
\hline 59943 & 24172 & 16959 & 76008 & 04121 & 99199 & 55271 & 38518 & 07155 & 97528 \\
\hline 45342 & 34103 & 48817 & 53536 & 03630 & 80439 & 17091 & 77911 & 87900 & 91034 \\
\hline 74881 & 27536 & 54074 & 82623 & 64322 & 32241 & 66784 & 14590 & 17966 & 72187 \\
\hline 77329 & 75480 & 19058 & 91100 & 21175 & 87860 & 98479 & 87996 & 39068 & 14348 \\
\hline 35196 & 84012 & 03780 & 47762 & 94498 & 89812 & 71238 & 54070 & 43360 & 61395 \\
\hline 84371 & 38352 & 85742 & 01610 & 41863 & 59977 & 58513 & 79876 & 87152 & 50249 \\
\hline 22980 & 08123 & 98993 & 35609 & 45405 & 57914 & 96884 & 23851 & 65979 & 03903 \\
\hline 58486 & 17927 & 91107 & 83002 & 90223 & 04731 & 88063 & 95720 & 91892 & 01246 \\
\hline 61376 & 95034 & 53865 & 29670 & 13302 & 67790 & 92887 & 69725 & 98265 & 90459 \\
\hline 23756 & 35575 & 07730 & 38317 & 40512 & 95941 & 66943 & 68526 & 24235 & 38609 \\
\hline 04044 & 43464 & 90762 & 94781 & 68427 & 50021 & 82905 & 33939 & 41037 & 54417 \\
\hline 60047 & 50681 & 64384 & 42320 & 46016 & 51491 & 23656 & 55597 & 47347 & 18863 \\
\hline 83531 & 86235 & 40884 & 45400 & 96397 & 37285 & 06290 & 04315 & 05773 & 18621 \\
\hline 06544 & 92307 & 69731 & 53410 & 63161 & 31227 & 10973 & 87011 & 59483 & 09370 \\
\hline 49791 & 25181 & 29805 & 45135 & 94955 & 77642 & 45637 & 28200 & 77295 & 40800 \\
\hline 21295 & 61442 & 44858 & 73413 & 19594 & 59741 & 39278 & 78953 & 24769 & 77854 \\
\hline
\end{tabular}


Anexo C - MASC - Escala Multidimensional de Ansiedade para Crianças

Nome:

Idade:

Sexo: Masc. Fem.

Data:

Série escolar:

(circule um)

Este questionário pergunta a você como você vem se sentindo, o que você tem pensado, tem sentido ou como tem agido recentemente. Para cada item, por favor faça um círculo ao redor do número que indica com que frequência a afirmativa é verdadeira para você. Se o que a sentença diz é verdade sobre você muitas vezes, circule 3 . Se ela é verdade sobre você algumas vezes, circule 2 . Se a sentença é verdade sobre você uma vez ou outra, circule 1 . Se dificilmente ou nunca a sentença é verdade sobre você, circule 0 . Lembre-se, não há respostas certas ou erradas, responda apenas como você vem se sentindo recentemente.

Aqui estão dois exemplos para lhe mostrar como completar o questionário. No exemplo A, se você muito poucas vezes tem medo de cachorro, você deve circular 1 , significando que a afirmativa raramente é verdadeira sobre você. No exemplo $B$, se às vezes os trovões o perturbam, você deve circular 2, significando

Nunca Raramente Às Frequentemente é é verdade vezes é é verdade sobre verdade sobre mim verdade mim sobre sobre $\operatorname{mim} \operatorname{mim}$ que a afirmativa é às vezes verdade sobre você.

Exemplo A Eu tenho medo de

cachorros
0

0
1

1

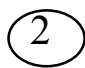

2
3

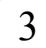

Exemplo B Trovões me

perturbam.

Agora tente esses itens você mesmo. Não se esqueça também de responder as questões no verso deste questionário.

\begin{tabular}{|l|l|c|c|c|c|}
\hline 1. & Eu me sinto tenso ou nervoso & 0 & 1 & 2 & 3 \\
\hline 2. & Eu costumo pedir permissão para fazer as coisas & 0 & 1 & 2 & 3 \\
\hline 3. & $\begin{array}{l}\text { Eu me preocupo que as outras pessoas dêem risada } \\
\text { de mim }\end{array}$ & 0 & 1 & 2 & 3 \\
\hline 4. & Eu fico com medo quando os meus pais saem & 0 & 1 & 2 & 3 \\
\hline 5. & Sinto falta de ar & 0 & 1 & 2 & 3 \\
\hline 6. & Eu fico atento se há algum perigo & 0 & 1 & 2 & 3 \\
\hline 7. & A idéia de ficar longe de casa me assusta & 0 & 1 & 2 & 3 \\
\hline 8. & Eu fico tremendo ou inquieto pais e & 0 & 1 & 2 & 3 \\
\hline 9. & $\begin{array}{l}\text { Eu me esforço para obedecer meus ou } \\
\text { professores }\end{array}$ & 0 & 1 & 2 & 3 \\
\hline 10. & $\begin{array}{l}\text { Eu tenho medo que os outros meninos (ou } \\
\text { meninas) gozem de mim }\end{array}$ & 0 & 1 & 2 & 3 \\
\hline 11. & Eu tento ficar perto da minha mãe ou meu pai & 0 & 1 & 2 & 3 \\
\hline 12. & Eu tenho tontura ou sensação de desmaio \\
\hline
\end{tabular}

Por favor, vire a folha; as questões continuam na próxima página... 


\begin{tabular}{|c|c|c|c|c|c|}
\hline & & $\begin{array}{l}\text { Nunca } \\
\text { é } \\
\text { verdade } \\
\text { sobre } \\
\text { mim }\end{array}$ & $\begin{array}{l}\text { Raramente } \\
\text { é verdade } \\
\text { sobre mim }\end{array}$ & $\begin{array}{l}\text { Às } \\
\text { vezes é } \\
\text { verdade } \\
\text { sobre } \\
\text { mim }\end{array}$ & $\begin{array}{l}\text { Frequentemente } \\
\text { é verdade sobre } \\
\text { mim }\end{array}$ \\
\hline 13 & Eu verifico as coisas antes de fazê-las & 0 & 1 & 2 & 3 \\
\hline 14 & $\begin{array}{l}\text { Eu me preocupo em ser chamado na } \\
\text { classe }\end{array}$ & 0 & 1 & 2 & 3 \\
\hline $\begin{array}{l}15 \\
\cdot\end{array}$ & $\begin{array}{l}\text { Eu me sinto desassossegado } \\
\text { (sobressaltado) }\end{array}$ & 0 & 1 & 2 & 3 \\
\hline 16. & $\begin{array}{l}\text { Eu tenho medo que os outros achem que eu sou } \\
\text { bobo }\end{array}$ & 0 & 1 & 2 & 3 \\
\hline 17. & Eu deixo as luzes acesas à noite & 0 & 1 & 2 & 3 \\
\hline 18. & Eu sinto dores no peito & 0 & 1 & 2 & 3 \\
\hline 19. & Eu evito sair sem minha família & 0 & 1 & 2 & 3 \\
\hline 20. & $\begin{array}{l}\text { Eu me sinto estranho, esquisito, ou fora da } \\
\text { realidade }\end{array}$ & 0 & 1 & 2 & 3 \\
\hline 21. & $\begin{array}{l}\text { Eu tento fazer coisas que vão agradar aos } \\
\text { outros }\end{array}$ & 0 & 1 & 2 & 3 \\
\hline 22. & $\begin{array}{l}\text { Eu me preocupo com o que os outros pensam } \\
\text { de mim }\end{array}$ & 0 & 1 & 2 & 3 \\
\hline 23. & $\begin{array}{l}\text { Eu evito assistir filmes ou programas de TV } \\
\text { que assustam }\end{array}$ & 0 & 1 & 2 & 3 \\
\hline 24. & Meu coração dispara ou "falha" & 0 & 1 & 2 & 3 \\
\hline 25. & Eu evito as coisas que me aborrecem & 0 & 1 & 2 & 3 \\
\hline 26. & Eu durmo junto de alguém da minha família & 0 & 1 & 2 & 3 \\
\hline 27. & Eu me sinto inquieto e nervoso & 0 & 1 & 2 & 3 \\
\hline 28. & Eu tento fazer tudo exatamente do jeito certo & 0 & 1 & 2 & 3 \\
\hline 29. & $\begin{array}{l}\text { Eu me preocupo em fazer alguma coisa boba ou } \\
\text { que me deixe sem graça }\end{array}$ & 0 & 1 & 2 & 3 \\
\hline 30. & $\begin{array}{l}\text { Eu fico com medo quando ando de carro ou de } \\
\text { ônibus }\end{array}$ & 0 & 1 & 2 & 3 \\
\hline 31. & Eu sinto mal estar no estômago & 0 & 1 & 2 & 3 \\
\hline 32. & $\begin{array}{l}\text { Se eu fico aborrecido ou com medo, eu conto } \\
\text { logo para alguém }\end{array}$ & 0 & 1 & 2 & 3 \\
\hline 33. & $\begin{array}{l}\text { Eu fico nervoso se eu tenho que fazer alguma } \\
\text { coisa em público }\end{array}$ & 0 & 1 & 2 & 3 \\
\hline 34. & $\begin{array}{l}\text { Tenho medo de tempo ruim, escuridão, altura, } \\
\text { animais ou insetos }\end{array}$ & 0 & 1 & 2 & 3 \\
\hline 35. & Minhas mãos tremem & 0 & 1 & 2 & 3 \\
\hline 36. & $\begin{array}{l}\text { Eu preciso ter certeza que as coisas estão } \\
\text { Seguras }\end{array}$ & 0 & 1 & 2 & 3 \\
\hline 37. & $\begin{array}{l}\text { Eu tenho dificuldade em chamar outros } \\
\text { meninos (ou meninas) para brincar comigo }\end{array}$ & 0 & 1 & 2 & 3 \\
\hline 38. & Minhas mãos ficam suadas ou frias & 0 & 1 & 2 & 3 \\
\hline 39. & Eu sinto vergonha & 0 & 1 & 2 & 3 \\
\hline
\end{tabular}


9 REFERÊNCIAS

2mam 
Allen HG. Brief report: Trichotillomania in an autistic male. Journal of Autism and Developmental Disorders. 1991; 21(1): 79-82.

American Psychiatric Association. Diagnostic and statistical manual of mental disorders, 4th ed. Washington (DC): APA; 2000.

Asbahr FR. Anxiety disorders in childhood and adolescence: clinical, and neurobiological aspects. Jornal de Pediatria. 2004; 80 (2): S28-34.

Barbirato F, Dias G. A mente do seu filho: como estimular as crianças e identificar os distúrbios psicológicos na infância. Rio de Janeiro: Editora Agir; 2009.

Beck AT, Emery G, Greenberg RL. Anxiety disorders and phobias: A cognitive perspective. New York: Basic Books, Inc Publishers; 1985.

Beglinger LJ, Gaydos B, Daniels O T, Duff K, Kareken DA, Crawford J, Fastenau PS, Siemers ER. Practice effects and the use of alternate forms in serial neuropsychological testing. Archives of Clinical Neuropsychology. 2005; 20: $517-$ 529.

Bernstein GA, Borchardt CM, Perwien AR. Anxiety disorders in children and adolescents: a review of the past 10 years. Journal of the American Academy of Child and Adolescent Psychiatry. 1996; 35(9):1110-9.

Birmaher B, Axelson DA, Monk K, Kalas C, Clark DB, Ehmann, M, Brigde J, Heo J, Brent DA. Fluoxetine for the treatment of childhood anxiety disorders. J Am Acad Child Adolesc Psychiatry. 2003; 42 (4): 415-23.

Cabrera CC, Sponholz A. Ansiedade e Insônia. In: Botega, NJ. Prática psiquiátrica no hospital geral: interconsulta e emergência. Porto Alegre: Artmed; 2002.

Cairns ED, Cammock, J. MFF - 20 Test de Emparejamiento de Figuras Conocidas 20. Madrid: TEA Ediciones, SA; 2002.

Calvo MG, Ramos PM, Estevez A. Test anxiety and comprehension efficiency: The role of prior knowledge and working memory deficits. Anxiety, Stress e Coping. 1992; 5(2): 125-138.

Capovilla FC. Teoria e pesquisa em avaliação neuropsicológica. São Paulo: Memnon; 2007. 
Carvalho SC, Marcourakis T, Gorenstein C. Memory performance in panic disorder patientes after chronic use of clomipramine. Journal of psychopharmacology. 2002; 16(3): $220-226$.

Castilho AF, Guteiérrez-Rojas ME. Selective attention, anxiety, depressive symptomatology and academic performance in adolescents. Journal of research in educational psychology. 2009: 17 (7): 49-76.

Castilho ARGL, Recondo R, Asbahr F, Manfro GG. Transtornos de Ansiedade. Revista Brasileira de Psiquiatria. 2000; 22(2): 20-23.

Cavedini P, Riboldi G, Dánnunci A, Belotti P, Cisima M, Bellodi L. Decisionmaking heterogeneity in obsessive-compulsive disorder: ventromedial prefrontal cortex function predicts differente treatment outcomes. Neuropsychologia. 2002; 40(2): 205-11.

Contreras F, Espinosa JC, Esguerra G, Haikal A, Polaino A, Rodrigues A. Selfefficacy, anxiety and academic performance in adolescent. Diversitas. 2005; 1 (2): 183-194.

Costa CZG. Comparação entre clomipramina e fluoxetina para o tratamento de transtornos de ansiedade em crianças e adolescentes. [dissertação]. São Paulo: Universidade de São Paulo; 2010.

Costello EJ, Egger HL, Angold A. The Developmental Epidemiology of Anxiety Disorders: Phenomenology, Prevalence, and Comorbidity. Child Adolescent Psychiatric Clinics of North American. 2005; 14: 631-648.

Cunha JA et al. Escalas Wechsler. In: Psicodiagnóstico- $V$. 50. Edição revisada e ampliada. Porto Alegre: Artmed, 2000.

Daleiden EL. Childhood Anxiety and Memory Functioning: A Comparison of Systemic and Processing Accounts . Journal of Experimental child psychology. 1998; 68(3): 216-235.

Degroot, A, Nomikos GG. Fluoxetine disrupts the integration of anxiety and aversive memories. Neuropsychopharmacology. 2005; 30: 391-400.

Delprette ZAP, Delprette A. Psicologia das habilidades sociais na infância: teoria e prática. Petrópolis: Editora Vozes; 2005. 
Derakshan N, Ansari TL, Shoker L, Hansard ME, Eysenck MW. Anxiety, inhibition, efficiency, and effectiveness: An investigation using the antisaccade task. Experimental Psychology. 2009; 56: 48-55.

Dutke S, Stober J. Test Anxiety, Working Memory, and Cognitive Performance: Supportive Effects of Sequential Demands. Cognition and Emotion. 2001; 15(3): 381-389.

Elliott, R. Executive functions and their disorders - imaging in clinical neuroscience. Br Med Bull. 2003; 65: 49-59.

Emerson C S, Mollet GA, Harrison DW. Anxious-depression in boys: an evaluation of executive functioning. Archives of Clinical Neuropsychology. 2005; 20(4): 53946.

Eysenck MW, Derakshan N, Santos R, Calvo MG. Anxiety and cognitive performance: attentional control theory. Emotion. 2007; 7(2): 336 - 353.

Farabaugh AH, Sonawalla SB, Fava M, Pedrelli P, Papakostas G I, Schwartz F, Mischoulon D. Differences in cognitive factors between "true drug" versus “placebo pattern' response to Fluoxetine as defined by pattern analysis. Human Psychopharmacology. 2006; 21(4): 221 - 225.

Fontelle LF, Mendlowicz MV, Mattos P, Versiani M. Aspectos neuropsicológicos do transtorno obsessivo-compulsivo e suas implicações terapêuticas. In: Oliveira IR, Rosário MC, Miguel EC. Princípios e Práticas em Transtornos do Espectro Obsessivo-Compulsivo. Rio de Janeiro: Editora Guanabara Koogan S. A; 2007.

Fox E, Russo R, Bowles R, Dutton K. Do threatening stimuli draw or hold visual attention in subclinical anxiety? Journal Exp Psychol gen. 2001; 130(4): 681 - 700. Gazzaniga MS, Ivry RB, Mangun GR. Neurociência cognitiva: a biologia da mente. Tradução de Angélica Rosat Consiglio et al. 2º Edição. Porto Alegre: Artmed; 2006. Golden CJ. Luria-Nebraska neuropsychological battery: children's revision. Los Angeles, CA: Western Psychological services; 1991.

Good KP, Kiss I, Buiteman C, Woodley H, Rui Q, Whitehorn D, Kopala L. Improvement in cognitive functioning in patients with first-episode psychosis during treatment with quetiapine: an interimanalysis. British Journal of psychiatry. 2002; 181: 45-49. 
Gorenstein C, Carvalho, SC, Artes R, Moreno RA, Marcourakis T. Cognitive performance in depressed patients after chronic use of antidepressants. Psychopharmacology. 2006; 185(1): 84-92.

Gorenstein C, Andrade LHSG, Zuardi AW. Escalas de Avaliação clínica em psiquiatria e psicofarmacologia. São Paulo: Lemos Editorial; 2000.

Graeff FG. Bases Biológicas da ansiedade. In: Kapczinski F, Quevedo J, Izquierdo I et al. Bases Biológicas dos transtornos psiquiátricos. 2º Edição. Porto Alegre: Artmed; 2004.

Gray JA, Naughton N. The neropsychology of anxiety. An Enquiry into the functions of septo-hippocampal system. Second Edition. Oxford Psychology Series; 2007.

Gruber SA, Yurgelun-Todd DA. Neuropsychological Correlates of Dru Abuse. In: Kaufman MJ. Brain Imaging in Substance Abuse: Research, clinical and forensic applications. New Jersey: Humana Press, 2001.

Gunther T, Holtkamp K, Jolles J, Herpertz-dahlmann B, Konrad K. Verbal memory and aspects of attentional control in children and adolescents with anxiety disorders or depressive disorders. Journal of Affective Disorders. 2004; 82(2): 265-269.

Hadwin J, Brogan J, Stevenson J. State anxiety and working memory in children: a test of processing efficiency theory. Educational Psychology. 2005; 25(4): 379 393.

Heaton RK, Chelune GJ, Tally JL, Kay GG, Curtiss G. Teste Wisconsin de Classificação de Cartas. São Paulo: Casa do Psicólogo; 2004.

Hindmarch, I. Cognition and anxiety: the cognitive effects of anti-anxiety medication. Acta Psychiatrica Scandinavica. 1998; 98(393): 89-94.

Hinshaw SP. Externalizing behavior problems and academic underachievement in childhood and adolescence: causal relationships and underlying mechanisms. Psychological Bulletin. 1992; 11(2): 127-155.

Holmes DS. Psicologia dos Transtornos Mentais. $2^{\circ}$. Edição. Porto Alegre: Artmed; 1997.

Kagan J, Reznick JS, Snidman N. Biological bases of childhood shyness. Science. 1987; 240 (4849): 167-171.

Kaplan HI, Sadock, BJ et al. Comprehensive Textbook of Psychaitry. $6^{\circ}$ Edição. Baltimore MD: Williams e Wilkins; 1995. 
Kashani J, Orvaschel H. A community study of anxiety in children and adolescents. American Journal of Psychiatry. 1990; 149: 121-135.

Kendall PC, Pimentel SS. On the physiological symptom constellation in youth with generalized anxiety disorder. J Anxiety Disord. 2003; 17: 211-21.

Khan A, Kolts RL, Rapaport MH, Krishnan KR, Brodhead AE, Browns WA. Magnitude of placebo response and drug-placebo differences across psychiatric disorders. Psychol Med. 2005; 35 (5): 743-9.

Kim MS, Park SJ, Shim MS, Kwon, JS. Neuropsychological profile in patients with obsessive-compulsive disorder over a period of 4-moth treatment. J. Psychiatr. Res. 2002; 36(4): $257-65$.

Kissack MR, Léon NCM. Transtorno de ansiedade generalizada e transtorno de pânico em crianças e adolescentes. In: Caballo, VE, Simón MA. Manual de Psicologia Clínica infantil e do adolescente. Transtornos Gerais. São Paulo: Livraria Santos Editora; 2007.

Korenblum CB, Chen XS, Manassis K, Schachar RJ. Performance Monitoring and response inhibition in anxiety disorders with and without comorbid ADHD. Depression and anxiety. 2007; 24(4): 227-232.

Kusche CA, Cook ET, Greenberg MT. Neuropsychological and Cognitive Functioning in Children With Anxiety, Externalizing, and Comorbid Psychopathology. Journal of Clinical Child Psychology. 1993; 22(2): 172-195.

Lau JYF, Pine DS. Elucidating risk mechanisms of gene-environment interactionson pediatric anxiety: integrating findings from neuroscience. Eur Arch Psychiatry Clin Neurosci. 2008; 258: 97-106.

Lezak MD. Neuropsychological Assessment. Third Edition, New York: Oxford Univ Press; 1995.

Loring DW. In: Dictionary of neuropsychology. New York: Oxford University Press; 1999.

Luria AR. Fundamentos de Neuropsicologia. Tradução de Juarez Aranha Ricardo. Rio de Janeiro: Livros Técnicos e Científicos; 1981.

Manassis K, Tannock R, Young A, John SF. Cognition in anxious children with attention deficit hyperactivity disorder: a comparison with clinical and normal children. Behavioral and Brain Functions. 2007; 24: 85-94. 
Marcelli D. Manual de psicopatologia da infância de Ajuriaguerra. $5^{\circ}$. Edição. Porto Alegre: Artmed; 1998.

March JS, Parker JD, Sulivan K, Stallings P, Conners CK. The Multidimensional Anxiety Scale for Children (MASC): factor structure, reliability, and validity. $J$ Am Acad Child Adolesc Psychiatry. 1997; 36: 554-565.

Marques SL, Pasian SR, Franco MAP, Panosso IR, Viana AB, Oliveira DA. Reliability of Goodenough test (1926) and CMMS (1993) in cognitive assessment of children with learning difficulties. Paidéia. 2002; 12(23):105-112.

Mattar FN. Análise crítica dos estudos de estraticação socioeconômica de ABAABIPEME. Revista de Administração. 1995; 30(1): 57-74.

Mclead C, Mathews A. Anxiety and allocation of attention to threat. The quarterly journal of experimental psychology. 1988; 40: 653-670.

Mcnaughton N. Cognitive dysfunction resulting from hippocampal hyperactivity - A Possible cause of anxiety disorder? Pharmacology Biochemistry and behavior. 1997; 56(4): 603-611.

Méndez FX, Olivares J, Bermejo RM. Características clínicas e tratamento dos medos, fobias e ansiedades específicas. In: Caballo VE, Simón MA. Manual de Psicologia Clínica infantil e do adolescente. Transtornos Gerais. São Paulo: Livraria Santos Editora; 2007.

Mercadante MT, Scahill L. Psicofarmacologia da criança - Um guia para crianças, pais e profissionais. São Paulo: Memnon Edições Científicas; 2005.

Micco JA, Henin A, Biederman J, Rosenbaum JF, Petty C, Rindlaub LA, M Murphy, Hirshfedl-Becker, DR. Executive functioning in offspring at risck for depression and anxiety. Depression and anxiety. 2009; 26: 780-790.

Monteiro MN. Um estudo da ansiedade e suas implicações no desempenho acadêmico. [Dissertação] Rio de Janeiro: Pontifícia Universidade Católica do Rio de Janeiro; 1980.

Murphy TK, Bengtson MA, Tan JY, Carbonell E, Levin GM. Selective serotonin reuptake inhibitors in the treatment of pediatric anxiety disorders: a review. Int Clin Psychopharmacol. 2000; 5(2): S47-63.

Nabas TR, Xavier GF. Atenção. In: Andrade VM, Santos FH, Bueno, OFA. Neuropsicologia Hoje. São Paulo: Artes Médicas; 2004. 
Naglieri JA, Goldstein S, Iseman JS, Schwebach A. Performance of children with attention deficit hyperactivity disorder and anxiety/ depression on the WISC-III and cognitive assessment system (CAS). Journal of Psychoeducational assessment. $2003 ; 21: 32-42$.

Nielen MM, Den BJ. Neuropsychological performance of OCD patients before and after treatment with fluoxetine: evidence for persistent cognitive deficits. Psychol. Med. 2003; 33(5): 917-25.

O'Jile JR, Schrimsher GW, O'Bryant SE. The relation of self-report of mood and anxiety to CVLT-C, CVLT, and CVLT-2 in a psychiatric sample. Archives of Clinical Neuropsychology. 2004; 20: 547- 553.

Oliveira MS, Laranjeira R, Jaeger A. Estudos dos prejuízos cognitivos na dependência do álcool. Psicologia, saúde e doenças. 2002; 3(2): 205-212.

Pawlowski J, Bandeira DR, Parente MAMP. Validity and reliability evidences of NEUPSILIN Brief neuropsychological assessment instrument. [Dissertação] Rio Grande do Sul: Universidade Federal do Rio Grande do Sul; 2007.

Phan KL, Wager TD, Taylor SF, Liberzon I. Functional neuroimaging studies of human emotions. CNS Spectr. 2004; 9(4): 258-66.

Pine DS, Guyer AE, Leibenluft E. Functional magnetic resonance imaging and pediatric anxiety. J Am Acad Child Adolesc Psychiatry. 2008; 47(11): 1217-1221.

Pine DS, Wasseman GA, Workman SB. Memory and anxiety in prepubertal boys at risk for delinquency. Journal of the American Academy of Child and Adolescent Psychiatry. 1999; 38(8): 1024-31.

Quevedo J, Feier G, Agostinho FR, Martins RM, Roesler R. Consolidação da memória e estresse pós-traumático. Revista Brasileira de Psiquiatria. 2003; 25(1): 25-30.

Research Unit on Pediatric Psychopharmacology Anxiety Study Group. Fluvoxamine for the treatment of anxiety disorders in children and adolescent. $N$ Engl $\mathrm{J} \mathrm{Med}$. 2001; 344(17): 1279- 1285 .

Rey A. Figuras Complexas de Rey. Teste de cópia e de reprodução de memória de figuras geométricas complexas. Revisão técnica e tradução de Teresinha Rey, Lucia Cristina Fleury Franco. São Paulo: Casa do Psicólogo; 1999. 
Rocha I. Estudos de ansiedade escolar: Avaliação de situações positivas e negativas, ansiedade e nível de realização. [Dissertação] São Paulo: Universidade de São Paulo; 1976

Saboya E, Franco CA, Mattos P. Relationship among cognitive processes in executive functions. J Bras Psiquiatr. 2002; 51 (2): 91-100.

Salthouse, TA, Atkinson, TM, Berish DE. Executive functioning as a potential of agerelated cognitive decline in normal adults. Journal of Experimental Psychology. 2003; 132(4): 566-594.

Sandler A. Placebo effects in developmental disabilities: implications for research and practice. Ment Retard Dev Disabil Res Rev. 2005; 11 (2): 164-70.

Santos FH. Funções executivas. In: Andrade VM, Santos F, Bueno OFA. Neuropsicologia Hoje. São Paulo: Artes Médicas; 2004.

Sapir S, Aronson AE. The relations between psychopathology and speed and language disorders in neurologic patients. Journal of speech and hearing disorders. 1990; 55: 503-509.

Sheslow D, Adams W. Administration Manual - WRAML 2, Wide Range Assessment of memory and learning 2o. version. USA; 2004.

Silva MFG. Estudo comparativo sobre o desempenho em provas de memória e atenção entre mulheres pré-menoupasadas deprimidas e não deprimidas. [Dissertação] São Paulo: Universidade de São Paulo; 1999.

Silva WV, Figueiredo VLM. Childhood anxiety and assessment instruments: a systematic review. Revista Brasileira de Psiquiatria. 2005; 27(4): 329-335.

Sourander A, Jensen P, Davies M, Niemelã S, Elonheimo H, Ristkari T et al. Who is at greatest risk of adverse long-term outcomes? The Finnish from the boy to a man study. J Am Acad Child Adolesc Psychiatry. 2007; 46(9):1148-61.

Souza I, Pinheiro MA, Mattos P. Anxiety Disorders in an attention deficit/ Hiperactivy disorder clinical sample. Arquivo Neuropsiquiatria. 2005; 63(2): 4079.

Spreen O, Strauss E. A Compendium of Neuropsychological Test. Second Edition. New York; 1998.

SPSS Base 14.0 for Windows User's Guide. SPSS Inc. Chicago, Il; USA, 2005. 
Stroop JR. Studies of interference in serial verbal reactions. Journal of Experimental Psychology. 1935, 18(6): 643-662.

Sullivan L. The Effect of Test Anxiety on Attention and Memory Skills in Undergraduate Students. Annual Review of Undergraduat Research at the college of Charleston. 2002; 1: 263-273.

Thompson JRJ, Lampron LB, Johanson DF, Eckstein TL. Behavior problems in children with the presenting problem of poor school performance. Journal of Pediatric Psychology. 1990; 15(1): 3-29.

Thompson PJ. Antidepressants and memory: a review. Hum Psychopharmacol. 1991; 6: 79-90.

Tobias S. Anxiety research in educational psychology. Journal of Education Psychology. 1980; 71(5): 573-582.

Toren P, Sadeh M, Wolmer L, Eldar S, Koren S, Weizman R, Laor N. Neurocognitive correlates of anxiety disorders in children: A preliminary report. Journal Anxiety Disorder. 2000; 14(3): 239-247.

Vasa RA, Nay RR, Klein, RG, Mannuzza S, Moulton JL, Guardino M, Merikangas A, Carlino AR, Pine DS. Memory deficits in children with and at risk for anxiety disorders. Depression and Anxiety. 2007; 24(2): 85-94.

Velligan DI, Bow-Thomas CC. Executive function in schizophrenia. Seminar in Clinical Neuropsychiatry. 1999; 4(1): 2-33.

Vloet TD, Konrad K, Herpertz-Dahlmann B, Polier GG, Gunther T. Impact of anxiety disorders on attentional functions in children with ADHD. Journal of Affective Disorders. 2010; 124: 283-290.

Wadswoth EJK, Moss SC, Simpson SAP, Smith AP. SSRIs and cognitive performance in a working sample. Human Psychophamacology: Clinical and Experimental. 2005; 20(8): 561-572.

Watts SE, Weems CF. Associations among Selective Attention, Memory Bias, Cognitive Errors and Symptoms of Anxiety in Youth. Journal of Abnormal Child Psychology. 2006; 34(6): 838-849.

Wechsler D. WASI - Wechsler Abbreviated Sacale of Intelligence. The Psychological Corporation, San Antonio; 1999. 
Wells A, Carter K. Preliminary tests of a cognitive model of generalized anxiety disorder. Behav Res Ther. 1999; 37: 585-594.

Welsh, MC, Huizinga M. Tower of Hanoi disk-transfer task: influences of strategy knowledge and learning on performance. Learning and individual differences. 2005; 15 (283-298).

Wigfeld A, Eccles JS. Test anxiety in elementary and secondary school students. Educational Psychologist. 1989; 24: 159-183.

Williams TP, Miller BD. Pharmacologic management of anxiety disorders in children and adolescents. Curr Opin Pediatr. 2003; 15(5):483-490. 
APÊNDICE

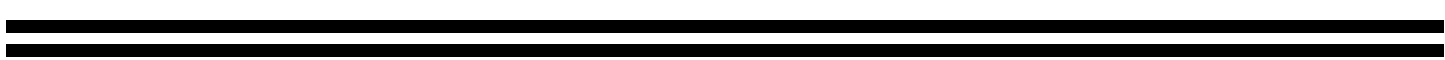


De acordo com os dados descritos acima em "Resultados", as crianças e adolescentes do grupo com transtornos de ansiedade apresentaram melhor desempenho intelectual após o tratamento medicamentoso $(\mathrm{p}=0,009)$ (tabela 7). Qualitativamente, pode-se dizer que $50 \%$ das crianças mantiveram a mesma faixa de desempenho na eficiência intelectual estimada, enquanto que $44,44 \%$ das crianças tiveram desempenho superior e 5,56\% inferior (ambos em relação à primeira avaliação) (Tabela 19).

Tabela 19 - Comparação do valor do QI estimado entre as crianças e adolescentes do grupo de ansiedade nas fases pré e pós-tratamento medicamentoso IPQ HC FMUSP - 2008 a 2011

\begin{tabular}{ccccc}
\hline QI A & $\begin{array}{c}\text { Faixa de } \\
\text { desempenho }\end{array}$ & QI B & $\begin{array}{c}\text { Faixa de } \\
\text { desempenho }\end{array}$ & $\begin{array}{c}\text { Tratamento } \\
\text { Medicamentoso }\end{array}$ \\
\hline 112 & $=\uparrow$ & 118 & $=\uparrow$ & Clomipramina \\
81 & $=\downarrow$ & 88 & $=\downarrow$ & Clomipramina \\
77 & $\downarrow$ & 93 & $=$ & Clomipramina \\
77 & $\downarrow$ & 74 & $\downarrow$ & Clomipramina \\
90 & $=$ & 91 & $=$ & Clomipramina \\
80 & $=\downarrow$ & 99 & $=$ & Fluoxetina \\
99 & $=$ & 96 & $=$ & Fluoxetina \\
89 & $=\downarrow$ & 88 & $=\downarrow$ & Fluoxetina \\
112 & $=\uparrow$ & 103 & $=$ & Fluoxetina \\
83 & $=\downarrow$ & 94 & $=$ & Fluoxetina \\
102 & $=$ & 114 & $=\uparrow$ & Placebo \\
93 & $=$ & 97 & $=$ & Placebo \\
109 & $=$ & 111 & $=\uparrow$ & Placebo \\
105 & $=$ & 111 & $=\uparrow$ & Placebo \\
77 & $\downarrow$ & 77 & $\downarrow$ & Placebo \\
96 & $=$ & 96 & $=$ & Placebo \\
83 & $=\downarrow$ & 96 & $=$ & Placebo \\
86 & $=\downarrow$ & 102 & $=$ & Placebo \\
\hline
\end{tabular}

FONTE: Rodrigues, São Paulo, 2011

Legenda: $\downarrow$ limítrofe; $=\downarrow$ abaixo da média; = média; $=\uparrow$ acima da média 
O mesmo aconteceu com três crianças e adolescentes, que foram excluídos da pesquisa devido ao valor do QI estimado ser abaixo de 70, ou seja, correspondente à faixa "retardo mental". Desses sujeitos, dois melhoraram e uma manteve o desempenho inalterado em relação à primeira avaliação.

Outro dado relevante foi a melhora observada nas crianças com transtornos de ansiedade após o tratamento medicamentoso, no desempenho do Teste Figura Complexa de Rey $(p=0,001)$. Nesse teste é fornecida a figura geométrica (figura 4) e solicitado que o sujeito a copie com o uso de lápis de cor. Após um período de tempo é solicitado que ele a reproduza mais parecido com a apresentada (Lezak, 1995).

Figura 4. Teste Figura Complexa de Rey

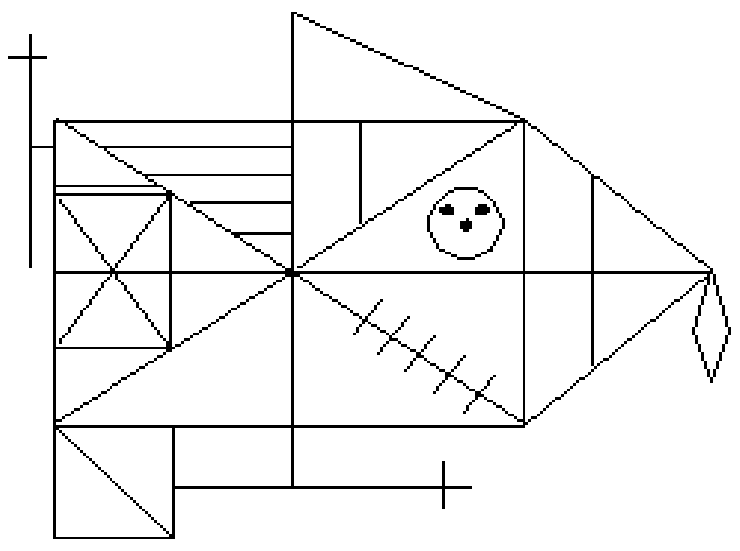

Salienta-se que, na análise de covariância realizada, os resultados para o teste Figura Complexa de Rey na memória não puderam ser considerados devido à diferença estatisticamente significativa em relação ao nível socioeconômico $(\mathrm{p}=0,044)$ (tabela 2). Porém, devido às características qualitativamente relevantes, serão exemplificados dois desempenhos de crianças e adolescentes do grupo com transtornos de ansiedade, comparando seus desempenhos nesse teste (na cópia e memória), antes e depois do tratamento medicamentoso (quadro 7 e 8). 
Quadro 7 - Comparação do desempenho no teste RCFT de uma criança com transtorno de ansiedade de 9 anos, com QI estimado na faixa média, antes e depois do tratamento medicamentoso - IPQ HC FMUSP - 2008 a 2011

\begin{tabular}{|l|l|l|}
\hline Pré-tratamento & \multicolumn{2}{|l|}{ Pós-tratamento } \\
\hline Cópia & Memória & Cópia \\
\hline
\end{tabular}

FONTE: Rodrigues, São Paulo, 2011

Quadro 8 - Comparação do desempenho no teste RCFT de um adolescente com transtorno de ansiedade de 15 anos, com QI estimado na faixa limítrofe na primeira avaliação e na média na segunda, antes e depois do tratamento medicamentoso - IPQ HC FMUSP - 2008 a 2011

\begin{tabular}{|ll|l|}
\hline Pré-tratamento & Pós-tratamento \\
\hline Cópia & Memória & Cópia \\
\hline
\end{tabular}

